\title{
Laboratory Measurements of Radon Diffusion Through Multilayered Cover Systems for Uranium Tailings
}

Rogers \& Associates Engineering Corporation
K. K. Nielson
F. A. Nederhand
V. C. Rogers
G. M. Sandquist
D. C. Rich
C. M. Jensen

December 1981

Prepared for

Pacific Northwest Laboratory under Subcontract B-A5527-A-P

for the U.S. Department of Energy

Pacific Northwest Laboratory

Operated for the U.S. Department of Energy

by Battelle Memorial Institute 


\section{NOTICE}

This report was prepared as an account of work sponsored by the United States Government. Neither the United States nor the Department of Energy, nor any of their employees, nor any of their contractors, subcontractors, or their employees. makes any warranty, express or implied, or assumes any legal liability or responsibility for the accuracy. completeness or usefulness of any information, apparatus. product or process disclosed, or represents that its use would not infringe privately owned rights.

The views, opinions and conclusions contained in this report are those of the contractor and do not necessarily represent those of the United States Government or the United States Department of Energy.

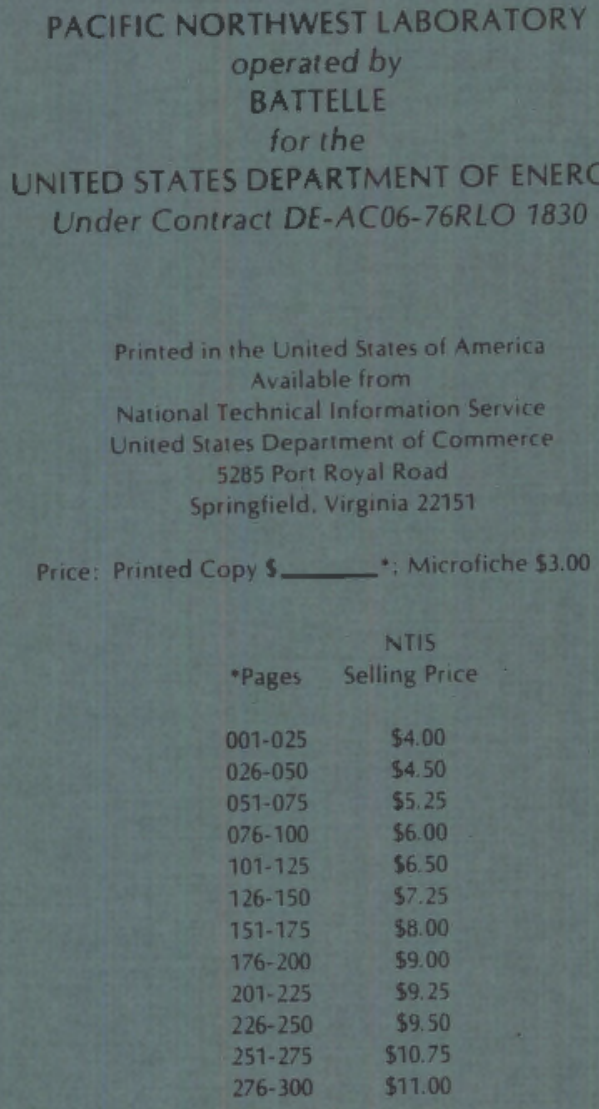


LABORATORY MEASUREMENTS OF RADON DIFFUSION THROUGH MULTILAYERED COVER SYSTEMS

FOR URANIUM TAILINGS

by

Kirk K. Nielson

Vern C. Rogers

David C. Rich

Frank A. Nederhand

Gary M. Sandquist

Craig M. Jensen

Rogers \& Associates Engineering Corp. Sa1t Lake City, Utah 84110

December 1981

\footnotetext{
Prepared for

Pacific Northwest Laboratory

Richland, Washington under

Subcontract B-A5527-A-P

Operated for the U.S. Department of Energy under contract DE-AC06-76RLO 1830
}

Pacific Northwest Laboratory

Richland, Washington 99352 
เ

$\bullet$ 


\section{ABSTRACY}

Laboratory measurements of radon fluxes and radon concentration profiles were conducted to characterize the effectiveness of multilayer cover systems for uranium tailings. The cover systems utilized soil and ciay materials from proposed disposal sites for the Vitro, Durango, Shiprock, Grand Junction and Riverton taitings piles. Measured radon fluxes were in reasonable agreement with values predicted by multilayer diffusion theory. Results obtained by using air-filled porosities in the diffusion calculations were similar to those obtained by using total porosities. Measured diffusion coefficients were a better basis for predicting radon fluxes than were correlations of diffusion coefficient with moisture or with air porosity. Radon concentration profiles were also fitted by equations for multilayer diffusion in the air-filled space. Layer-order effects in the multilayer cover systems were examined and estimated to amount to 10 to 20 percent for the systems tested.

Quality control measurements in support of the multilayer diffusion tests indicated that moisture absorption was not a significant problem in radon flux sampling with charcoal canisters, but that the geometry of the sampler was critical. The geometric design of flux-can samplers was also shown to be important. Enhanced radon diffusion along the walls of the test columns was examined and was found to be insignificant except when the columns had been physicaliy disturbed. Additional moisture injected into two test columns decreased the radon flux, as expected, but appeared to migrate into surrounding materials or to be lost by evaporation. Control of moisture content and compaction in the test columns appeared to be the critical item affecting the accuracies of the experiments. 


\section{ACKNOWLEDGEMENTS}

The authors appreciate the helpful discussions and data provided by $G$. W. Gee of Pacific Northwest Laboratory. They are also indebted to Authur Sutherland, Narawana Tappan, Mary Lou Mauch and Linda Jiran for administrative support and technical support. 


\section{CONTENTS}

1. INTRODUCTION

1.1 RELATIONSHIP TO OTHER RADON STUDIES $\quad . \quad$. $\quad . \quad$ • 2

1.2 SCOPE OF TASKS 2 AND 3 .

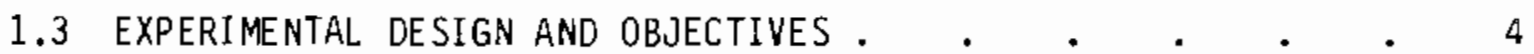

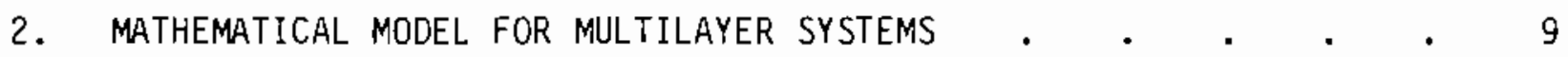

2.1 SUMMARY OF TASK 1 MULTILAYER MODEL . . . . . . . . 13

2.2 PREDICTED BEHAVIOR OF MULTILAYER SYSTEMS $\quad$ • • • • • 15

2.2.1 Layer-Order Effects and Parameter Coupling . . . 15

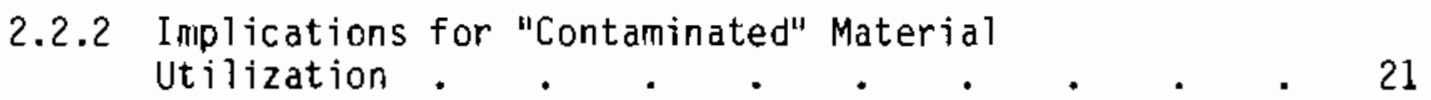

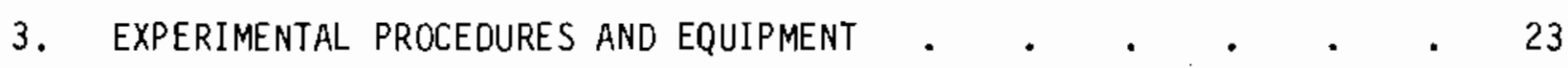

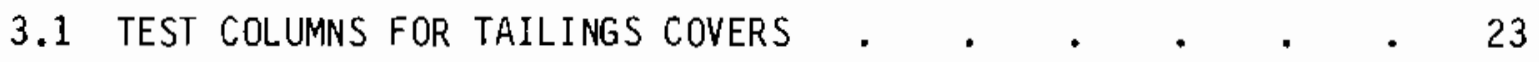

3.1 .1 Construction of Columns . . . . . . 24

3.1.2 Monitoring Procedures for Radon Fluxes $\quad$. $\quad$. $\quad$. 29

3.1.3 Monitoring Procedure for Radon Concentration Profiles . . . . . . . . 35

3.1.4 Monitoring of Soil Moistures and Temperatures . $\quad 38$

3.2 SMALL-SAMPLE TRANSIENT DIFFUSION MEASUREMENTS $\quad . \quad$. 39

4. QUALITY CONTROL MEASUREMENTS .

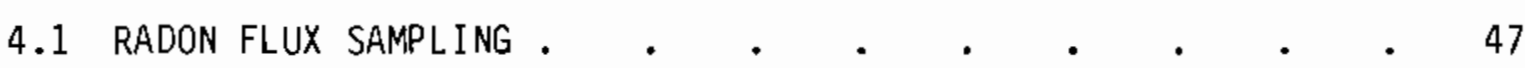

4.1.1 Effects of Moisture on Radon Flux Sampling . • • 48

4.1.2 Effects of Radial Diffusion in Radon Fiux Sampiing . 51

4.1.3 Comparison of Flux Cans with Charcoal Canisters . . 60

4.1.4 Test for Column Edge Effects . . . . . 62

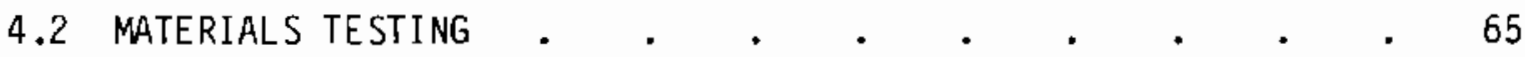

4.3 CALIBRATION WITH STANDARD MATERIALS $\quad . \quad$. . . . 68 
5. SAMPLE COLLECTION AND CHARACTERIZATION . . . . . . . 75

5.1 SAMPLE SITE OESCRIPTIONS . . . . . . . . . . 75

5.2 SAMPLE COLLECTION ANO HANDLING . . . . . . . 78

5.3 SAMPLE ENGiNeERING PROPERTIES . . . . . . . . . . . 79

5.4 SAMPLE MOISTURE AND DRAINAGE CHARACTERISTICS . . . . 79

5.5 SAMPLE RADIUM ACTIVITY AND EMANATION COEFFICIENTS . . 89

6. EXPERIMENTAL RESULTS ANO DISCUSSION . . . . . . . . . 93

6.1 RADON RELEASE FROM BARE TAILINGS SOURCES . . . . . . 93

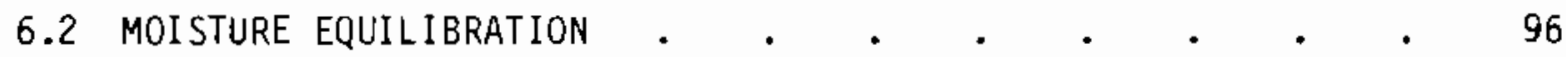

6.3 RADON FLUX MEASUREMENTS AND DIFFUSION COEFFICIENTS. . . 98

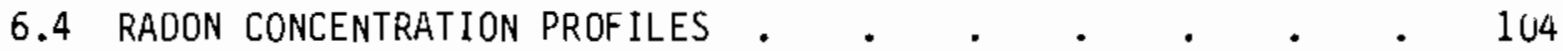

6.5 LAYER-ORDER EFFECTS . . . . . . . . . . 108

6.6 MOISTURE AOOITION TO COLUMNS 6 ANO 10 .

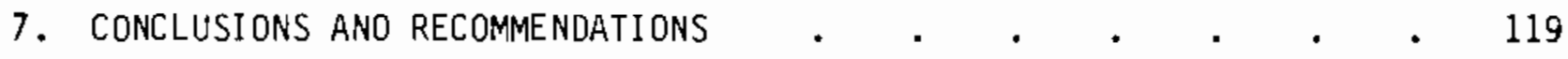

8. REFERENCES . . . . . . . . . . . . . . . 123 
FIGURES

1.1 Configurations of the E leven Radon Test Columns . . . . 5

2.1 I llustration of Layer-Order Effects Resulting Onily from

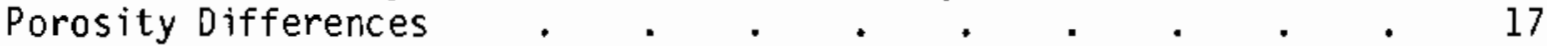

2.2 Illustration of Layer-Order Effects Resulting Only from

Differences in Effective Bulk Diffusion Coefficients . . . 19

2.3 Variation in Radon Flux Expected to Result from Varying the

Position of the Clay Layer in a Two-Component Cover System . $\quad 20$

2.4 Comparison of Radon Fluxes from Multilayered Tailings Cover

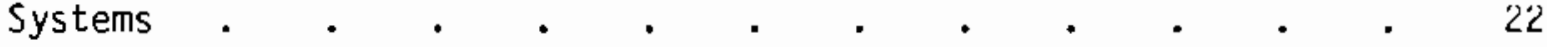

3.1 Construction Diagram of Radon Diffusion Test Columns . . . 25

3.2 Radon Flux Sampling with Flux Car and Lucas Cell . . . . 30

3.3 Radon Flux Sampling with a Charcoal Canister. . . . . 36

3.4 Calibration of Soil Moisture Cells in Terms of Soil

Capillary Pressure. . . . . . . . . . 40

3.5 Calibration of Soil Moisture Cells for Vitro Tailings . . . 41

3.6 Time-Dependent Radon Diffusion Measurement Apparatus . . . 43

4.1 Moisture Uptake and Its Effect on Charcoal-Canister Radon

Flux Sampling . . . . . . . . . . . . 49

4.2 Variation in Radon Flux Sampling Efficiency with Sampling Time - 53

4.3 Radon Accumulation During Flux-Can Sampling . . . . . 54

4.4 Comparison of Charcoal Canister Flux-Sampling Geometries . $\quad 58$

4.5 Comparison of Radon Flux-Can Geometries . . . . . . . 59

4.6 Experimental Arrangement for Testing Radon Diffusion . . . 66

5.1 Water Retention Characteristic Curves for Vitro Cover
Materials. . . . . . . . . 85

5.2 Water Retention Characteristic Curves for Durango Cover
Materials. . . . . . . . . 86

5.3 Water Retention Characteristic Curves for Shiprock Cover
Materials. . . . . . . . . . 87 
5.4 Water Retention Characteristic Curves for Riverton Cover

Materials. . . . . . . . . . . . 88

6.1 Moisture Equilibration Curves for Column 8 . $\quad . \quad$. $\quad . \quad$. $\quad 97$

6.2 Radon Concentration Profile in Column 10 . . . . . 105

6.3 Effects of Moisture Addition on Radon Flux in Column 6. . . 111

6.4 Effects of Moisture Addition on Radon Flux in Column 10 . $\quad 112$

6.5 Moisture Profile After Water Addition to Column 6. . . . . 116

6.6 Moisture Profile After Water Addition to Coiumn 10 . . . 117 


\section{$\underline{\text { TABLES }}$}

3.1 Initial Thicknesses Densities and Porosities of Cover Material Test Layers

3.2 Radon-Daughter Equilibrium Factors, $f_{B}$, Calculated from the Bateman Equation

4.1 Comparison of Radon Fiux Measurements on Bare Tailings Sources

4.2 Comparison of Radon Fluxes from Total and Partial Column

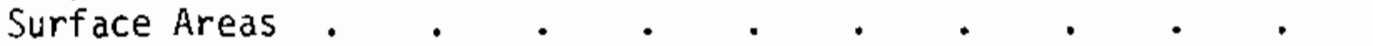

4.3 Radon Diffusion Coefficients for Experimental Materials . . 69

4.4 Calibration of Lucas Cells . . . . . . . . . . 71

4.5 Interlaboratory Comparison of Radium Determinations . . . 73

5.1 Results of Modified Proctor Tests on Tailings and Cover Materials. . . . . . . . . . . 80

5.2 Sieve Analyses of Taijings and Cover Materials . . . . 81

5.3 Radium Activities and Emanation Coefficients of Test Materials . 83

6.1 Bare Source Fluxes and Diffusion Coefficients for the Test Columns . . . . . . . . . . . . 95

6.2 Summary of Time-Dependent Radon Diffusion Tests . . . . . . g9

6.3 Comparison of Measured Radon Fluxes with Fluxes Calculated from Transient Diffusion Measurements . . . . . . . 101

6.4 Comparison of Measured Radon Fluxes with Fluxes Calculated from Predicted Diffusion Coefficients . • • • . . 103

6.5 Radon Diffusion Coefficients Estimated from Radon Concentration Profiles in Test Columns . . . . . . . . . 107

6.6 Moistures Measured on Clay Samples . . . . . . . . 115 


\section{INTRODUCTION}

The release of radon gas from uranium mill tailings piles is recognized as a significant potential health hazard due to the ability of radon to induce lung cancer via elevated airborne alpha activity. The release of gaseous radon results from a chain of long-lived radioactive precursors originating with uranium-238, which is mostly removed in the milling process. The intermediate species of radium and thorium are not significantly removed by milling, however and continue to produce radon over time scales of thousands, and hundred of thousands of years, respectively. 8ecause the mill tailings are removed from their original subterranean environment, and have been ground and leached, the resulting radon gas effluent to the atmosphere is usually increased and in closer proximity to poputated areas.

The Uranium Mill Tailings Radiation Control Act ${ }^{(1)}$ of 1978 provided for the Uranium Mill Tailings Remedial Action Program (UMTRAP) to be administered by the Department of Energy to deal with inactive uranium tailings sites. Under this program, the Department of Energy is conducting research aimed at controlling radioactive effluents from uranium mill tailings piles. The work reported herein constitutes a part of that research effort.

Due to the large costs involved in remedial action on inactive uranium tailings sites, tailings cover designs which minimize costs and maximize use of local materials are desirable. Thin clay covers have been shown to effectively reduce radon effluents, but such covers are subject to cracking and physical damage if directly exposed to the environmerit. Multilayered tailings cover designs have been proposed for several practical reasons such as protection of the clay cap by a thicker overburden fill, and provision of a topsoil layer suitable for revegetation. However, the mathematical basis for describing radon diffusion in such composite systems was only recently developed as the 
computer code, RAECO, (2) under Task 1 of this project. The present report provides laboratory data on radon diffusion in multilayered systems to verify experimentally the behavior predicted by the multilayer mathematical model.

\subsection{RELATIONSHIP TO OTHER RADON STUDIES}

The laboratory experiments reported herein are part of a larger research effort being conducted by Rogers and Associates Engineering Corporation for the Department of Energy (DOE) under a subcontract to Battelle, Pacific Northwest Laboratories. Other tasks of this research effort include: the recently completed task of developing a mathematical model for radon diffusion and cost optimization of multilayered systems; a task dealing with experimental moisture addition to radon test columns; and a task aimed at understanding and correlating climatology with field moisture conditions on a regional basis.

Since the interaction of tailings cover layers depends in large part on the diffusion coefficients and porosities of the individual layer materials, a detajled understanding of moisture effects is essential to interpret adequately the behavior of a multilayer system. Recent studies at Ford, Bacon and Davis Utah, Inc., (3) and later at Battelle, Pacific Northwest Laboratories (4) have indicated the major effect of water in limiting the diffusion of radon in earthen materials. Continuing laboratory research at Ford, Bacon and Davis is extending the general data base on mojsture effects on radon diffusion, and laboratory and field efforts underway at Battelle have applied an air-filled porosity model to explain moisture effects in the aggregate composite materials being tested in their Grand Junction field tests. Under a separate subcontract with Battelle to the U.S. Nuclear Regulatory Commission, Rogers and Associates 
is also developing a theoretical model to explain the mechanisms of moisture effects on radon diffusion.

Previous studies $(5,6)$ at Ford, Bacon and Davis have examined radon diffusion in single-layer tailings covers, and have considered the effect of vegetation, chemical stabilizers and additives on the tailings covers. A major effort is underway at Battelle to characterize the effectiveness as tailings covers, of asphalt sealants $(7)$ and aggregate composite mixtures. These are being applied in layered configurations in field tests at Grand Junction, Colorado. The use of bio-barriers $(8)$ and revegetation are also being examined at Battelle, and can affect radon containment by the covers. The possible effects of chemical leaching and salt migration are aiso being examined by Geocheristry and Environmental Chemistry Research, Inc., for effects on the long-tern effectiveness of tailings covers.

Although most early research dealt with single-layer covers, it is recognized that remedial action will probably utilize multilayer systems. Current field studies and reclamation plans for active mills are thus using layered composites. The Generic Environmental Impact Statement on Uranium Milling $(g)$ suggested an approximate mathernatical formulation for its analys is, and an earlier report ${ }^{(10)}$ described approximate methods and results of multilayer cover analysis. The Task 1 report ${ }^{(2)}$ is the first exact formulation for a general n-layer system, however, and it is now supported by the present experimental results, and by further multijayer earthen cover tests being conducted by Battelle.

\subsection{SCOPE OF TASKS 2 AND 3}

The present experimental effort entailed the construction of eleven test columns to test possible multilayer cover configurations using materials from 
five of the high-priority inactive tailings site regions. (11) A complete study of radon diffusion in multilayer covers and in the component layers was conducted for the Vitro materials, and selected configurations were evaluated for the other sites. Site-specific cover materials were collected and preserved at near-ambient mo istures for compaction into the test columns. Each column was monitored for moisture content, radon flux, and radon concentration profiles to permit evaluation of the model used by the RAECO code. (2) Diffusion coefficients of individual layers, needed as input to the model, were measured using a rapid, time-dependent method described in Section 3.2. Two composite cover systems were duplicated, but with different layer sequences to check for layer-order effects which are predicted by the Task 1 model. Quality control measurements were also made to assure the adequacy of the test materials for radon containment and to assure proper calibration of equipment and application of methods. Additional moisture was injected into two of the Vitro test columns, following the Task 2 experiments. The resulting radon fluxes and moisture profiles were measured as part of Task 3 , and are reported here. The remaining experiments under Task 3 are continuing and will be reported separately.

\subsection{EXPERIMENTAL DESIGN AND OBJECTIVES}

Two major experimental efforts comprised the verification of the Task 1 multilayer model. First, the behavior of radon in multilayer systems was experimentally demonstrated and second, the radon diffusion coefficients for the material in each layer were measured in order to perform the multilayer analysis.

The multilayer cover systems which were tested are illustrated in Figure 1.1. The group of five colurnns made from Vitro cover materials have the following purposes: Column 8 was made as a control column to be kept in its original state during later experiments (Task 3) in which water would be added 

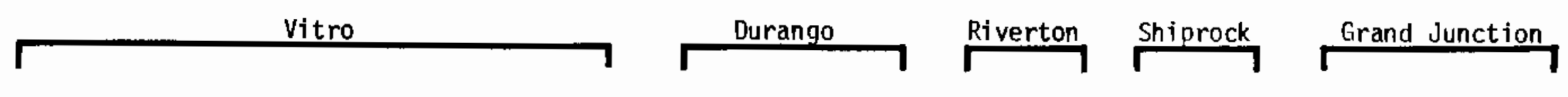

v

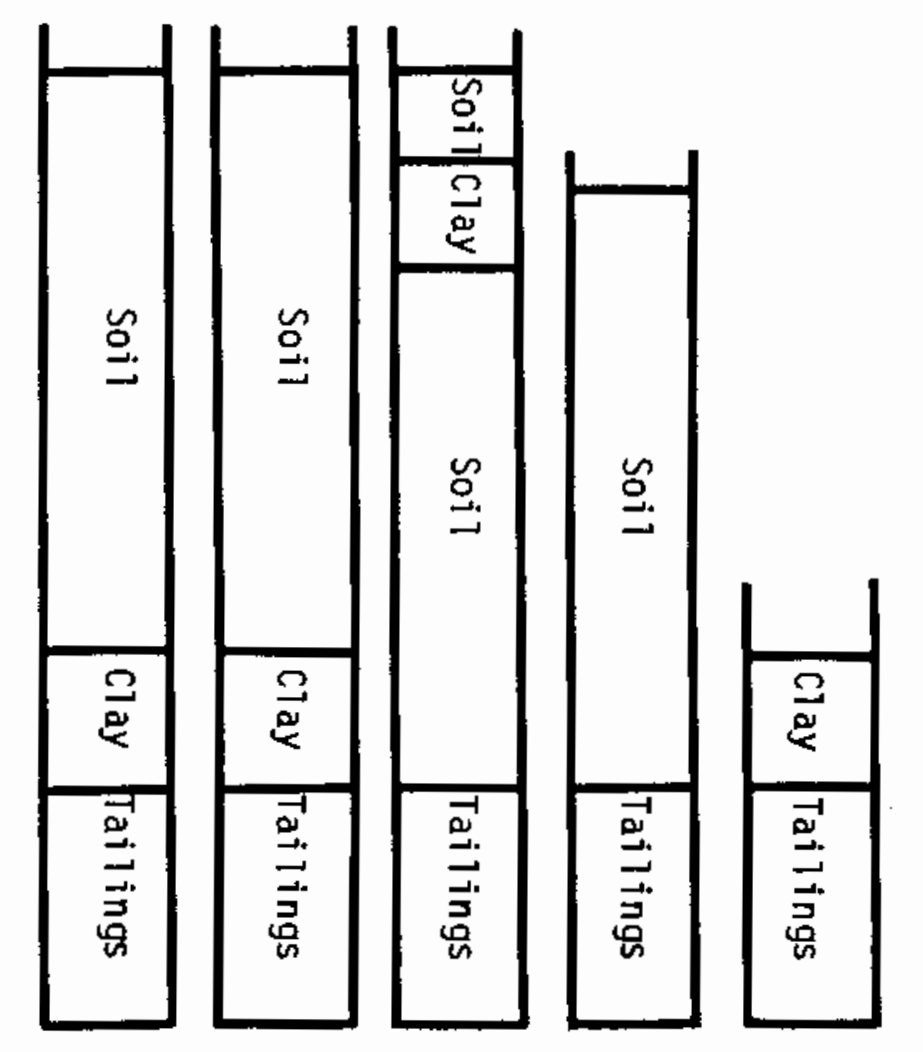

$8 \quad 10$

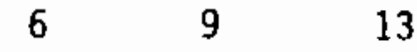

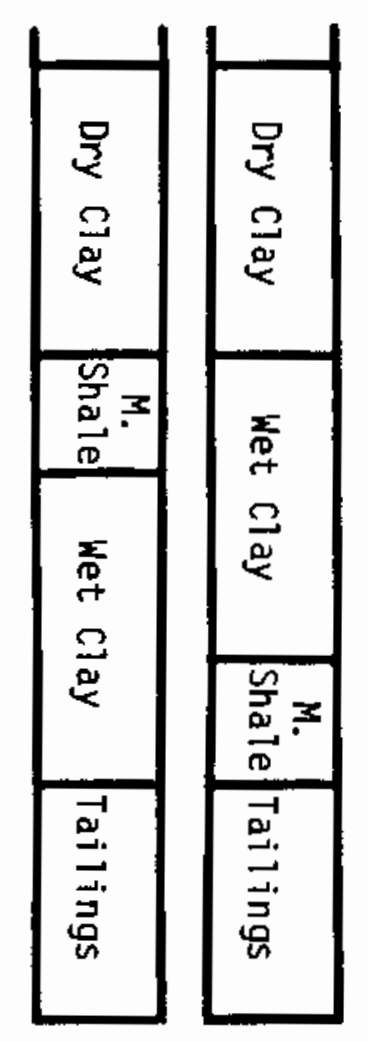

2

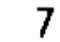

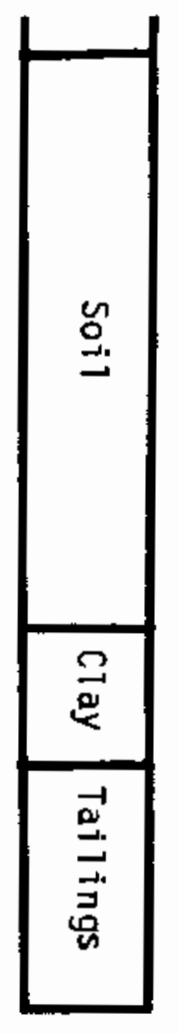

1

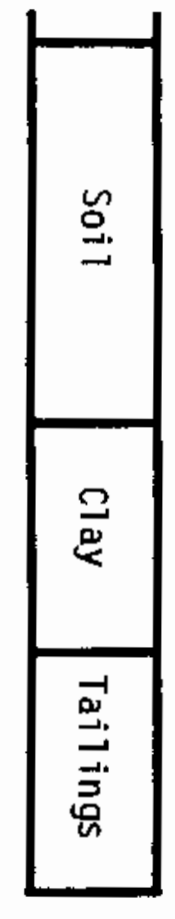

4
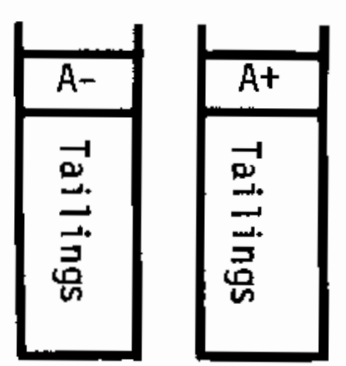

Nolumn

11

15 
to other columns. Columns 8 and 10 both served to evaluate the basic cover configuration with Vitro materials. Column 6 was constructed to test for layerorder effects by comparison with Column 10. Both columns 6 and 10 were designated for later water addition in Task 3. Columns 9 and 13 were designed to measure the single material diffusion coefficients pertinent to the other vitro columns, and to provide a basis for comparing diffusion coefficients measured by static methods with those from the time-dependent measurements.

Columns 2 and 7 were similariy constructed to examine layer-order effects and interaction of cover layers using Ourango cover materials. Columns 1 and 4 were simply designed to evaluate typical multilayer configurations for Riverton and Shiprock materials. Columns 11 and 15 were prepared to evaluate the dry aggregate mixtures used in the 1980 Grand Junction field tests.

Experimental monitoring of the columns included radon flux and concentration profile measurements, and moisture profile measurements. The radon concentration profiles alone determine a unique set of parameters to describe a given column with the multilayer model. The radon fluxes from the bare source and through the cover also characterize the muitilayer cover effectiveness, and when analyzed with the component radon diffusion coefficients, permit a separate description of the radon transport in a given column. Related measurements including radium and emanation measurements and porosity of the cover layers were conducted in order to characterize as completely as possible the test systems and hence explain more accurately the radon transport actually occurring. Individual layer diffusion coefficients were measured separately in a small-sample transient diffusion apparatus using identical individual soil materials at similar moistures and packed to densities similar to those in the Targer test columns. The resulting diffusion coefficients were applied to the multilayer diffusion analys is.

The objectives of this experimental work were to demonstrate with experi- 
mental data the adequacy of the multilayer diffusion model to describe radon fluxes and concentration profiles, and to demonstrate the occurence of layerorder effects which are predicted by the model.

The injection of additional water into columins 6 and 10 was designed to iliustrate the effects of moisture on the performance of a multilayer cover system, and to demonstrate its mobility in such a system. 


\section{MATHEMATICAL MODEL FOR MULTILAYER SYSTEMS}

The diffusion of radon through multiple layers of differing porous materials was described by gas diffusion theory. It was assumed that radon diffusion resulted from a one-dimensional concentration gradient; hence, radon diffusion in only the vertical direction was considered. The one-dimensional, vertical diffusion conditions are identically applicable to typical field conditions in which horizontal concentration gradients are negligible, and also to the test columns, in which horizontal gradients are avoided by the column walls. Transient effects were also avoided by allowing the multilayer systems to reach secular equilibrium.

The one-dimensional, steady-state diffusion of radon through a moist, unsaturated earthen material can be described as the combined diffusion in the gasand liquid-filled pore volumes of the material. The gas-phase diffusion can be described by

$$
D_{a}^{\prime} \frac{d^{2} C_{a}}{d x^{2}}-\lambda C_{a}+Q_{a} / p=0
$$

where

$$
\begin{aligned}
& D_{a}^{\prime}=\text { the diffusion coefficient in the air-filled pore space }\left(\mathrm{cm}^{2} / \mathrm{s}\right) \\
& C_{a}=\text { the concentration of radon in the air }\left(\mathrm{pCi} / \mathrm{cm}^{3}\right) \\
& \lambda=\text { the radon decay constant }\left(2.1 \times 10^{-6} / \mathrm{s}\right) \\
& Q_{a}=\text { the radon source into the } \operatorname{air}\left(\mathrm{pCi} / \mathrm{cm}^{3} \mathrm{~s}\right) \\
& P=\text { the air-filled pore space }\left(\mathrm{cm}^{3} / \mathrm{cm}^{3}\right)
\end{aligned}
$$

A corresponding equation can be written for diffusion in the liquid-filled pore regions. A solution to these two equations which also accounts for radon exchange 
between the liquid and gas phases has recently been developed in separate research for the U.S. Nuclear Regulatory Commission. This general approach to multiphase diffusion defines the radon concentration in the total pore space, $C$, as

$$
c=c_{a}(1-m)+c_{w} m
$$

where

$$
\begin{aligned}
& C_{w}=\text { the concentration of radon in the water-filled space } \\
& \left(p C i / c m^{3}\right) \\
& m=\text { the volume fraction of moisture saturation. }
\end{aligned}
$$

The resutting dual-phase diffusion equation, given in equation $2-3$, is the traditional expression for radon diffusion.

$$
\bar{D} \frac{d^{2} C}{d x^{2}}-\lambda C+Q / P=0
$$

where

$$
\begin{aligned}
\bar{D}= & \text { the average radon diffusion coefficient for the combined } \\
& \text { gas- and liquid-filled pore space }\left(\mathrm{cm}^{2} / \mathrm{s}\right) \\
Q= & \text { the radon source into the air-and liquid-filled pore } \\
& \text { volumes }\left(\mathrm{pCi} / \mathrm{cm}^{3}\right) \\
P= & \text { the total gas- and liquid-filled porosity }\left(\mathrm{cm}^{3} / \mathrm{cm}^{3}\right)
\end{aligned}
$$

Equation 2-1 is very similar to the equation used in reference 4 to calculate radon diffusion through porous earthen materials. Both equations are components of the general expression given in equation 2-3. Use of the equation from reference 4 differs from the use of equation 2-1 in the following three areas: 
a) It accommodates diffusion in near-saturated media by adding the diffusion coefficient for radon in water to the empirical expression for the diffusion coefficient. b) It does not explicitly consider the radon exchange between the air and water in the pore space. c) It assumes that all free radon is generated in the air-filled portion of the pore spaces.

A comparison of equations 2-1 and 2-3 j1lustrates the identical form of the gas-phase and dual-phase diffusion equations. Because of their identical form, the same form of the solution can be used to analyze radon transport through the total pore space as well as the transport in the gas-filled space only, obviously, the values and definitions of radon concentration, diffusion coefficient, and source strength are different for these two definitions of the diffusion medium.

The static and transient measurements of diffusion coefficients in this and previous related studies $(3,5,6)$ directly yielded empirical values for the diffusion coefficient $\bar{D}$, which is a function of the density, moisture content, pore structure, and perhaps other parameters of the subject material. As in the previous studies, this dual-phase diffusion coefficient is also expressed as the ratio of the effective bulk diffusion coefficient to the total porosity. This report retains the notation used in the Task 1 report (2) (multilayer diffusion model) for this ratio,

$$
\bar{D}=\frac{D}{P}
$$

The effect of moisture on radon diffusion coefficients has been studied and expressed in two empirical correlations. One of these ${ }^{(3)}$ relates measured values of $D / P$ to soil moistures (1-30\% wet wt) with a simple exponential fit, and is consistent with diffusion coefficients taken from published literature over a slightly greater moisture range. This correlation applies to the dual-phase pore 
fluid. The other empirical correlation, (4) based on some of the same data plus other measurements on near-saturated materials, relates the diffusion coefficient of the air-filled pore space to the air-filled porosity, and adds the diffusion coefficient for radon in water as a lower limit for $D_{a}^{\prime}$. This correlation applies to the assumption that a11 radon transport occurs in the air-filled pore space. Since for cover materials the source term is generally very small, and since the value of the empirically determined diffusion coefficients can accommodate many unknown characteristics of radon transport, both correlations for the diffusion coefficient yield similar results when applied correctly.

Because of the variations in moisture and compaction in the present multilayer cover tests, each of the above models (total porosity and air-filled porosity) is usefut in interpreting the multilayer diffusion data. The results were accordingly interpreted with two parallel calculation procedures, one considering diffusion in the total pore space and the other assuming diffusion in only the air-filled pore regions. For the latter assumption, the measured diffusion coefficients, $D_{a}^{\prime}$, were related to the effective bulk diffusion coefficients $\left(D_{a}\right)$ using the air-fillied porosity, as

$$
D_{a}^{\prime}=\frac{D_{a}}{p}
$$

In order to apply the diffusion equation to a multilayer system, appropriate boundary conditions were applied to each layer to couple the solutions to equation 2-3 for the combined system. The mathematical framework for dealing with multilayer systems was developed under Task 1 and is described in a separate report.

The following sections sumarize that report and describe the performance predicted by the coupled, multilayer equations. 


\subsection{SUMMARY OF TASK 1 MULTILAYER MODEL}

[c. The general, multilayer radon diffusion model was developed to accommodate an arbitrary number $(n)$ of porous materials, each of which was characterized by a thickness $\left(d_{i}\right)$, a diffusion coefficient $\left(D_{j}\right)$, a porosity $\left(P_{i}\right)$, and a radon source $\left(Q_{j}\right)$. Equations 2-3 and 2-4 were generalized as

$$
D_{i} \frac{d^{2} C_{j}(x)}{d x^{2}}-P_{i} \lambda C_{i}(x)+Q_{i}=0,
$$

where the previous definitions apply to the material in the $i^{\text {th }}$ layer. The general solution to equation 2-6 for the radon concentration in laver $i$ was

$$
C_{i}(x)=A_{i} \exp \left(a_{i} x\right)+B_{i} \exp \left(-a_{i} x\right)+S_{i}
$$

where

$$
\begin{aligned}
& a_{i}=\left(P_{i} \lambda / D_{i}\right)^{\frac{1}{2}} \\
& S_{i}=Q_{i} /\left(P_{i} \lambda\right)
\end{aligned}
$$

and $A_{i}$ and $B_{i}$ were constants determined by the boundary conditions for the layer. The radon flux associated with each layer was defined by Fick's law as

$$
J_{i}(x)=-D_{i} \frac{d C_{j}(x)}{d x}
$$


The boundary conditions for each layer which were used to define the constants in Eq 2-7 were defined to be continuous radon concentration and continuous radon flux across each layer interface, or

$$
c_{i}\left(x_{i}\right)=C_{i+1}\left(x_{i}\right)
$$

and

$$
-D_{i} \frac{d C_{i}\left(x_{j}\right)}{d x}=-D_{i+1} \frac{d C_{i+1}\left(x_{i}\right)}{d x}
$$

Additional boundary conditions at the top and bottom of the multilayer system were also defined. At the bottom of the tailings system $(x=0)$, it was assumed that the radon flux was a known constant, $\mathrm{J}_{0}$, where

$$
J_{0}=-D_{1} \frac{d C_{1}(0)}{d x}
$$

At the top boundary of the system (i.e., at the soil-air interface), it was assumed that the radon concentration was a known constant, $C_{a}$, where

$$
c_{a}=c_{n}\left(x_{n}\right)
$$

The resulting system of equations for the general $n$-layer system were solved in matrix form to determine the constants $A_{i}$ and $B_{j}$. The matrix to be solved was pent-diagonal, permitting upper triangulation and backward solving for the constants. This procedure involved eliminating the non-zero elements below the main diagonal of the matrix by forming an augmented matrix from the matrix equation. Details of this mathematical procedure are given in the Task 1 report. (2) 
The resulting calculations were rapid and minimized the computation time and round-off errors otherwise associated with a complete matrix inversion. Once the $A_{i}$ and $B_{i}$ constants were determined, the radon concentration and flux could be determined at any point in the multilayer system by applying Eqs 2-7

and 2-8. The computer code $\operatorname{RAECO}^{(2)}$ was used to perform these calculations.

\subsection{PREDICTED BEHAVIOR OF MULTILAYER SYSTEMS}

Several interesting properties of multilayer cover systems became apparent in the process of exercising the multilayer computer code. One of these was the existence of layer-order effects. The effectiveness of a given layer in reducing radon flux in a multilayer system was found to depend not only upon its own properties, but also on the properties of the surrounding layers. Hence, the order in which the components of a multilayer system are arranged affects its effectiveness in reducing radon flux. The magnitude of layer-order effects was examined, and found to depend on the coupling of the more basic parameters of diffusion coefficient and porosity of the component layers. More obviously, the radium content of component layers also causes a layerorder effect which has implications for the possible utilization of contaminated materials in the cover systems. The following sections describe these interactions among cover layers in greater detail.

\subsubsection{Layer-Order Effects and Parameter Coupling}

The defining parameters which distinguish one layer from another are usually considered to be material composition (mineralogy, etc.), moisture, porosity, particle size, and perhaps other related physical characteristics. 
With respect to radon flux reduction, only the porosity, diffusion coefficient, and radon source strength are significant. Parameters such as particle size and moisture must therefore be expressed in terms of their effect on diffusion coefficient and porosity for evaluation of their effects. The interdependence of porosity and diffusion coefficient further complicates a complete analys is. However, for analys is of multilayer cover systems and layer-order effects, independent consideration of these two parameters is adequate.

Coupling groups of equations of the form of Eq 2-7 for a multilayer system causes the diffusion coefficient and porosity of one layer to affect not only its own performance but also that of the surrounding layers. Because of this interaction, a given cover layer attenuates radon flux by differing degrees depending on the properties of nearby layers. A measure of the effect of this interaction was obtained by running the multilayer diffusion code for a twolayer cover system and independently varying the porosity and the diffusion coefficient of each layer.

In the analyses for which the layer porosities were varied, it was assumed that the effective bulk diffusion coefficient, represented by $D$, remained constant for both of the cover layers and for the tailings. A value of $10^{-3} \mathrm{~cm} / \mathrm{s}$ was used. It was also assumed in this analysis that the tailings source was infinitely thick and had a porosity of 0.2 , and that the two cover layers each had a thickness of $136 \mathrm{~cm}$. The resulting fluxes are i17ustrated in Figure 2.1 as ratios of fluxes from normal cover order (a, b, tailings) to fluxes from inverse cover order (b, $a$, tailings). As illustrated, placement of the high-porosity layer adjacent to the tailings source results in the greatest attenuation of radon flux. Layer-order effects amounting to a factor of 1.6 resulted from varying the porosity over the range of 0.02 to 0.5 . 


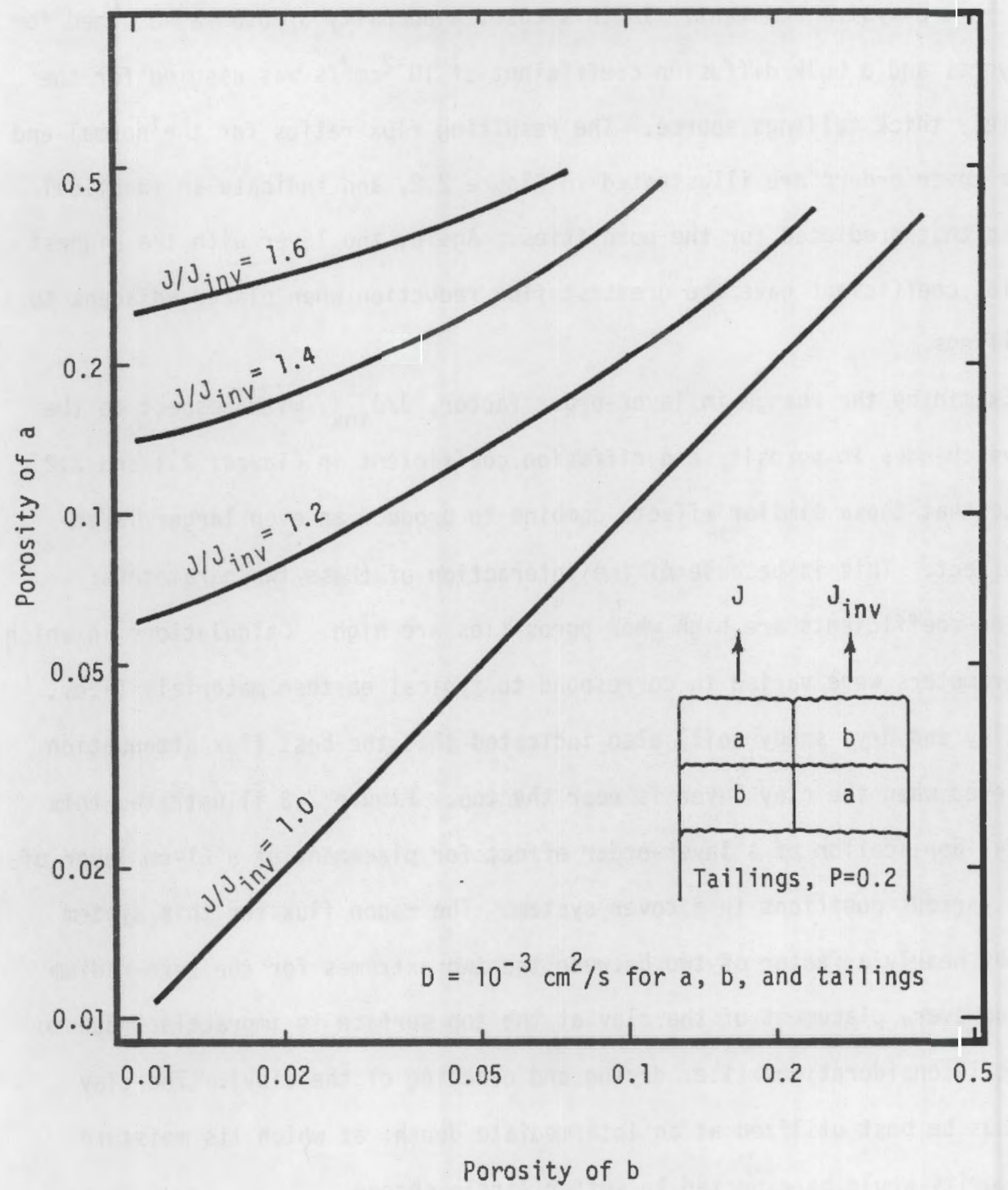

FIGURE 2.1 ILLUSTRATION OF LAYER-ORDER EFFECTS RESULTING ONLY FROM POROSITY DIFFERENCES. 
A similar analysis was performed by running the multilayer code and varying the effective diffusion coefficients of the cover layers while keeping all porosities in the system constant. In this case, a porosity of 0.3 was assumed for all layers, and a bulk diffusion coefficient of $10^{-2} \mathrm{~cm}^{2} / \mathrm{s}$ was assumed for the infinitely thick tailings source. The resulting flux ratios for the normal and inverse cover orders are illustrated in Figure 2.2, and indicate an identical trend to that predicted for the porosities. Again, the layer with the highest diffusion coefficient gave the greatest flux reduction when placed adjacent to the tailings.

Examining the change in layer-order factor, $\mathrm{J} / \mathrm{J}_{\mathrm{inv}}$, with respect to the relative changes in porosity and diffusion coefficient in Figures 2.1 and 2.2 indicate that these similar effects combine to produce an even larger layerorder effect. This is because of the interaction of these two parameters: diffusion coefficients are high when porosities are high. Calculations in which both parameters were varied to correspond to typical earthen materials (i.e., moist clay and dry, sandy soil) also indicated that the best flux attenuation is achieved when the clay layer is near the top. Figure 2.3 illustrates this practical application of a layer-order effect for placement of a $61-\mathrm{cm}$ layer of clay in various positions in a cover system. The radon flux for this system varies by nearly a factor of two between the two extremes for the zero-radium case. However, placement of the clay at the top surface is impractical due to mechanical considerations (i.e. drying and cracking of the clay). The clay would thus be best utilized at an intermediate depth, at which its moisture and integrity would be expected to suffer little change. 


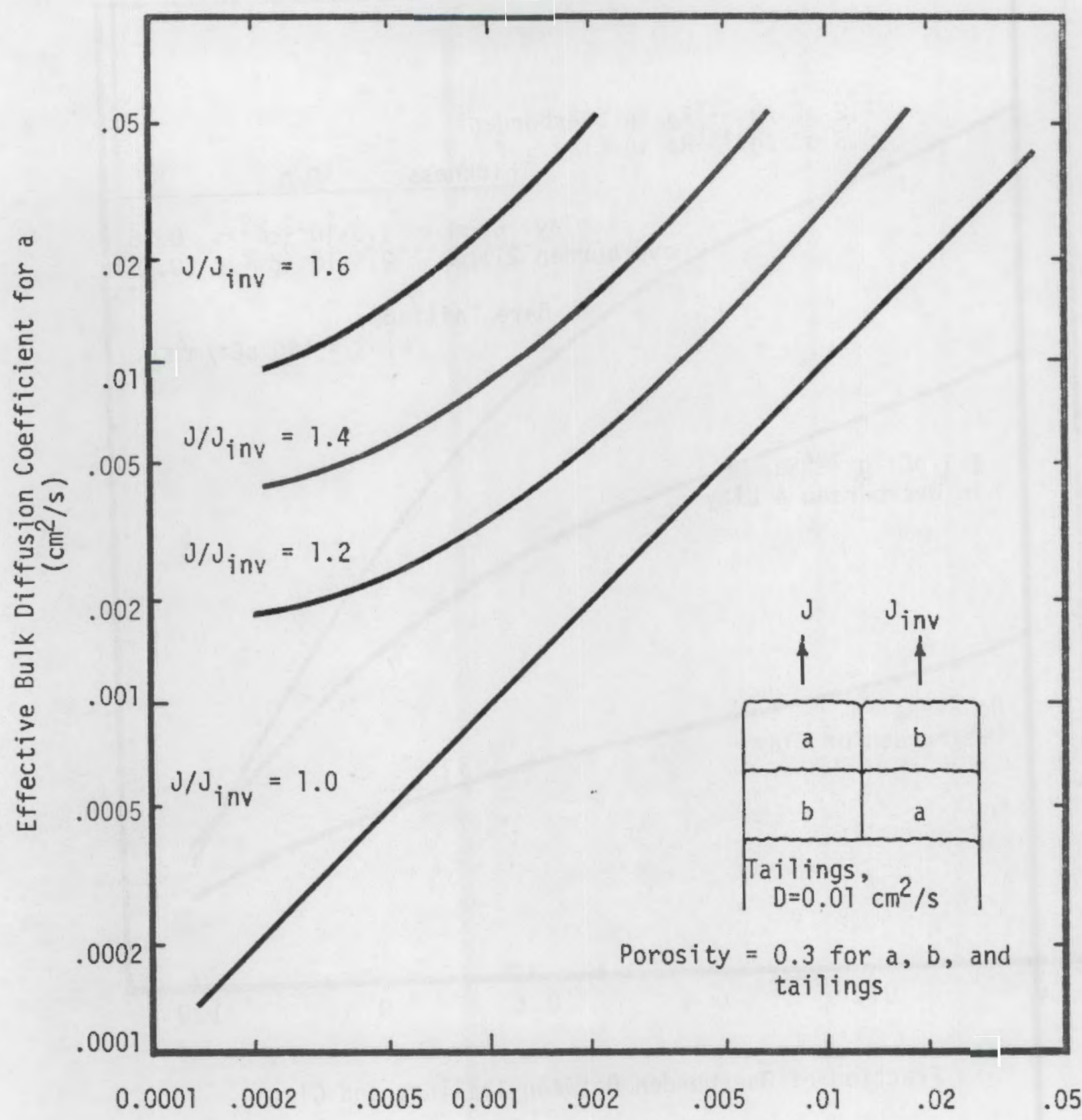

Effective Bulk Diffusion Coefficient for b $\left(\mathrm{cm}^{2} / \mathrm{s}\right)$

FIGURE 2.2 ILLUSTRATION OF LAYER-ORDER EFFECTS RESULTING ONLY FROM DIFFERENCES IN EFFECTIVE BULK DIFFUSION COEFFICIENTS. 


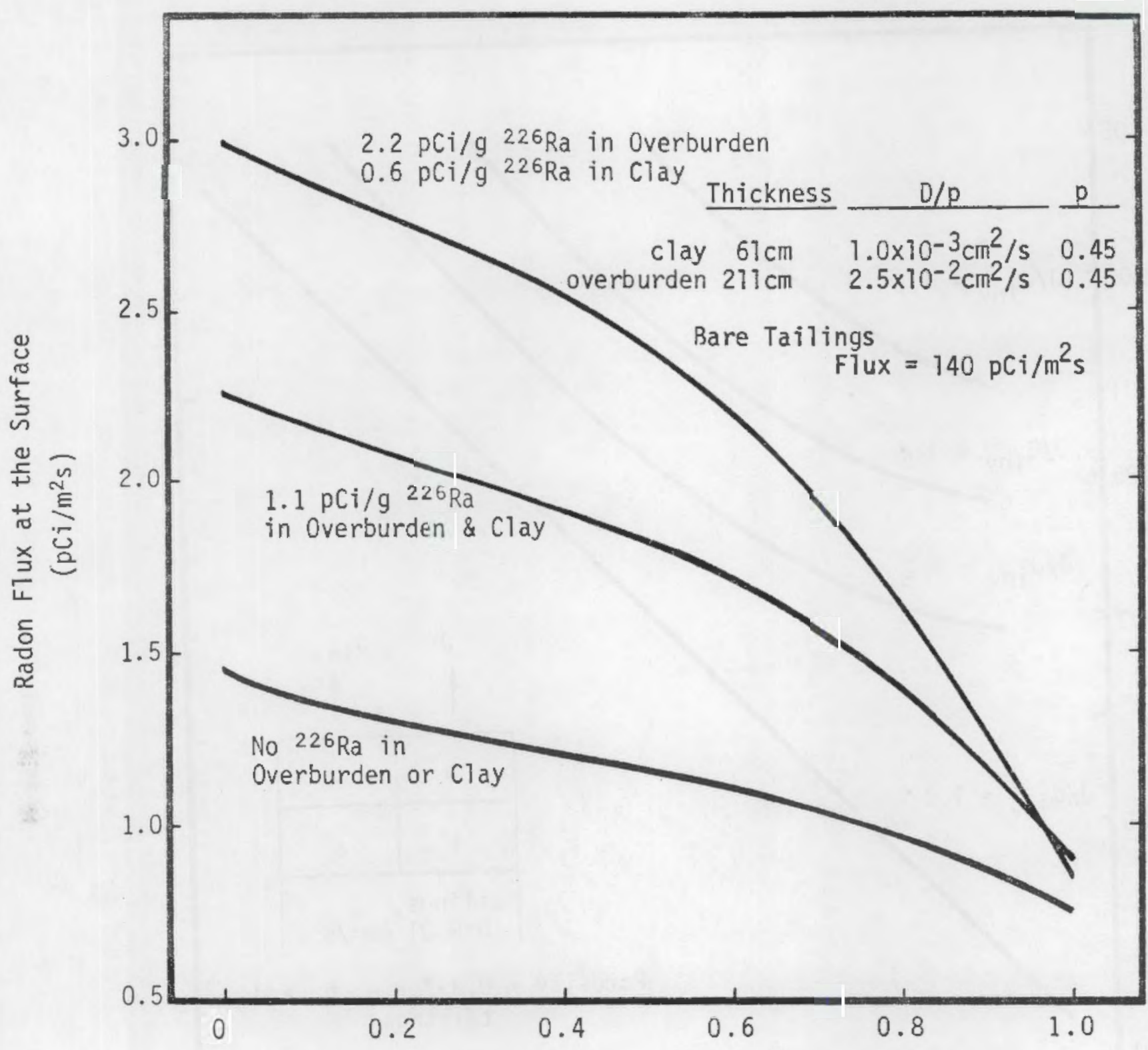

Fraction of Overburden Between Tailings and CTay

FIGURE 2.3 VARIATION IN RADON FLUX EXPECTED TO RESULT FROM VARYING THE POSITION OF THE CLAY LAYER IN A TWO-COMPONENT COVER SYSTEM. 


\subsubsection{Implications for "Contaminated" Material Utilization}

It is perhaps obvious that, if cover materials containing elevated radium are to be used, they will be most beneficial if placed adjacent to the tailings source. In such a configuration, they can provide significant reduction of the larger flux from the tailings while contributing only a minimal increase in flux due to their own radium content. The presence of different quantities

of radium in different cover layers can also change the effects of layer order, as illustrated in Figure 2.3.

Calculations with the multilayer code predict that contaminated cover material can be used effectively in multilayer systems. In fact, the radon flux from a cover system containing a layer of contaminated material could actually be lower than with identical layers of clean materials if the contaminated layer is used in a different order, such that its radon effluent is reduced by other layers, and the residual flux elevation is offset by layer-order effects. This scenario is illustrated in Figure 2.4, which shows the equilibrium radon flux which would escape from the top cover surface as additional material is placed on the cover system. Figure 2.4 also shows that virtually the same flux escapes from a $3-\mathrm{m}$ thick cover system if contaminated overburden is used in the first $91-\mathrm{cm}$, as if corresponding clean material is used in the same manner. Such a tailings cover could therefore provide for the disposal of mildly contaminated materials which may otherwise create a disposal problem, and at the same time provide additional effectiveness to the primary tailings reclamation system. 


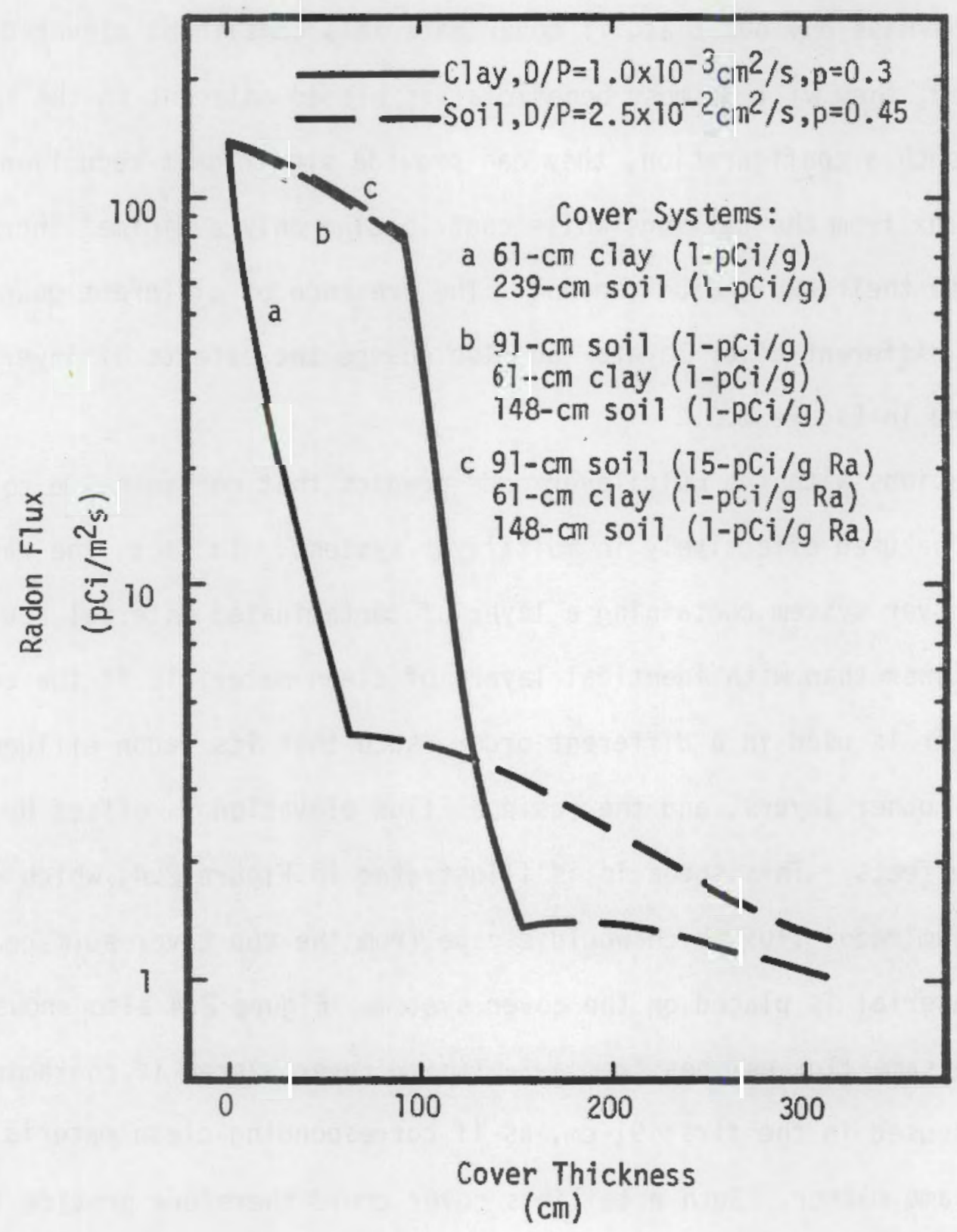

FIGURE 2.4 COMPARISON OF RADON FLUXES FROM MULTILAYERED TAILINGS COVER SYSTEMS. 


\section{EXPERIMENTAL PROCEDURES AND EQUIPMENT}

The experimental measurements conducted to characterize the multilayer tailings covers were primarily accomplished with the test columns described by Figure 1.1. The additional requirement for individual layer diffusion coefficients was met by using a separate, time-dependent method which reduced the monitoring and material requirements of the larger test columns. The following sections give details of the radon test columns, the time-dependent diffusion apparatus, and the procedures used in making the radon measurements.

\subsection{TEST COLUMNS FOR TAILINGS COVERS}

Multilayered tailings covers were compacted into test columns containing a layer of uranium mill tailings as the radon source. The bare tailings source was monitored for radon flux for 30-60 days after its initial compaction to achieve a reliable measure of the equilibrium radon flux released from the bare source. When a stable (reproducible) radon flux from the bare sources was achieved, the appropriate layers of cover materials were compacted on top of the tailings. Radon fluxes were again monitored from the top of the cover surface, and radon concentration profiles were determined from gas samples at selected points in the cover. Moistures were also monitored via electrical resistance moisture probes at selected points in the cover. The radon measurements were continued until the radon and moisture measurements showed no further trends with time. Details of the construction of the columns and the procedures used for monitoring radon fluxes, radon concentration profiles, and moistures are given in the following sections. 


\subsubsection{Construction of Columns}

Columns were initially constructed using $30-\mathrm{cm}$ diameter galvanized steel tubes (26 ga) with soldered seams and end caps. The tailings were mixed and shovelled directly into the bottom sections of the tubes and compacted with $6-\mathrm{kg}$ hammers. Grab samples were collected from the material added to the columns at $\sim 15 \mathrm{~cm}$ intervals of column height, and were used for moisture, radium and emanation coefficient measurements. The tailings consisted of mixed sand and slime fractions, and were compacted at approximately their ambient field moisture ( 18\% by weight) to achieve good compaction.

Due to the high moisture and salt content of the tailings, many of the galvanized steel tubes corroded to the point of breakthrough after two to three months. Due to the radon gas escape through the resulting pinholes in the tubes, cover materials could not be added directly to these columns. All but three (Columns 4,11 and 15) of the compacted tailings plugs were accordingly removed by cutting away the metal tubes and transferred in nearly intact condition into plastic pipes. The tailings were then recompacted and allowed to re-equilibrate to obtain a new set of bare flux measurements. The three columns left in metal tubes were covered with several coats of asphalt to avoid radon loss through possible pinhole leaks in the metal walls.

The construction of the plastic columns is illustrated in Figure 3.1. The 30-cm diameter PVC pipe had a $1.1-\mathrm{cm}$ wall thickness, and was used in 1.2-m long sections to facilitate handling. A 1.8-cm thick PVC plate was welded to the bottom of one section of the pipe, and the inner seams of the weld were additionally sealed with PVC-cement to minimize the possibility 


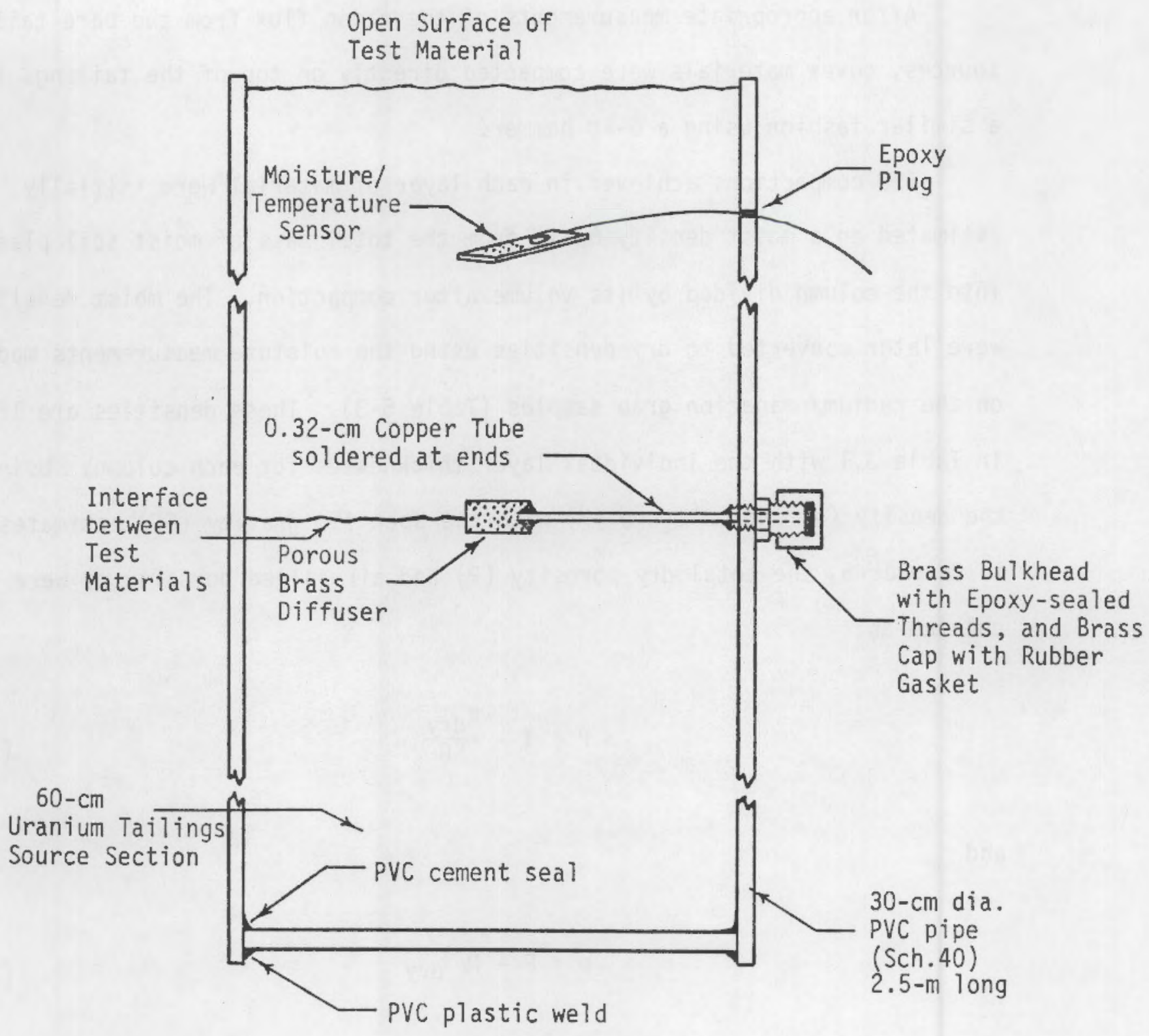

FIGURE 3.1 CONSTRUCTION DIAGRAM OF RADON DIFFUSION TEST COLUMNS. 
of radon gas leakage. Two electrical resistance probes for measuring moistures and temperatures were inserted at the time of compaction into the tailings at the 15 and $45-\mathrm{cm}$ heights, and their cables were passed through an epoxy plug to the outside of the plastic pipe.

After appropriate measurements of the radon flux from the bare tailings sources, cover materials were compacted directly on top of the tailings in a similar fashion using a $6-\mathrm{kg}$ hammer.

The compactions achieved in each layer of material were initially estimated on a moist density basis from the total mass of moist soil placed into the column divided by its volume after compaction. The moist densities were later converted to dry densities using the moisture measurements made on the radium/emanation grab samples (Table 5-3). These densities are listed in Table 3.1 with the individual layer thicknesses for each column. Using the density $(\rho)$ and moisture $(M)$ with the specific gravity (SG) estimates given in Chapter 5, the total dry porosity (P) and air-filled porosity $p$ ) were calculated as:

$$
P=1-\frac{\rho_{d r y}}{S G}
$$

and

$$
p=P-M p d r y
$$

These porosities are also summarized for each layer in Table 3.1.

Gas sampling ports were installed at the interfaces between different materials, and at selected points in the middle of certain cover sections. The ports are illustrated in Figure 3.1, and consisted of a porous brass 
TABLE 3.1

INITIAL THICKNESSES, DENSITIES AND POROSITIES OF COVER MATERIAL TEST LAYERS

\begin{tabular}{|c|c|c|c|c|c|c|}
\hline Column & Material & $\begin{array}{l}\text { Thickness } \\
\text { (cm) } \\
\end{array}$ & $\begin{array}{l}\rho_{\text {moist }} \\
\left(\mathrm{g} / \mathrm{cm}^{3}\right)\end{array}$ & $\begin{array}{c}\text { Pdry } \\
\left(\mathrm{g} / \mathrm{cm}^{3}\right)\end{array}$ & $\begin{array}{c}P \\
\left(\mathrm{~cm}^{3} / \mathrm{cm}^{3}\right)\end{array}$ & $\left(\mathrm{cm}^{3} / \mathrm{cm}^{3}\right)$ \\
\hline 1 & Tailings & 66 & 1.59 & 1.49 & 0.45 & 0.35 \\
\hline 1 & Riverton Clay & 30 & 1.56 & 1.30 & 0.52 & 0.26 \\
\hline 1 & Riverton Soil & 147 & 1.66 & 1.61 & 0.40 & 0.35 \\
\hline 2 & Tailings & 63 & 1.59 & 1.45 & 0.46 & 0.32 \\
\hline 2 & Durango Wet $\mathrm{Cl}$ ay & 76 & 2.06 & 1.74 & 0.36 & 0.04 \\
\hline 2 & Mancos Shale & 29 & 1.96 & 1.82 & 0.33 & 0.18 \\
\hline 2 & Durango Dry Clay & 74 & 1.65 & 1.55 & 0.43 & 0.34 \\
\hline 4 & Tailings & 60 & 1.76 & 1.68 & 0.38 & 0.30 \\
\hline 4 & Shiprock Clay & 61 & 1.39 & 1.15 & 0.57 & 0.34 \\
\hline 4 & Shiprock Soil & 97 & 1.57 & 1.48 & 0.45 & 0.36 \\
\hline 6 & Tailings & 68 & 1.55 & 1.42 & 0.47 & 0.34 \\
\hline 6 & Vitro Soil & 125 & 2.16 & 1.89 & 0.30 & 0.03 \\
\hline 6 & Vitro Clay & 30 & 1.74 & 1.42 & 0.47 & 0.15 \\
\hline 6 & Vitro Soil & 20 & 2.00 & 1.82 & 0.33 & 0.15 \\
\hline 7 & Tailings & 61 & 1.63 & 1.51 & 0.44 & 0.32 \\
\hline 7 & Mancos Shate & 30 & 2.30 & 2.10 & 0.22 & 0.025 \\
\hline 7 & Durango Wet Clay & 76 & 2.01 & 1.64 & 0.39 & 0.02 \\
\hline 7 & Durango Dry $\mathrm{Clay}$ & 76 & 1.66 & 1.56 & 0.42 & 0.32 \\
\hline 8 & Tailings & 63 & 1.52 & 1.41 & 0.48 & 0.37 \\
\hline 8 & Vitro Clay & 30 & 1.65 & 1.29 & 0.52 & 0.16 \\
\hline 8 & Vitro Soil & 150 & 1.81 & 1.60 & 0.41 & 0.19 \\
\hline 9 & Tailings & 62 & 1.56 & 1.49 & 0.45 & 0.38 \\
\hline 9 & Vitro Soil & 152 & 1.71 & 1.53 & 0.43 & 0.25 \\
\hline 10 & Tailings & 65 & 1.62 & 1.50 & 0.44 & 0.32 \\
\hline 10 & Vitro Clay & 33 & 1.71 & 1.35 & 0.50 & 0.14 \\
\hline 10 & Vitro Soil & 145 & 1.86 & 1.66 & 0.39 & 0.19 \\
\hline
\end{tabular}


TABLE 3.1 (CONT'D)

INITIAL, THICKNESSES, DENSITIES AND POROSITIES OF COVER MATERIAL TEST LAYERS

\begin{tabular}{|c|c|c|c|c|c|c|}
\hline Column & Material & $\begin{array}{l}\text { Thickness } \\
(\mathrm{cm})\end{array}$ & $\begin{array}{l}\rho_{\text {moist }} \\
\left(\mathrm{g} / \mathrm{cm}^{3}\right)\end{array}$ & $\begin{array}{c}\rho \mathrm{dry} \\
\left(\mathrm{g} / \mathrm{cm}^{3}\right)\end{array}$ & $\begin{array}{c}P \\
\left(\mathrm{~cm}^{3} / \mathrm{cm}^{3}\right) \\
\end{array}$ & $\begin{array}{c}P \\
\left(\mathrm{~cm}^{3} / \mathrm{cm}^{3}\right)\end{array}$ \\
\hline 11 & Tailings & 62 & 1.71 & 1.63 & 0.40 & 0.32 \\
\hline 11 & A- (aggregate) & 11.4 & 1.94 & 1.89 & 0.30 & 0.25 \\
\hline 13 & Tailings & 61 & 1.54 & 1.44 & 0.47 & 0.37 \\
\hline 13 & Vitro Clay & 30 & 1.61 & 1.31 & 0.51 & 0.21 \\
\hline 15 & Tailings & 61 & 1.72 & 1.61 & 0.40 & 0.29 \\
\hline 15 & A+ (aggregate) & 12.7 & 2.04 & 1.98 & 0.27 & 0.21 \\
\hline
\end{tabular}


gas-line filter sealed to a $0.32-\mathrm{cm}$ diameter copper tube which was in turn soldered to a brass bulkhead fitting which was screwed and epoxy-sealed to the PVC pipe. The bulkhead was capped when not in use with a gas-tight cap. In the case of the galvanized steel columns, the bulkhead fittings were soldered in the tube wall. Each of the tall columns described by Figure 1.1 typically had five gas sampling ports and five moisture/temperature probes.

Extensions were attached to the 1.2-m base sections of the PVC pipes using $30-\mathrm{cm}$ diameter PVC pipe couplers and sealing with PVC plastic primer and cement. The galvanized steel extensions were attached to Column 4 by epoxy-sealing the metal tube connections. The top surfaces of the cover material were left exposed to the room atmosphere.

The test columns were located in a laboratory enclosure which was kept at a slightly negative pressure with respect to the building atmosphere to exhaust continuously radon effluents from the columns and to avoid introduction of radon into the building ventilation system. Temperature, humidity and barometric pressure were continuously monitored inside the laboratory enclosure.

\subsubsection{Monitoring Procedures For Radon Fluxes}

Radon fluxes were routinely sampled using a flux accumulator can and Lucas Cell arrangement as illustrated in Figure 3.2. For comparative purposes, a number of flux measurements were also conducted using a modified flux can arrangement in which the flux can covered the entire top of the column, and other measurements were conducted using charcoal canisters.

The procedure for using the flux cans was similar to that of Wilkening. (12) The Lucas Cell was first evacuated with a vacuum pump $(<10 \mu \mathrm{m} \mathrm{Hg})$ and counted 


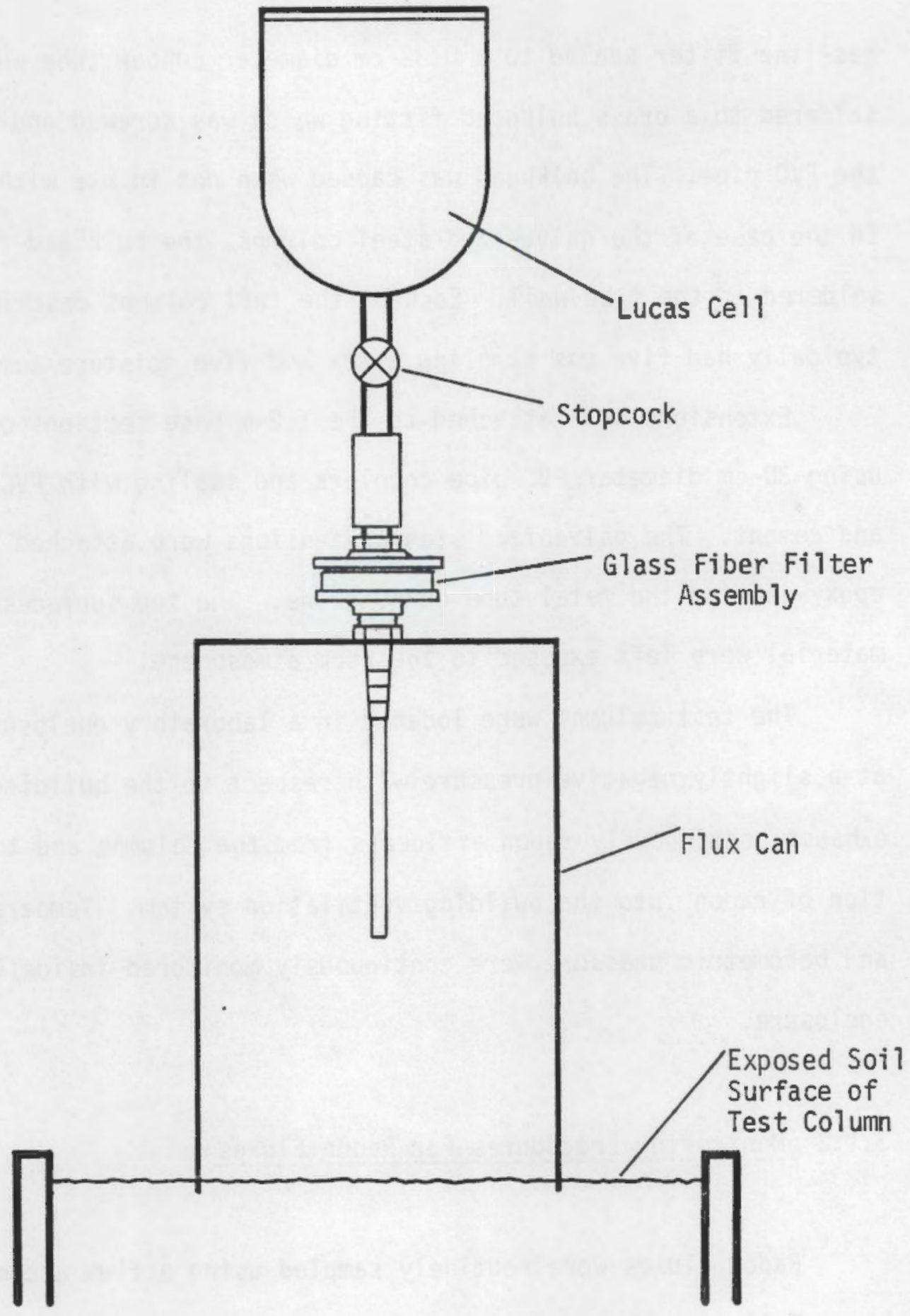

FIGURE 3.2 RADON FLUX SAMPLING WITH FLUX CAN AND LUCAS CELL. 
to determine its background alpha activity. The cell was then attached to the 3.2-liter flux can via a tygon tube which was in turn attached to a $2.5-\mathrm{cm}$ diameter filter holder containing a type A/E (Gelman) glass-fiber filter to avoid particulate contamination of the Lucas Cell. The Lucas-Cell-can assembly was then placed on the exposed soil surface of the column being tested and allowed to accumulate radon over a ten-minute interval. At the end of the sampling interval, the stopcock was opened to draw a $100-\mathrm{cm}^{3}$ air sample from the volume of the flux can and was again closed. The Lucas Cell was then allowed to stand for at least an hour for radon daughter ingrowth before being counted.

The Lucas Cells (Rocky Mountain Scientific Glassware, Aurora, Colorado), were similar to those first described by Lucas. (13) The cells were typically counted for ten minutes on a $3.8-\mathrm{cm}$ diameter photo tube connected to a scalertimer (Model 2200, Ludlum Measurements Inc., Sweetwater, Texas), equipped with a variable threshold, high voltage and amplifier gain. The scaler response was adjusted prior to use to achieve optimum response with minimum background. Initial calibration and quality control checks of the counting system are described in Chapter 4.

Radon fluxes were computed from the alpha counting data using Eq 3-3:

$$
J=\frac{(\text { Cnt }-B k) \lambda}{e^{-\lambda t}-e^{-\lambda\left(t+t_{C}\right)}} \frac{V_{c a n}}{V_{c e 11} t_{s} A_{c a n} \varepsilon f_{B}(3 \alpha / d i s)(0.037 \mathrm{dps} / p C i)} \text {, }
$$

where

$$
\begin{aligned}
\mathrm{J} & =\text { radon flux }\left(\mathrm{pCi} / \mathrm{m}^{2} \mathrm{~s}\right) \\
\mathrm{Cnt}= & \text { counts observed during counting interval } \mathrm{t}_{\mathrm{C}} \\
\mathrm{Bk}= & \text { background counts prior to sample collection } \\
& \text { for same interval, } \mathrm{t}_{\mathrm{C}}
\end{aligned}
$$




$$
\begin{aligned}
& \lambda \quad=\text { radon decay constant }\left(2.1 \times 10^{-6} s^{-1}\right) \\
& t \quad=\text { time from sample collection to start of count (s) } \\
& t_{c}=\text { counting time interval ( } s \text { ) } \\
& V_{\text {can }}=\text { volume of flux can (liters) } \\
& V_{\text {ce } 11}=\text { volume of Lucas cell (1iters) } \\
& t_{s}=\text { flux sampling time interval (s) } \\
& A_{\text {can }}=\text { soil surface area covered by flux can }\left(m^{2}\right) \\
& \epsilon \quad=\text { absolute Lucas cell efficiency } \\
& f_{B}=\text { Radon-daughter equilibrium factor, from Table } 3.1
\end{aligned}
$$

The numerical values in Eq 3-3 account for the emission of three alpha particles from the disintegration of each radon atom, and convert from units of disintegrations per second to picocuries. Lucas Cell efficiency calibrations are described in Chapter 4. The radon-daughter equilibrium factor accounts for the disequilibrium between the radon daughters ${ }^{214} p_{0}$ and $218 p_{0}$ and their parent ${ }^{222} \mathrm{Rn}$ when the cell is counted less than 230 min after the time of sample collection. Typical equilibrium factors are presented in Table 3.2, as calculated from the Bateman equation. (14) A value of unity is used for all times beyond 240 minutes.

A modified flux sampling procedure was used for measuring possible nonuniform flux from the top of the test column. This procedure utilized the 10-30 cm high empty space at the top of the column as the sampling volume, and entailed sealing a $30-\mathrm{cm}$ diameter cap to the top of the column. The cap was fitted with a sampling port and tube which reached to the center of the void space, in a similar manner to the flux can arrangement illustrated in Figure 3.2. The cap was sealed into place with tape at the beginning of the (10-min) sampling period, and sample collection and counting were 
identical to the standard flux-can procejure. The modified procedure sampled over the entire column diameter, and could detect possible channeling of radon along walls due to soil shrinkage.

Radon fluxes were also sampled, on a limited scale, using charcoal canisters. The methods for using the canisters were similar to those reported previously. $(3,15)$ The canister sampling arrangement is illustrated in Figure 3.3, and consisted of an 8.3-cm diameter, 4.1-cm high can containing a type GMA charcoal cartridge (Mine Safety Appliance, Pittsburgh, Pennsylvania), and a protective filter paper. The charcoal cartridge was heated to $125^{\circ} \mathrm{C}$ for $12 \mathrm{~h}$ in a ventilated oven prior to use to expel any radon and moisture accumulated by previous usage or during storage. The cooled cartridge was sealed in a polyethylene bag until use.

Sample collection was initiated by inserting the canister and protective filter paper into the sampling can, and pressing the resulting assembly into the soil surface to be sampled. Void space was minimized by inserting until the cartridge assembly contacted the soil surface. The filter paper prevented contamination of the cartridge by soil. After a typical sampling interval of $4 \mathrm{~h}$, the cartridge was removed from the can and sealed in a polyethylene bag for a 4 h equilibration period prior to counting.

Radon adsorbed on the charcoal was analyzed by gamma-ray spectroscopy using the $609-\mathrm{keV}$ peak from ${ }^{214} \mathrm{Bi}$. The cartridge was counted near the surface of a $13 \times 13-\mathrm{cm} \mathrm{NaI}$ (T1) scintillation crystal coupled to a multichannel pulse-height analyzer. The sample and detector were positioned in a shielded counting chamber having $10-\mathrm{cm}$ lead or $25-\mathrm{cm}$ steel walls. The counts in the 609-keV peak were summed over 10-minute intervals and were corrected for background using appropriate regions on each side of the peak. 
Calibration of the gamma counts was based on a pitchblende ore standard, (16) and is described in Chapter 4.

Radon fluxes sampled by charcoal canisters were calculated using Equation 3-4:

$$
J=\frac{C n t \lambda^{2}}{\left.\varepsilon A_{C}\left(1-e^{-\lambda t} s\right)\left(e^{-\lambda t}-e^{-\lambda\left(t+t_{C}\right.}\right)\right)(0.037 \mathrm{dps} / p C i)} \text {, }
$$

where

$$
\begin{aligned}
& \text { Cnt }=\text { net counts in } 609-\mathrm{keV} \text { peak during counting interval } t_{c} \\
& \lambda=\text { radon decay constant }\left(2.1 \times 10^{-6} s^{-1}\right) \\
& \varepsilon \quad=\text { detector efficiency (counts/disintegration) } \\
& A_{C}=\text { soil surface area sampled by canister }\left(\mathrm{m}^{2}\right) \\
& t_{s}=\text { flux sampling time interval (s) } \\
& t \text { = time from end of flux sampling to beginning of count (s) } \\
& t_{c}=\text { counting time interval (s) }
\end{aligned}
$$

This equation assumes that all radon exhaled from the soil surface beneath the canister was adsorbed onto the charcoal and remained there until the canister was counted, and that the presence of the canister did not alter the radon flux inside the sampling area. These assumptions are validated in Chapter 4.

\subsubsection{Monitoring Procedure For Radon Concentration Profiles}

Profiles of the radon concentrations at various heights in the test columns were measured using Lucas Cells to sample the soil gas from the sampling ports illustrated in Figure 3.1. The procedure, as with the flux 
TABLE 3.2

RADON-DAUGHTER EQUILIBRIUM FACTORS, $f_{B}$, CALCULATED FROM THE BATEMAN EQUATION

$\underline{t(\min )}$

0

10

20

30

40

50

60

70

80

90

100

110

120
$\underline{f_{B}}$

0.333

0.638

0.691

0.727

0.763

0.799

0.832

0.862

0.887

0.909

0.927

0.942

0.954 $\underline{t(\min )}$

130

140

150

160

170

180

190

200

210

220

230

240

250
$\underline{f_{B}}$

0.964

0.972

0.978

0.983

0.988

0.991

0.993

0.995

0.997

0.998

0.999

1.000

1.000 


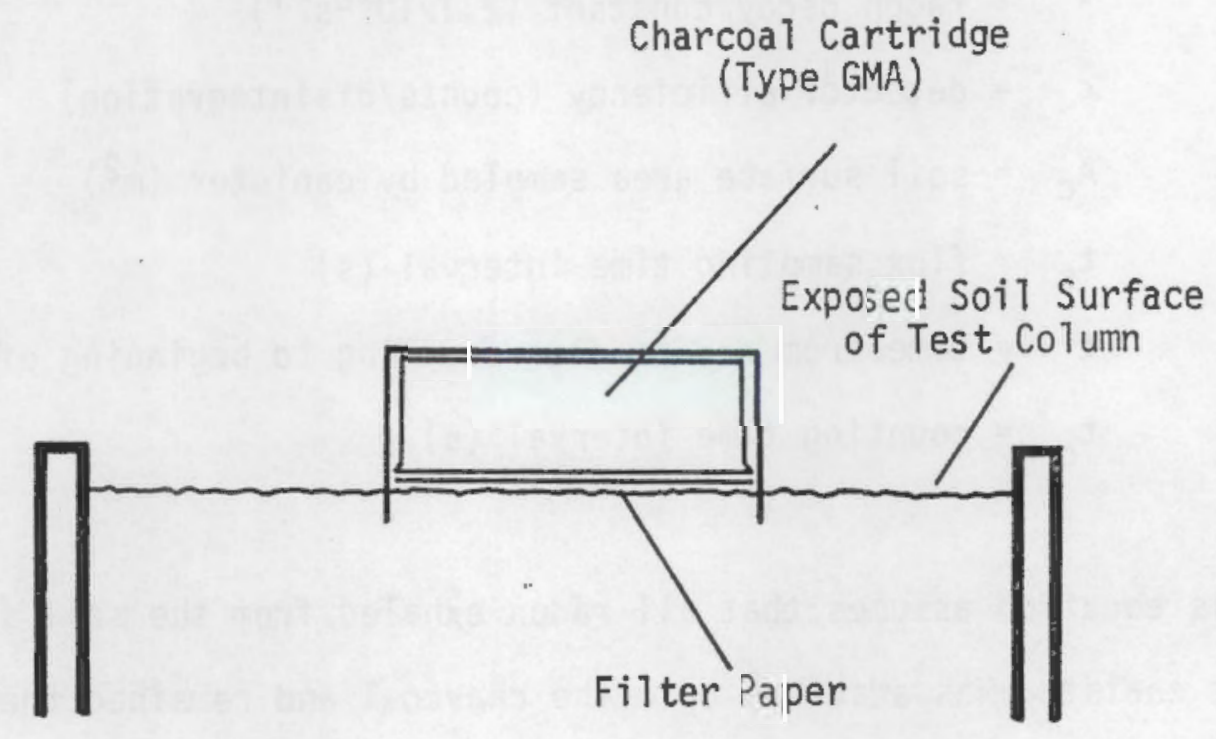

FIGURE 3.3 RADON FLUX SAMPLING WITH A CHARCOAL CANISTER. 
measurements, involved preparation of the Lucas Cell by evacuating and counting of its background alpha activity. The cell was then attached to a glass-fiber filter assembly, which was in turn screwed onto the buikhead of the sampling port. The stopcock of the Lucas Cell was opened for approximately ten seconds to draw the sample of soil gas, and was again closed. The cell was allowed to equilibrate for at least $1 \mathrm{~h}$, after which it was counted with the phototube assembly described earlier.

The radon concentration was then calculated as:

$$
C=\frac{(\text { Cnt }-B k) \lambda}{e^{-\lambda t}-e^{-\lambda\left(t+t_{C}\right)}} \frac{1}{\left(V_{c e} 11^{-V}\right) \varepsilon f_{B}(3 \alpha / d i s)(0.037 \mathrm{dps} / p C i)}
$$

where all definitions are identical to those in Equation 3-3. In this case, the Lucas Cell volume is corrected by an increment $V_{\Delta}$ to account for the incomplete sample volume collection which occured in cases of wet clays. In such cases, the air permeability in the clay was so low that the $100-\mathrm{cm}^{3}$ volume of air could not be sampled. The value of the correction volume was measured on all samples after the Lucas Cell counting was completed. The measurement was accomplished by attaching a long $0.4-\mathrm{cm}$ diameter tygon tube to the Lucas Cell and placing the opposite end into a beaker of water. The Lucas Cell valve was then opened to draw water into the tube with whatever vacuum remained due to incomplete sample collection. The water level in the tube was then matched with that in the beaker and marked. The volume, $V_{\Delta}$, was then computed from the cross-sectional opening of the tube multiplied by the observed water-filled length. 


\subsubsection{Monitoring of Soil Moistures and Temperatures}

Soil moistures and temperatures were measured using a moisture/temperature meter (Mode1 MC-3D2, Soiltest, Inc., Evanston, Illinois), and the moisture/temperature cells (MC-360, Soiltest, Inc.), illustrated in Figure 3.1. The cells were installed at the time of column construction, and contained two plates separated by a fiberglass binding. The binding provided a coupling which varied with the moisture content of the surrounding medium, and, being porous, caused the observed resistance to vary nearly directly with the pore pressure or "suction" of the water in the soil medium. The meter provided an $A C$ potential which was used with appropriate circuitry for the resistance measurement. The cells also contained a thermister which was used to monitor the temperature profiles in the columns, with the same meter. Soil moistures and temperatures were monitored weekly in the test columns by sequentially connecting each probe to the meter.

Calibration of the moisture cells was accomplished by relating the initial cell readings after column construction to the initial moisture content of the soil materials as determined from grab samples. The calibration was performed in terms of cell resistance versus capillary pressure in order to provide a universal cell calibration which would be valid for all of the soil materials. Figure 3.4 illustrates this calibration, which was based on the Vitro, Durango and Riverton materials. Shiprock data were excluded due to a time lag between column construction and moisture cell measurements. The Grand Junction data were excluded because the water retention characteristic curves were not available to relate the actual moistures to capillary pressures. The data in Figure 3-4 were fitted to a quadratic by least-squares to obtain the functional relationship 


$$
\log (R)=-8.55+5.17 \log (P)-0.438[\log (P)]^{2},
$$

which is readily used with water retention curves for each material (Chapter 5) to relate cell resistance to the weight percentage of water.

A separate calibration was performed for the tailings material in anticipation that the cell resistance would be affected by its higher salt content. This calibration was performed directly in terms of cell resistance versus percentage moisture, as illustrated in Figure 3.5 , because the calibration was unique to the tailings material.

\subsection{SMALL-SAMPLE TRANSIENT DIFFUSION MEASUREMENTS}

In order to use the multilayer radon diffusion model, ${ }^{(2)}$ developed under Task 1, to analyze the diffusion in the multilayer test columns, certain parameters must be known to characterize each component layer. One of these is the radon diffusion coefficient of the layer. Because radon diffusion coefficients vary so greatly with changes in compaction and moisture, ${ }^{(3)}$ it was necessary to measure the individual material diffusion coefficients at approximately the same moisture and compaction as they had in the test columns.

The diffusion coefficients for the Vitro cover materials were determined from the flux data from Columns 9 and 13, which had single-layer covers. These diffusion coefficients were then adjusted for moisture and porosity differences from corresponding materials in the multilayer columns $(6,8$ and 10). A comparison of the diffusion coefficients measured in Columns 9 and 13 with those measured on the same materials by a small sample transient (SST) method enabled use of the SST method for defining 


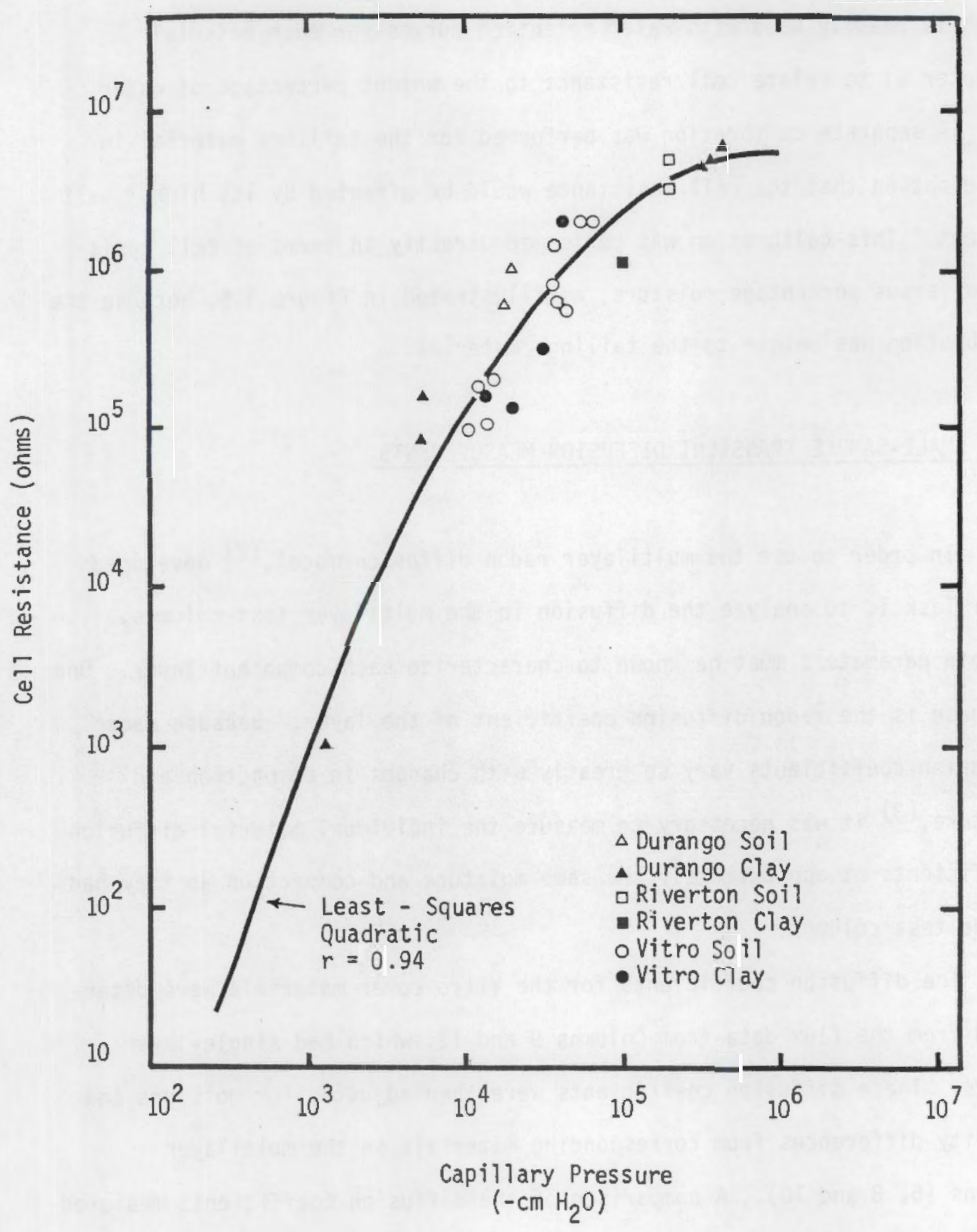

FIGURE 3.4 CALIBRATION OF SOIL MOISTURE CELLS IN TERMS OF SOIL CAPILLARY PRESSURE. 


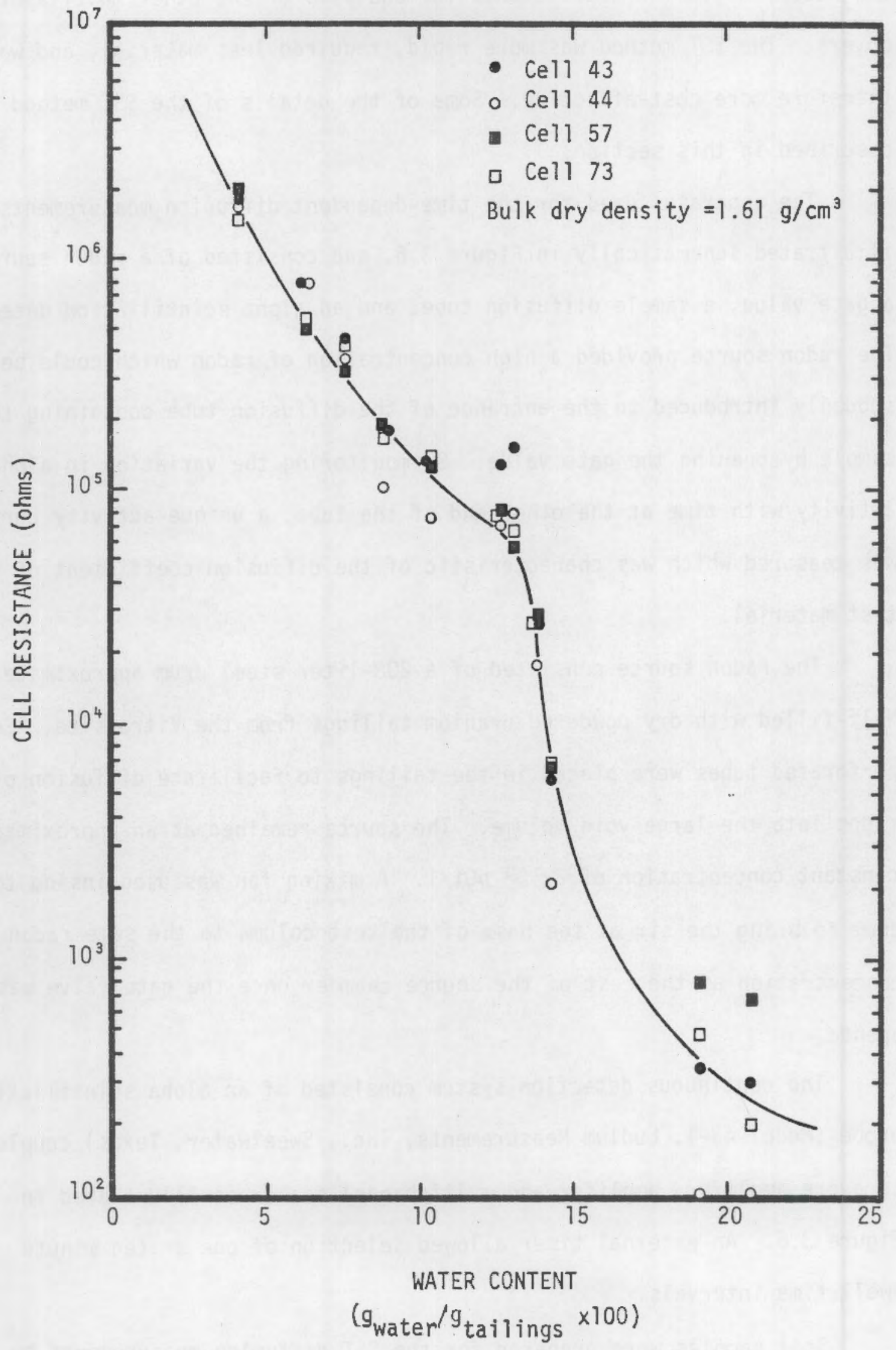

FIGURE 3.5 CALIBRATION OF SOIL MOISTURE CELLS FOR VITRO TAILINGS 
the needed diffusion coefficients for analys is of the other multilayered covers. The SST method was more rapid, required less materiaT, and was therefore more cost-effective. Some of the details of the SST method are described in this section.

The apparatus used for the time-dependent diffusion measurements is illustrated schematically in Figure 3.6, and consisted of a radon source, a gate value, a sample diffusion tube, and an alpha scintillation detector. The radon source provided a high concentration of radon which could be suddenly introduced to the entrance of the diffusion tube containing the sample by opening the gate valve. By monitoring the variation in alpha activity with time at the other end of the tube, a unique activity curve was measured which was characteristic of the diffusion coefficient of the test materia1.

The radon source consisted of a 208-liter steel drum approximately half-filled with dry powdered uranium tailings from the Vitro site. Several perforated tubes were placed in the tailings to facilitate diffusion of radon into the large void volume. The source remained at an approximately constant concentration of $3 \times 10^{5} \mathrm{pCi} / 1$. A mixing fan was used inside the drum to bring the air at the base of the test column to the same radon concentration as the rest of the source chamber once the gate valve was opened.

The continuous detection system consisted of an alpha scintillation probe (Model 43-1, Ludlum Measurements, Inc., Sweetwater, Texas) coupled to a pre-amplifer, amplifer and multichannel scaler as illustrated in Figure 3.6. An external timer allowed selection of one or ten minute dwell time intervals.

Soil samples were prepared for the SST diffusion measurements by first 


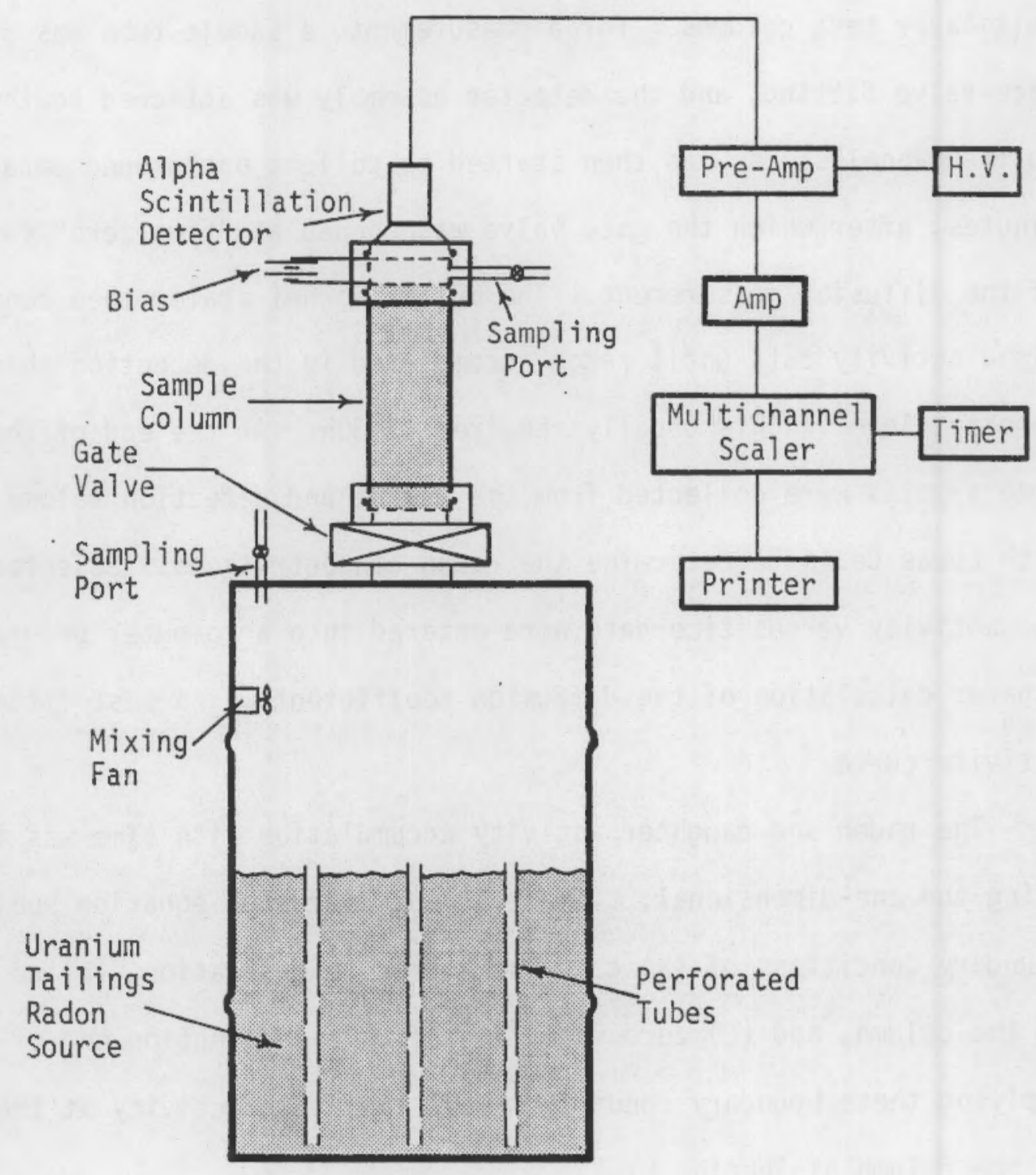

FIGURE 3.6 TIME-DEPENDENT RADON DIFFUSION MEASUREMENT APPARATUS. 
bringing their moisture content to the appropriate level, and then compacting them into the plastic diffusion tubes. Care was taken to closely approximate the average moisture and compaction of the corresponding material layers in the multilayer test columns. For a measurement, a sample tube was attached to the gate-valve fitting, and the detector assembly was attached to the tube. The multi-channel scaler was then started to collect background data for several minutes, after which the gate valve was opened at "time zero" for initiation of the diffusion measurement. The multi-channel scaler then continued to collect alpha activity data until radon accumulated in the detection chamber reached a constant level. This usually required $12-30 \mathrm{~h}$. At the end of the data collection, grab samples were collected from the source and detection volume sampling ports with Lucas Cells to determine the radon concentrations. Selected points from the activity versus time data were entered into a computer program for a leastsquares calculation of the diffusion coefficient which best fitted the observed activity curve.

The radon and daughter activity accumulation with time was interpreted using the one-dimensional, time-dependent diffusion equation subject to the boundary conditions of (a) constant source concentration, (b) no initial radon in the column, and $(c)$ zero radon flux from the detection end of the column. Applying these boundary conditions gave the radon activity at the detector end of the column of length, L,

$$
C(L, t)=C_{0} \sum_{n=1}^{\infty} \frac{(-1)^{n-1}(2 n-1)}{\left(\frac{\lambda L^{2}}{\pi D}\right)+\frac{(2 n-1)^{2} \pi}{4}}\left[1-\exp \left(-\lambda t-\frac{(2 n-1)^{2} \pi D t}{4 L^{2}}\right)\right]
$$


It was assumed that the only radon daughters in the detection volume were those both there; i.e., no daughters diffused from the soil column into the detection volume. Equation 3-7 was therefore coupled with the Bateman equations ${ }^{(14)}$ for calculating the daughter ingrowth with time for the increasing radon parent activity. The coupled equations were analyzed with a computer to calculate the total alpha activity at any time as a function of the column length. The computer code used this algorithm iteratively to select the diffusion coefficient which best characterized the observed alpha activity curve. The data analys is program permitted entry of ten alpha activities and times selected from the breakthrough and final plateau regions of the activity curve, which were fitted by least squares to the optimum diffusion coefficient. 



\section{QUALITY CONTROL MEASUREMENTS}

Experiments dealing with radon sampling or diffusion have traditionally involved high uncertainties due to sampling errors, analytical errors or uncontrolled experimental variables such as climatological variations, soil moisture and mechanical variations, or unexpected sources or leaks in experimental systems. Some of the discrepancies in radon literature have also resulted from the lack of standard methods or equipment among different laboratories. The uncertainties and lack of inter-laboratory comparison have sometimes caused difficulty in adequately interpreting and utilizing past research results.

In an effort to document the present experimental methods and verify their adequacy for the multilayer tailings cover research, a variety of supporting experiments and measurements were conducted. These are described in the following sections and deal with radon flux sampling, testing of radon leakage through experimental materials, and calibrations of the measurement equipment.

\subsection{RADON FLUX SAMPLING}

Several experiments were conducted in connection with radon flux sampling procedures and equipment. Both charcoal canisters and flux cans were evaluated in an effort to demonstrate their suitability for monitoring the multilayer test columns. The flux-sampling experiments specifically dealt with the effects of moisture on radon flux sampling, the effects of radial diffusion due to a high radon concentration inside the sampling container, a comparison of fluxcan and charcoal canister sampling methods, and an evaluation of the precision of the flux-measurement procedures. The following sections discuss these experiments in detail. 
Because of the need for comparing flux-measurement methods and sampling devices, a standard radon flux source was prepared by placing $\sim 45-\mathrm{cm}$ of dry tailings into a 170-liter can and covering them with a 15-cm layer of dry sand. The resulting flux source was shown to be uniform over its $50-\mathrm{cm}$ diameter by simultaneous sampling with flux-cans and also with charcoal canisters. This source was used for most of the following quality-control experiments.

\subsubsection{Effects of Moisture on Radon Flux Sampling}

When a charcoal canister is exposed to a moist soil surface for collection of a radon flux sample, it also absorbs water vapor from the soil surface. It has been reported ${ }^{(17)}$ that elevated moisture in the activated charcoal lowers its efficiency for radon adsorption. The following experiment was therefore designed to demonstrate the magnitude of the interference of moisture with radon flux sampling using type GMA charcoal canisters as described in Chapter 3.

Because of the time and uncertainties involved in letting the charcoal absorb water vapor from a soil surface, several charcoal canisters were directly moistened by injecting water into the center of the charcoal mass with a hypodermic syringe. The canisters were dried to constant weight beforehand, and were allowed to equilibrate for several days in individual sealed plastic bags after the injection to permit uniform moisture distribution. The canisters were again weighed to determine their moisture content, and were then exposed to the standard radon flux source for a 4-h interval.

The resulting observed radon fluxes, normalized to unity, are illustrated in Figure 4.1. The moisture caused a forty percent decrease in the observed flux when present in quantities of $20-25 \mathrm{~g}$, which corresponds to approximately 


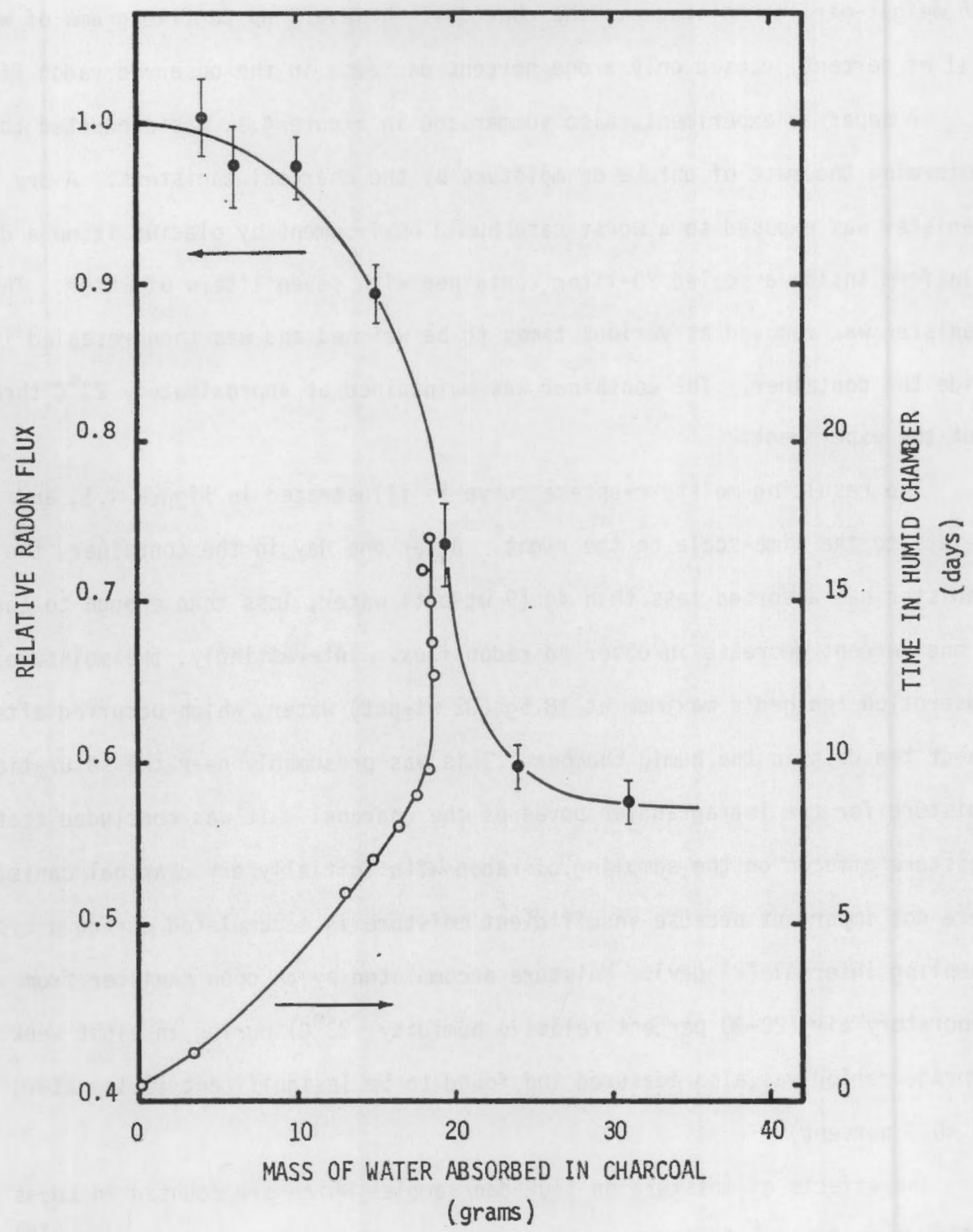

FIGURE 4.1 MOISTURE UPTAKE ANO ITS EFFECT ON CHARCOALCANISTER RADON-FLUX SAMPLING. 
36 weight-percent moisture in the charcoal. However, up to five grams of water (11 wt percent) caused only a one percent decrease in the observed radon flux. A separate experiment, a1so summarized in Figure 4.1 , was conducted to determine the rate of uptake of moisture by the charcoal canisters. A dry canister was exposed to a worst case humid environment by placing it on a dry platform inside a sealed 20-liter container with seven liters of water. The canister was removed at various times to be weighed and was then resealed inside the container. The container was maintained at approximately $23^{\circ} \mathrm{C}$ throughout the experiment.

The resulting moisture-uptake curve is illustrated in Figure 4.1 , and refers to the time-scale on the right. After one day in the container, the canister had absorbed less than $4 \mathrm{~g}$ ( 9 wt-pct) water, less than enough to cause a one percent decrease in observed radon flux. Interestingly, the moisture absorption reached a maximum at $18.5 \mathrm{~g}$ ( $32 \mathrm{wt}-\mathrm{pct}$ ) water, which occurred after about ten days in the humid chamber. This was presumably near the saturation moisture for the intragranular pores of the charcoal. It was concluded that moisture effects on the sampling of radon with initially dry charcoal canisters were not important because insufficient moisture is accumulated during a typical sampling interval ( $<1$ day). Moisture accumulated by an open canister from laboratory air $\left(20-30\right.$ percent relative humidity, $\left.23^{\circ} \mathrm{C}\right)$ during an eight week storage period was also measured and found to be insignificant $(0.1 \mathrm{~g}$ water, or $<0.3$ percent).

The effects of moisture on flux-can samples which are counted in Lucas Cells were also considered to be insignificant. The work of H.F. Lucas (18) demonstrated by direct addition of water to a Lucas Cell that the humidity in the cell did not lower its efficiency when it was properly coated on the inside with conducting materials. Lucas reported that under low-humidity conditions, 
static charges could affect the counting efficiency by attraction of the radon daughters to more or less sensitive regions of the cell. The Lucas Cells used in this work (Rocky Mountain Scientific Glassblowing, Aurora, Colorado) were prepared with an interior conductive coating which avoided the humidity effects.

\subsubsection{Effects of Radial Diffusion in Radon Flux Sampling}

The process of sampling the radon flux at a soil surface usually causes a perburbation in the radon flux, potentially biasing the measurement. The magnitude of the perturbation can be minimized with appropriate procedural precautions, but it may become significant with many sampling methods under certain conditions such as those of high radon flux and high diffusivity. The methods examined here include the charcoal-canister and flux-can sampling methods.

The usual cause of the flux-sampling perturbation is the accumulation of a high radon concentration inside the radon-collection volume of the sampler. The high concentration causes a potential negative bias in the flux measurement by two mechanisms. First, the lower radon concentration gradient in the sampling area lowers the radon flux from the area as predicted from basic diffusion equations (Chapter 2). This mechanism requires a relatively high accumulated radon concentration to lower significantly the radon flux, however, and is probably not the dominant effect in sampling from an open system. Instead, the second mechanism, that of radial diffusion, occurs to relieve the otherwise high concentration which would accumulate inside the sampling device. Several experiments were conducted to define the sampling-time and geometric parameters needed to assure that the radon flux sampling in the present work was not subject to significant bias. The following paragraphs describe these experiments.

In order to define the time interval over which radon flux accumulation 
was linear, sampling-time comparisons were conducted with both charcoal-canister samplers and flux-can samplers. As expected, the charcoal-canister samplers permitted a much longer sampling interval due to the removal of gaseous radon by adsorption on the charcoal. Ten flux samples were collected sequentially from each of two test sources. One was a bare tailings source (61-cm thick $x$ $30-\mathrm{cm}$ diameter) identical to those used for the multilayer test columns, and the other was the sand-covered tailings source described at the beginning of this chapter. The sampling procedure and flux calculations were as described in Chapter 3, and the sampling intervals varied from 16 to 7800 minutes. The radon fluxes measured over these intervals are illustrated in Figure 4.2.

As illustrated, sampling intervals of up to $1700 \mathrm{~min}$ ( $<1$ day) yielded fluxes which were still within the uncertainties of the fluxes collected over shorter intervals for both experiments. The fitted curves suggested that a bias of 5-10 percent did not occur until the sampling time reached 1000 min, and that the bias from the 4h sampling intervals used in this study was small compared to other sources of variation. The upper curve in Figure 4.2 also indicates that the type GMA charcoal canisters adsorbed up to $9 \times 10^{5} \mathrm{pCi}$ of radon on $40 \mathrm{~g}$ of granular charcoal.

A similar sampling-time experiment was conducted using flux-accumulator cans and sampling with Lucas Cells as described in Chapter 3 . The results of this experiment are summarized in Figure 4.3 in terms of the total radon concentration accumulated inside the sampling can. Least-squares fitting of the data to a quadratic gave the relation of radon concentration ( $\mathrm{C}, \mathrm{pCi} / \mathrm{liter}$ ) to sampling time $(t, \min )$ as

$$
C=51.9+57.2 t-0.32 t^{2}
$$




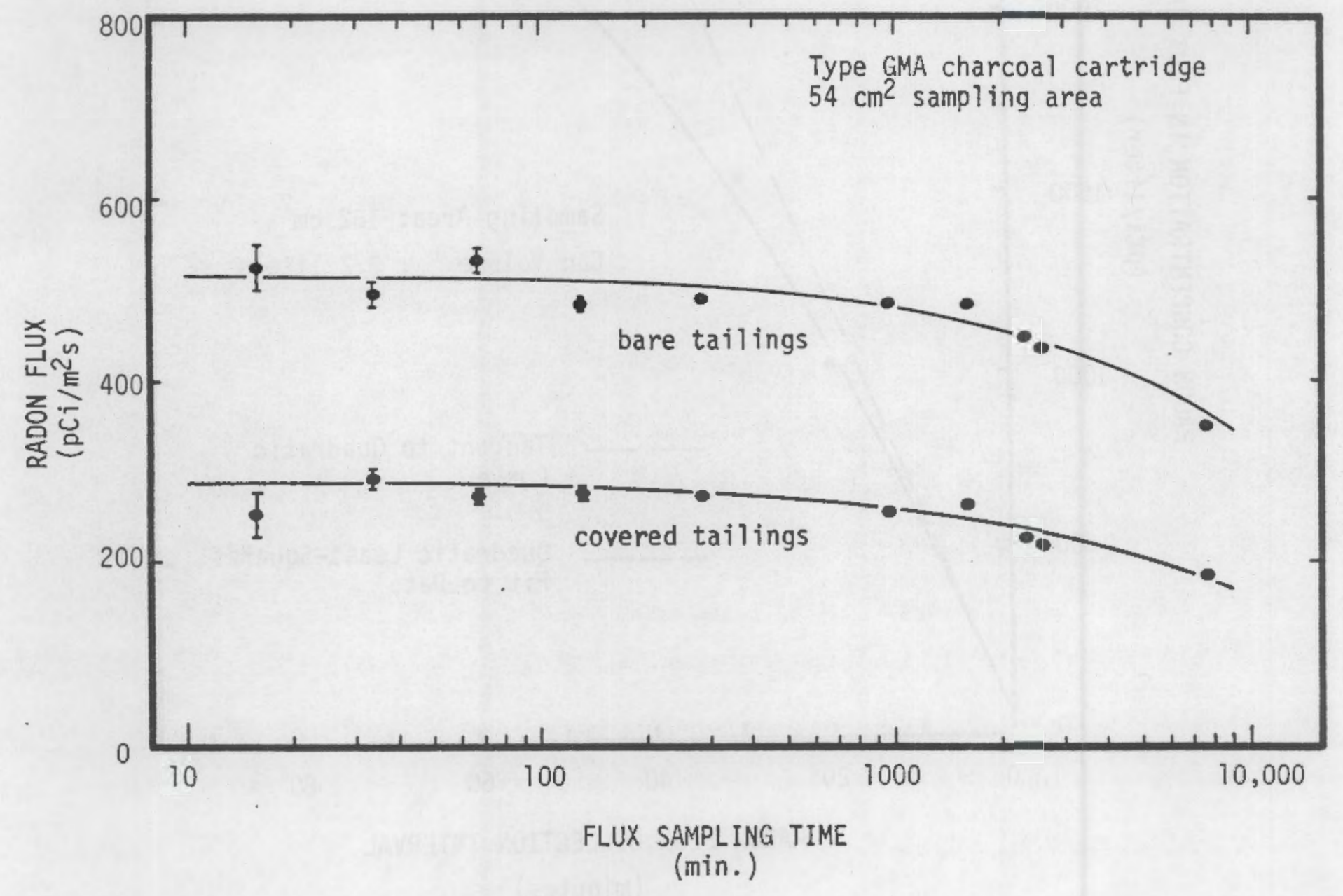

FIGURE 4.2 VARIATION IN RADON FLUX SAMPLING EFFICIENCY WITH SAMPLING TIME. 


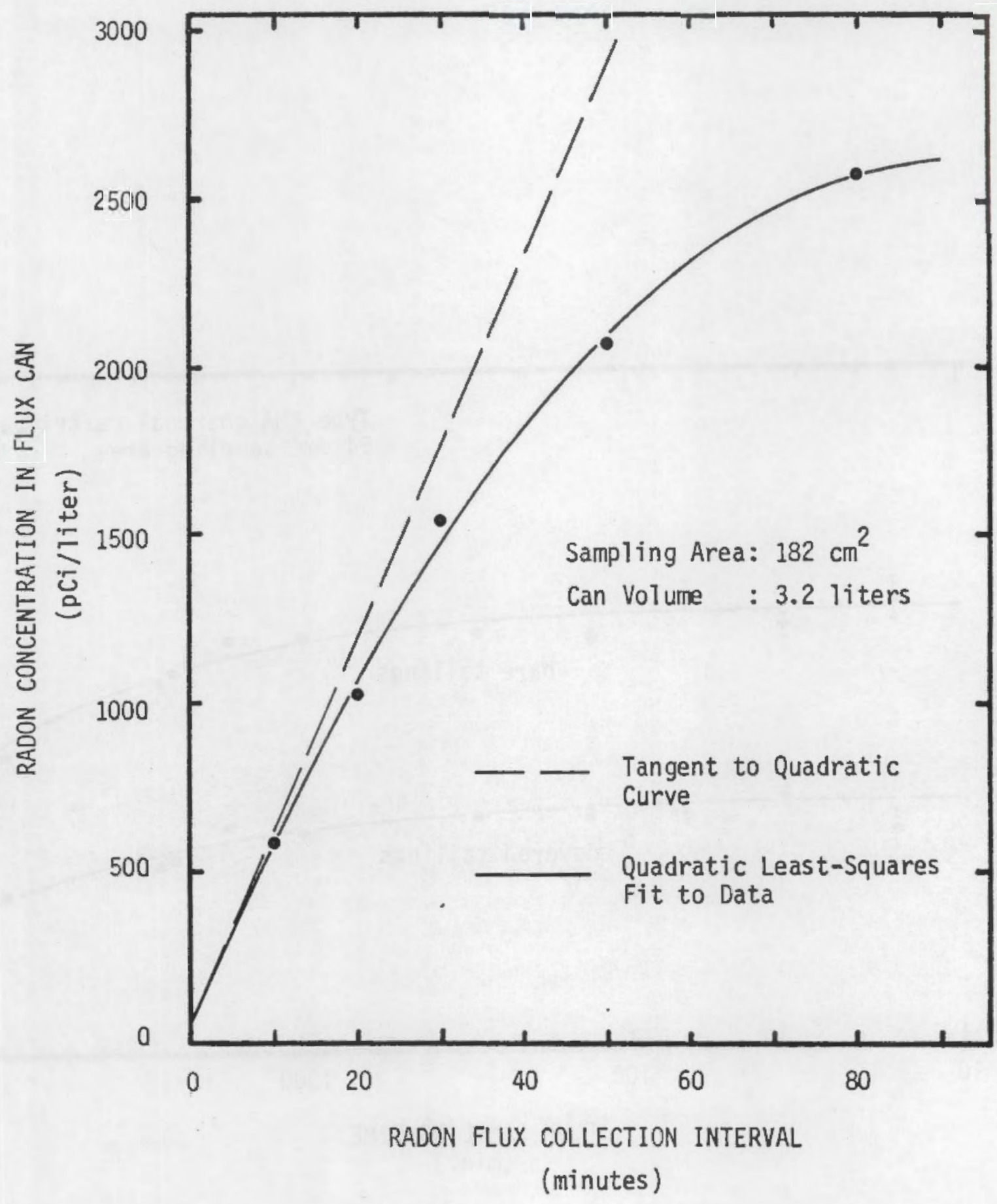

FIGURE 4.3 RADON ACCUMULATION DURING FLUX-CAN SAMPLING. 
From the fitted curve and its tangent at $t=0$, the relative error due to the radon buildup and the resulting radial diffusion around the can was estimated to be approximately five percent for a 10-min sampling interval, 11 percent for a 20-min interval, and 33 percent for a 60-min interval. The bias suggested for the 10-min sampling intervals used in this study was approximately the same magnitude as the typical uncertainty in individual flux-can measurements. This bias estimate probably represented a worst-case, however, in that the radon flux ( $\left.170 \mathrm{pCi} / \mathrm{m}^{2} \mathrm{~s}\right)$ was relatively high, and the diffusion coefficient of the dry-sand covering the tailings source was high, permitting greater radial diffusion than would be expected in a more dense material of lower diffusion coefficient.

In order to observe experimentally the effect of radial diffusion around a flux-can sampler, a 25-cm diameter can was placed in the center of the sandcovered tailings source to perturb the radial distribution of radon flux from the source. After twenty four hours, charcoal canister flux samples were collected in the annular region outside the can and compared with similar flux measurements prior to placement of the can. The resulting fluxes were 300 $\mathrm{pCi} / \mathrm{m}^{2} \mathrm{~s}$, compared with an undisturbed flux of $260 \mathrm{pCi} / \mathrm{m}^{2} \mathrm{~s}$, or an enhancement by a factor of 1.2. This is similar to the magnitude expected from a computer calculation in two-dimensional cylindrical geometry from the equation

$$
\nabla^{2} C-\frac{P \lambda C}{D}+\frac{Q}{D}=0,
$$

which gives an expected radon flux distribution around a perturbing region of radius $R_{0}$ from a source of radius $R_{1}$ as defined by Eq 4-3, 


$$
\begin{aligned}
& J(r)=D \beta_{0}\left[\frac{Q}{p \lambda}+\left(\frac{R_{0}}{R_{1}}\right)^{2}\left(C_{2}-C_{1}\right)-C_{2}\right] \tanh \left(\beta_{0} H\right) \\
& -2 D\left(C_{1}-C_{2}\right) \frac{R_{0}}{R_{1}} \sum_{n=1}^{\infty} \frac{\beta_{n} \tanh \left(B_{n} H\right)}{W_{n} J_{0}^{2}\left(W_{n}\right)} J_{1}\left(W_{n} \frac{R_{0}}{R_{1}}\right) J_{0}\left(W_{n} \frac{r}{R_{1}}\right)
\end{aligned}
$$

$C_{1}$ and $C_{2}=$ radon concentrations inside and outside the perturbing region, where

$$
H=\text { the thickness of the layer in which radial diffusion is }
$$
allowed.

$$
B_{n}=\left(\frac{P \lambda}{D}+\frac{W_{n}{ }^{2}}{R_{1}^{2}}\right)^{\frac{1}{2}}
$$

$J_{0}$ and $J_{i}=$ Bessel functions of zero ${ }^{\text {th }}$ and first order

$$
\begin{aligned}
& W_{n}=\text { roots of the equation } J_{1}(w)=0 \text { (i.e., } W_{0}=0, W_{1}=3.83171 \text {, } \\
& \text { etc). }
\end{aligned}
$$

Because of the limited area of the flux test source, the detailed distribution of radon flux as a function of distance from the perturbing region could not be measured.

The sample-time dependence of flux sampling by charcoal canister and flux cans is also dependent on the geometry of these samplers, which determines the rate of radon concentration change. Several measurements were made which suggest important design criteria for radon flux samplers.

The charcoal canister sampling arrangement illustrated in Figure 3.3 was 
compared with several other designs in an effort to sample radon from a larger, and hence more representative surface area. Three of the designs compared are illustrated in Figure 4.4. They gave fluxes varying from 100 to $270 \mathrm{pCi} / \mathrm{m}^{2} \mathrm{~s}$. It appeared that the presence of an air gap between the charcoal and the emanating surface permitted an increased radon concentration (measured at 600-1000 $\mathrm{pC} i / 1)$ in the gap which tended to depress the observed radon flux, due to radial diffusion as well as incomplete collection of the radon on the charcoal. The $25-\mathrm{cm}$ diameter sampler amplified this problem by requiring the radon to diffuse over an even greater distance through air before being adsorbed by the charcoal. This caused an even greater concentration of radon in the void volume (measured at $2400 \mathrm{pCi} / 1)$.

If the flux sample times were increased beyond the $4 \mathrm{~h}$ used for these measurements, one may expect the ultimate decline in efficiency observed in the sample-time experiment, due to the approaching saturation of the charcoal with radon. With decreased sampling times, the radon concentration build-up would be reduced, decreasing the potential error due to radial diffusion, but increasing the error due to incomplete collection of the radon on the charcoal. It therefore appears that for passive radon flux sampling with charcoal canisters, the air-filled volume inside the sampler should be minimized in order to expedite radon adsorption and avoid high radon concentrations at the soil surface.

The geometry of flux-can samplers was also examined to evaluate possible bias due to radial diffusion and also due to non-uniform vertical radon distribution in the air volume. A fixed sample time of 10 min was used to evaluate various flux cans of varying heights, as illustrated in Figure 4.5. Their diameters were nominally equal and were not controlled because only the height of the cans affect the rate of radon concentration change. As illustrated, the 4 and $6-\mathrm{cm}$ high cans had lower fluxes than the $17-\mathrm{cm}$ can which was used in the test column measurements. The low fluxes were attributed to a high concentration 


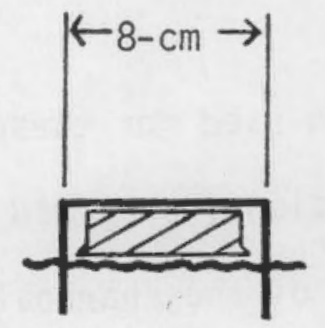

$$
\begin{gathered}
J=270+14 \\
n=7
\end{gathered}
$$

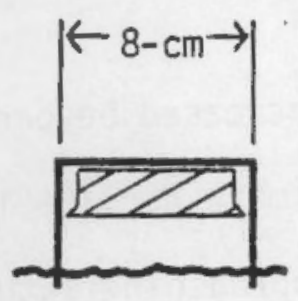

$J=220 \pm 20$ $n=5$

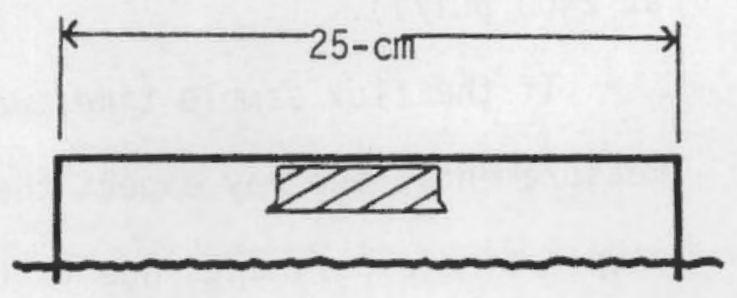

$J=96 \pm 10$ $n=5$

FIGURE 4.4 COMPARISON OF CHARCOAL CANISTER FLUX-SAMPLING GEDMETRIES. MEANS AND STANDARD DEVIATIONS OF n FLUX MEASUREMENTS ARE IN $\mathrm{pCi} / \mathrm{m}^{2} \mathrm{~s}$. 


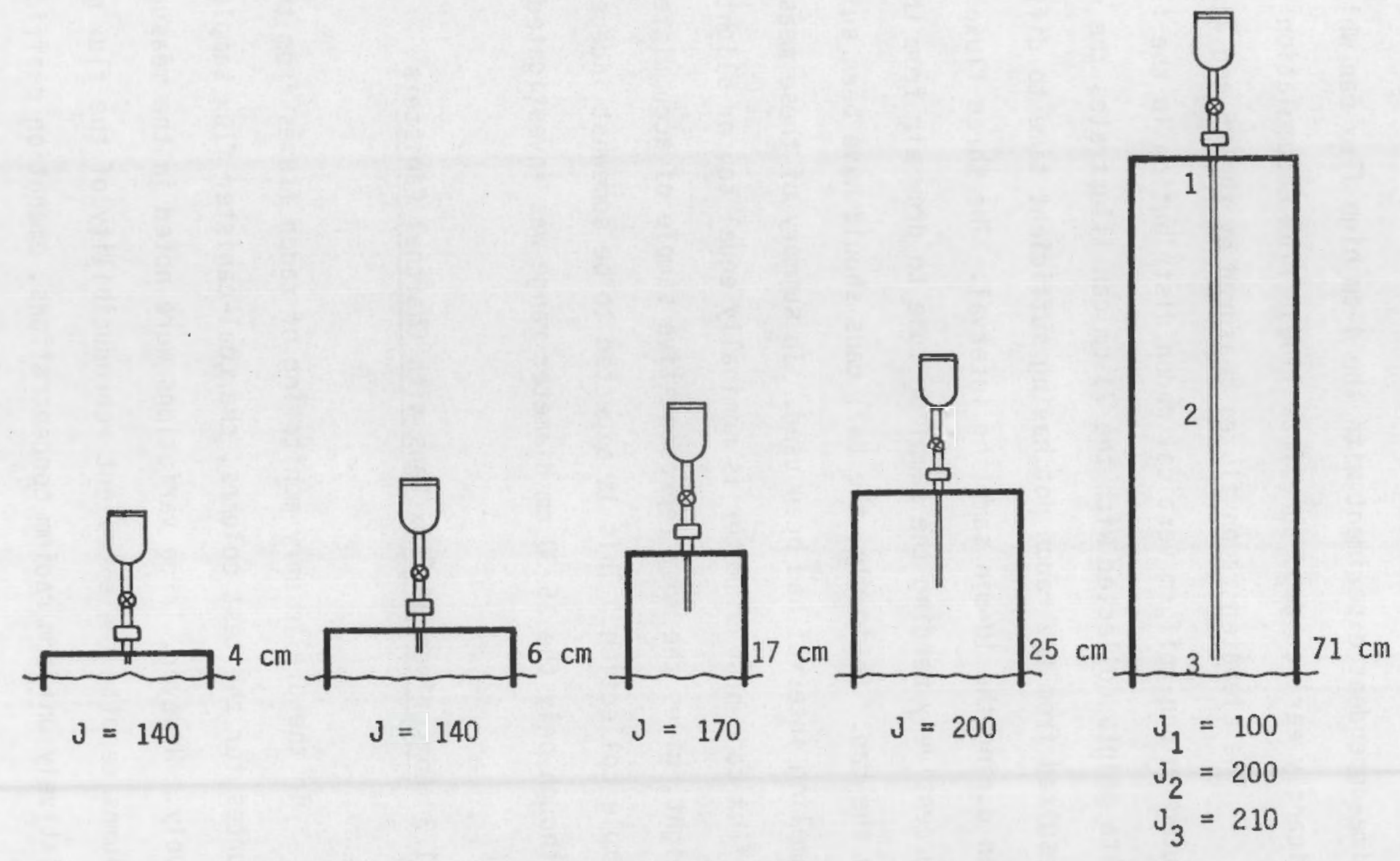

FIGURE 4.5 COMPARISON OF RADON FLUX-CAN GEOMETRIES. 
build-up and resulting radial diffusion. This was confirmed in a separate time-dependent experiment with the 4- $\mathrm{cm}$ high flux can which exhibited a significantly earlier departure from linear flux accumulation than did the $17-\mathrm{cm}$ can. The elevated radon fluxes measured by the 25 and $71-\mathrm{cm}$ cans were attributed to non-uniform vertical radon distribution in the flux cans. The three data points collected with the $71-\mathrm{cm}$ can illustrates the non-uniformity which resulted from the radon not having sufficient time to diffuse to the top of the can during the 10 -min sampling interval. The three fluxes were measured by successively bending the sampling tube to draw air from the indicated heights in the can. Obviously, the tall cans should have been suitable if a longer sampling interval had been used. In summary of these measurements, it appears that a flux can whose diameter is nominally equal to, or slightly greater than its height, gives the most representative sample of accumulated radon for a 10-min sample collection. This is expected to be somewhat independent of can diameter, although only the $15-30 \mathrm{~cm}$ diameter range was investigated.

\subsubsection{Comparison of Flux Cans with Charcoal Canisters}

In the preliminary monitoring of radon fluxes from the bare tailings sources for the test columns, charcoal-canister flux samples were used exclusively. However, large variations were noted in the measured fluxes between columns despite the excellent reproducibility of the flux measurements and the relatively uniform radium concentrations, emanation coefficients, moistures and compactions of the tailings sources. Subsequent monitoring by samplers of larger area indicated that much of the variation was a result of the small sampling area and the inhomogenous sand/slime regions in the tailings sources. These data are presented in Table 4.1 to illustrate the individual precision 
TABLE 4.1

COMPARISON OF RADON FLUX MEASUREMENTS ON BARE TAILINGS SOURCES

Source

Radon Flux $\left(\mathrm{pCi} / \mathrm{m}^{2} \mathrm{~s}\right)$

Charcoal Canister

(8- $\mathrm{cm}$ dia)

$n=10$

1

2

3

4

5

6

7

8

9

10

11

12

13

14

15

16

Mean of Sources

$(n=16)$

$470 \pm 30$

$480 \pm 220$
Charcoal Canister (25-cm dia) $n=9$

$190 \pm 10$

$200 \pm 10$

$200 \pm 10$

$210 \pm 10$

$310 \pm 10$

$270 \pm 20$

$290 \pm 10$

$300 \pm 20$

$290 \pm 20$

$250 \pm 10$

$340 \pm 10$

$310 \pm 10$

$310 \pm 20$

$340 \pm 10$

$260 \pm 10$

$300 \pm 10$

Flux Can (15-cm dia) $n=7$

$290 \pm 20$

$210 \pm 20$

$160 \pm 20$

$220 \pm 20$

$500+20$

$490 \pm 10$

$560 \div 60$

$520 \pm 50$

$540 \pm 70$

$420 \pm 20$

$660 \pm 20$

$620 \pm 30$

$570 \pm 50$

$670 \pm 40$

$440 \pm 60$

$570 \pm 40$

$270 \pm 50$

$470 \pm 150$ 
achieved with each type of sampler as well as the decreased variation among columns which resulted from larger-diameter samplers. The $25-\mathrm{cm}$ diameter sampler was the type illustrated in Figure 4.4 .

The individual relative uncertainties using the small charcoal canister samplers were on the order of seven percent, and a comparable precision was obtained with the flux-can samples. The large charcoal canister samples demonstrated a slightly better overall relative uncertainty of five percent, but gave generally lower results than the other two. The indications of bias with the large diameter sampler were as noted previously, and probably resulted from the large air space between the tailings surface and the charcoal-canister. The inhomogeneity of the tailings sources was illustrated by the progressively decreasing standard error of the means with sampler diameter presented at the bottom of Table 4.1 .

An intercomparison of flux-can and charcoal-canister flux measurements was conducted using the sand-covered source. Eight charcoal canister samplers were simultaneously exposed to the source for a four-hour period, during which five flux-can samples were sequentially collected over ten minute intervals. The charcoal-canister samples yielded a mean flux of $210 \pm 4 \mathrm{pCi} / \mathrm{m}^{2} \mathrm{~s}$, and the flux can samples averaged $189 \pm 4 \mathrm{pCi} / \mathrm{m}^{2} \mathrm{~s}$. The ten percent bias can be partly explained (five percent) by the non-linear rate of accumulation of radon by the flux can, as noted previously, The total bias can also be attributed to the absolute uncertainties in calibration of the Lucas Cell scintillation counting system and the charcoal-canister, gamma-ray detection system.

\subsubsection{Test for Column Edge Effects}

The method of sampling radon fluxes from the test columns entailed 
sampling from a known area in the central part of the exposed soil surface. Estimation of the total flux from the column therefore required assumption of uniform flux for the entire soil surface. The validity of this assumption was questioned due to the possibility of channeling of radon along the column walls. Such channeling could occur due to shrinkage of the soil due to drying, mechanical shocks to the column walls, or poor compaction of the soil into the test column.

A series of measurements was therefore conducted to determine whether radon channeling along the column walls was a significant source of error in the present tests. The measurements were conducted by sampling fluxes from the entire cross-sectional area of the columns. Sample collection was accomplished by sealing a metal cap across the top of the column, and using the protruding column walls as the lateral boundaries of the "flux can." The same Lucas Cell, filter, and sample tube arrangement was used as illustrated in Figure 3.2. Sample collection times were 10 minutes.

The results of these flux measurements are presented in Table 4.2. It can be seen that the total area fluxes were generally within the uncertainty of the fluxes measured from the partial area. The notable exceptions were Columns $4,7,8$ and 15 . Columns 4 and 15 were both galvanized steel columns whose cover materials had been removed. It is expected that the enhanced edge-diffusion from these tailings sources resulted from the physical disruption of these columns during cover removal and flexing of the metal tubes. Columns 7 and 8 were contained in the more rigid PVC pipes, and their enhanced edgediffusion was attributed to significant moisture losses, as observed with the moisture probes, and resulting shrinkage of soil away from the column walls. These losses occured in the latter part of the experiment, and did not significantly influence the fluxes during the first two months after column construction. 
TABLE 4.2

COMPARISON OF RADON FLUXES FROM TOTAL AND

PARTIAL COLUMN SURFACE AREAS

Column

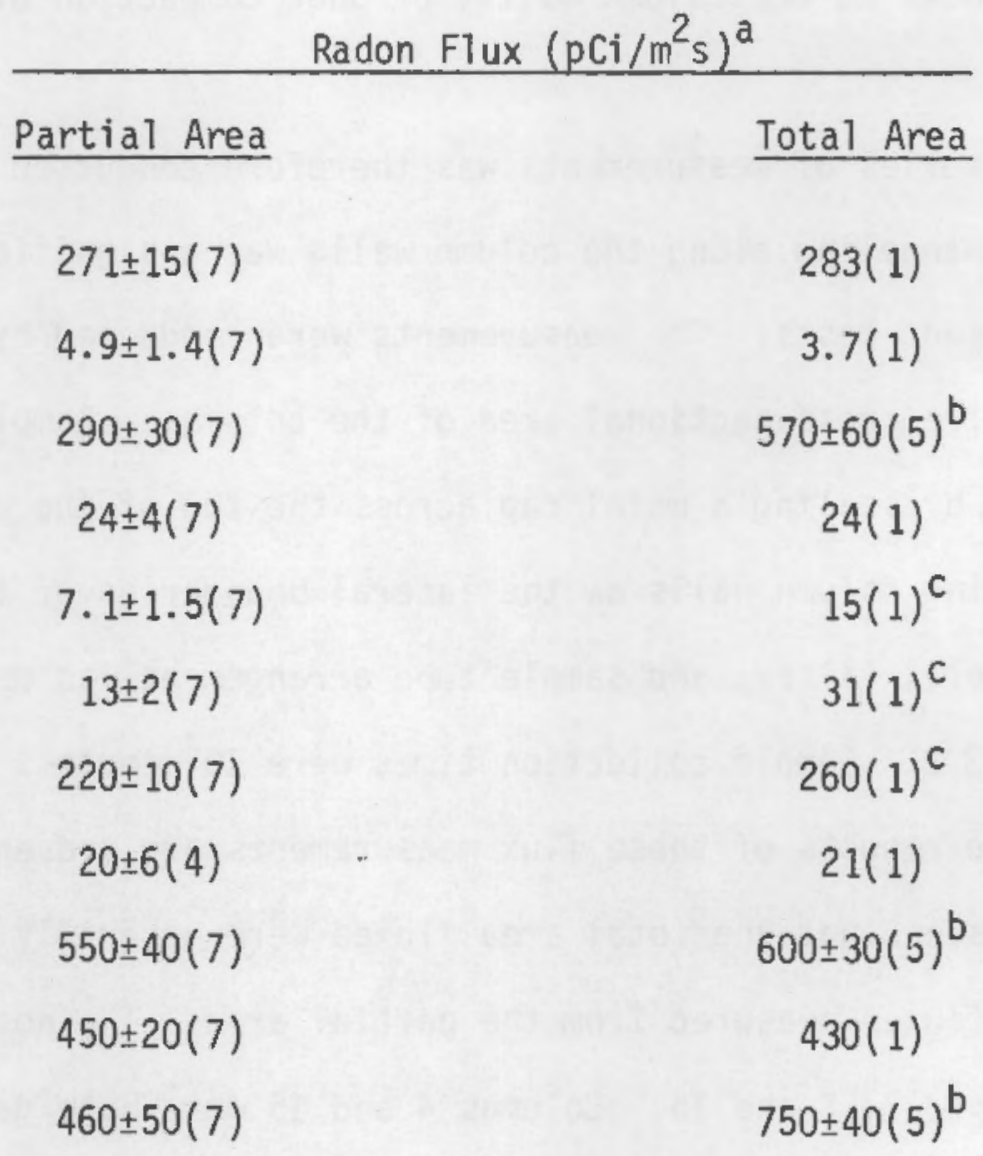

15

1

2

4

6

7

8

9

10

11

13

.

(1) 


\subsection{MATERIALS TESTING}

Several experiments were conducted to evaluate possible radon gas leakage through some of the materials used in the radon test columns or supporting procedures. The experiments were designed to measure the equilibrium radon concentration gradient which was supported by a given thickness of a given material. In order to make the results more generally applicable to specific problems, they were expressed as diffusion coefficients for the given material. Two experimental arrangements were used for the measurements to accommodate the geometric differences in layered materials versus tubular materials. These arrangements and the resulting data are described in the following paragraphs.

Diffusion through layered materials was measured by sealing 150g of uranium tailings inside an 8- $\mathrm{cm}$ diameter, 4- $\mathrm{cm}$ high $\mathrm{can}$, with the test material serving as the lid. The can was then sealed inside a larger (4-1iter) can as illustrated in Figure 4.6A, and allowed to equilibriate for 30-90 days. After equilibration, the radon concentration inside the larger can was measured with a Lucas Ce11. The activity of gaseous radon in the can was determined by direct gamma-counting of the can $\left(609-\mathrm{keV},{ }^{214} \mathrm{Bi}\right)$ with a NaI scintillation detector, and applying the emanation coefficient of 0.22 (Table 5.3) to estimate the fraction which had been emanated. The volume containing the gaseous radon was estimated from the can volume $\left(V_{c a n}\right)$, the tailings mass $\left(m_{t}\right)$, the weight-fraction of moisture in the tailings (M), and the specific gravity of the tailings (SG), as

$$
V_{\text {void }}=V_{\text {can }}-M_{t}\left(\frac{1-M}{S G}-M\right)
$$

The diffusion coefficient for the material was then estimated from the 


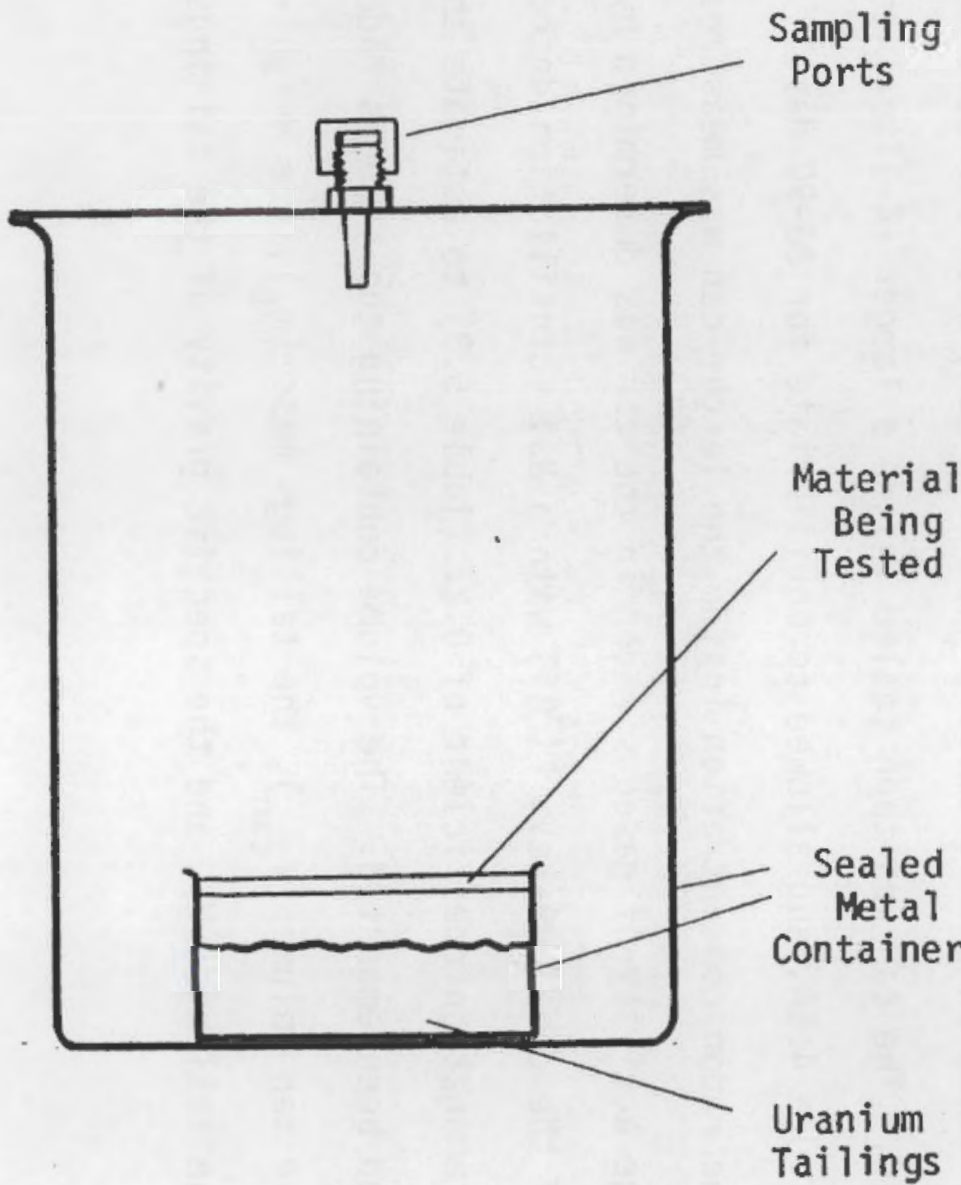

A

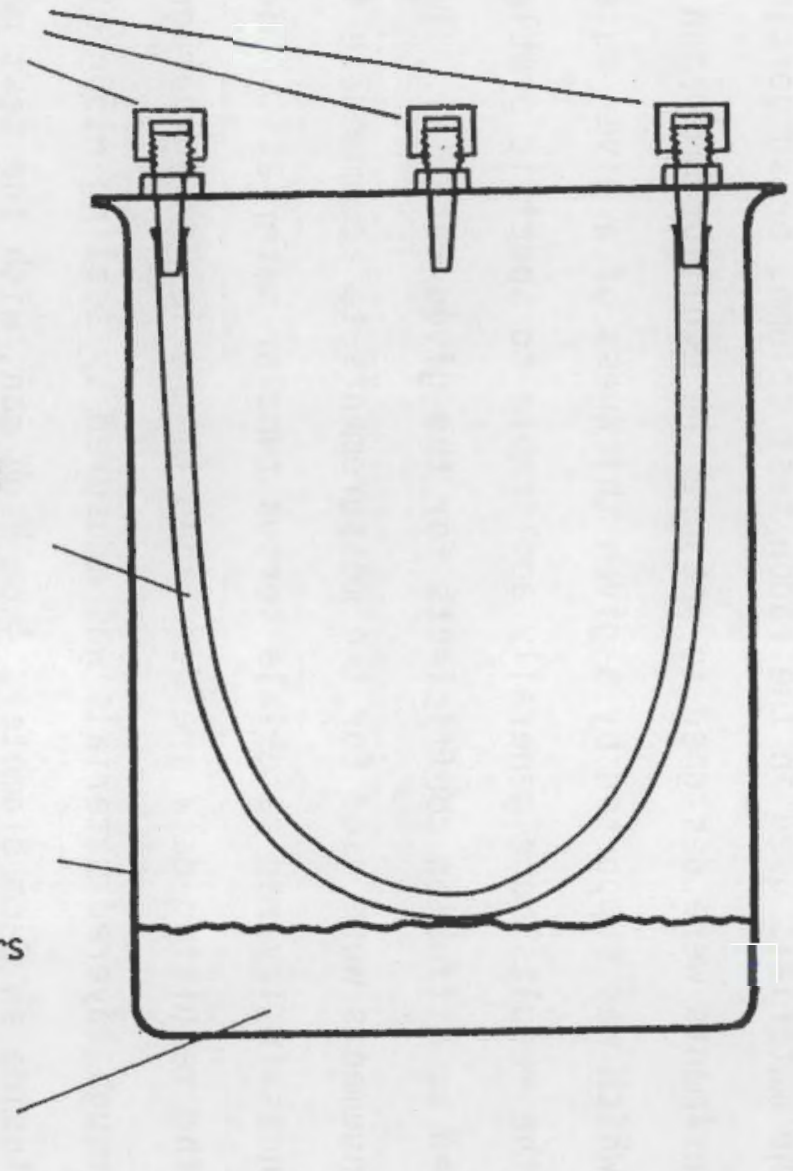

B

FIGURE 4.6 EXPERIMENTAL ARRANGEMENT FOR TESIING RADON DIFFUSION THROUGH (A) SHEET MATERIALS AND (B) TUBING MATERIALS. 
simple exponential relationship between concentrations,

$$
\frac{C}{C_{0}}=\exp \left(-x \sqrt{\lambda / D^{T}}\right)
$$

The diffusion coefficient ( $\left.D^{\prime}\right)$ was therefore calculated as

$$
D^{\prime}=\frac{\lambda x^{2}}{\left[\ln \left(C_{0} / C\right)\right]^{2}} \text {, }
$$

where $\lambda$ is the radon diffusion coefficient $\left(2.1 \times 10^{-6} s^{-1}\right), x$ is the material thickness $(\mathrm{cm}), \mathrm{C}_{0}$ is the radon concentration in the small can (pCi/liter), and $C$ is the radon concentration in the large can ( $p C i / l i t e r)$.

Diffusion through tubular materials was similarly measured by attaching the tube to be tested to two sampling ports in the lid of a four liter can as illustrated in Figure 4.6B. Several hundred grams of uranium tailings were placed in the bottom of the can, after which it was sealed and allowed to equilibrate for 30-90 days. After equilibration, the concentration in the can $\left(C_{0}\right)$ was sampled with one Lucas Cell and that in the tube $(C)$ with another. Because the tube volume was typically less than that of the Lucas Cell, the cell was used to collect part of the sample from one port, drawing a partial vacuum in the tube. The opposite port was then opened to allow room air to sweep the remaining radon into the Lucas Cell. The typical tube volume was 15 percent of the Lucas Cel1 volume.

Radon diffusion coefficients were similarly calculated from the tube wall thickness, $x$, and the concentrations in the can and the tube using Eq 4-6. The concentration in the tube was corrected by the ratio of the tube volume to the 
Lucas Cell volume prior to use.

PVC and ABS plastic pipes were tested using $\mathrm{SCH}-40$ (D.8-cm wall thickness) pipe sections to correspond with the materials used in the multilayer test columns. The leak testing was accomplished using pipe caps on a short section of the pipe which was partially filled with tailings and fitted with a sampling port. The capped pipe section was placed inside a larger can as in the other test 111 ustrated in Figure 4.6 and treated by an otherwise identical procedure.

Diffusion coefficients for the materials tested are listed in Table 4.3. The latex and silicone tubing samples both exhibited high permeability to radon gas, resulting in nominally equivalent concentrations, and they are therefore not recommended for application in radon research. Polyethyene tubing had the lowest diffusion coefficient of the tubes tested, but still had a higher diffusion coefficient than the sheet materials .

The plastic pipes demonstrated adequate radon containment for use in the test columns, as did the epoxy used for sealing the moisture probe wire entrances. The rubber materials used for gaskets and the tubing used in drawing radon gas samples were also shown to be adequate for their respective experimental applications.

\subsection{CALIBRATION WITH STANDARD MATERIALS}

Calibrations of the Lucas Cells and the gamma-ray spectrometer were both accomplished by intercomparison measurements with standard reference materials. The Lucas Cell efficiencies were based on samples from the standard radon dilution chamber of the U.S. Bureau of Mines in Denver, Colorado, and the gammaray spectrometer efficiency was measured with respect to a well-characterized, $(16,19,20)$ equilibrated pitchblende sample originating with the DOE Health 
RADON DIFFUSION COEFFICIENTS FOR EXPERIMENTAL MATERIALS

Material

Silicone Sealant

Epoxy Casting Resin

EPDM Sealant

Paraffin

Asphalt

5-Minute Epoxy

PVC Plastic Pipe

ABS Plastic Pipe

EPDM Rubber Sheet

CIM (Rubber Sheet)

Mylar

Polyethylene Sheet

Polycarbonate Plastic Sheet

Latex Tubing

Silicone Tubing

Rubber Tubing

Tygon Tubing

Polyethelene Tubing \begin{tabular}{c}
$D / p$ \\
$\left(\mathrm{~cm}^{2} / \mathrm{s}\right)$ \\
\hline
\end{tabular}

$1.1 \times 10^{-7}$

$5.4 \times 10^{-8}$

$1.4 \times 10^{-8}$

$9.5 \times 10^{-9}$

$6.9 \times 10^{-9}$

$2.4 \times 10^{-9}$

$1.2 \times 10^{-8}$

$9.5 \times 10^{-9}$

$5.1 \times 10^{-10}$

$4.4 \times 10^{-10}$

$<10^{-10}$

$<10^{-10}$

$<10^{-10}$

$<.1$

$<.1$

$9.9 \times 10^{-6}$

$3.8 \times 10^{-6}$

$2.0 \times 10^{-7}$ 
Services Laboratory at Idaho Falls, Idaho. The latter efficiency was also compared with an independent counting system at Pacific Northwest Laboratory in Richland, Washington. The following paragraphs describe these calibrations.

Eleven Lucas Cells were calibrated against six standard cells at the Bureau of Mines by sampling from the standard radon dilution chamber with cells from each group in the interspersed sequence indicated in Table 4.4. The chamber contained approximately $1.5 \mathrm{~m}^{3}$ of air which was continuously flushed with a stream of air which had passed over a standard radium source at a known rate. The mean radon concentration inside the chamber was $1490 \pm 20 \mathrm{pCi} / 1$ as determined by counting the standard cells at the Bureau of Mines. Efficiencies of the other Lucas Cells were determined from the mean radon concentration and the observed activity in the individual cells as counted in the RAE Laboratory in Salt Lake City. The efficiencies were calculated by rearranging Equation 3.5 . Two counts were performed on each cell, and the resulting efficiencies were averaged as reported in Table 4.4. Individual cell efficiencies were determined to approximately two percent relative uncertainity, based on about 1.3 percent relative uncertainty in counting statistics and 1.3 percent relative uncertainty in the radon concentration calibration.

Calibration of the gamma-ray spectrometer was based on a $15.7-\mathrm{g}$ aliquot of the standard pitchblende sample ${ }^{16}$ from the DOE Health Services Laboratory. Two in-house standards (VT-1 and VT-2) were prepared and calibrated against the pitchblende standard for routine use in sample analysis and system standardization. All three samples were sealed in $8-\mathrm{cm}$ diameter by $4-\mathrm{cm}$ metal cans and were used after an initial 30-day equilibration period to assure equilibrium between the ${ }^{214} \mathrm{Bi}$ daughter of radon and the ${ }^{226} \mathrm{Ra}$ parent. The VT-1 and VT-2 standards consisted of $221.4-\mathrm{g}$ and $238.4-\mathrm{g}$ aliquotes of dry uranium tailings, respectively. The sealed samples wera leak-tested by sealing inside a larger 
TABLE 4.4

CALIBRATION OF LUCAS CELLS

\begin{tabular}{|c|c|c|c|c|c|c|c|c|c|c|}
\hline \multirow[b]{2}{*}{ Cell } & \multirow[b]{2}{*}{$\begin{array}{c}\mathrm{Bkgr} \\
(\mathrm{c} / 10) \\
\end{array}$} & \multirow[b]{2}{*}{$\begin{array}{l}\text { Sample } \\
\text { Time } \\
\end{array}$} & \multicolumn{3}{|c|}{ Count 1} & \multicolumn{3}{|c|}{ Count 2} & \multirow[b]{2}{*}{$\begin{array}{c}\text { Mean } \\
\text { Efficiency }\end{array}$} & \multirow{2}{*}{$\begin{array}{l}\text { Radon } \\
\text { Conc. } \\
(\mathrm{pC} i / \mathrm{i})\end{array}$} \\
\hline & & & $\begin{array}{l}\text { Decay } \\
\text { (min) } \\
\end{array}$ & $\begin{array}{l}\text { Activity } \\
(\mathrm{c} / 10)\end{array}$ & Eff. & $\begin{array}{l}\text { Decay } \\
\text { (min) }\end{array}$ & $\begin{array}{l}\text { Activity } \\
(\mathrm{c} / 10)\end{array}$ & Eff. & & \\
\hline BM1 & 11 & $13: 07$ & -- & 6690 & -- & -- & -- & -- & -- & 1490 \\
\hline BM2 & 9 & $13: 13$ & -- & 6676 & -- & -- & -- & -- & -- & 1480 \\
\hline 108 & 56 & $13: 16$ & 1174 & 6350 & 0.74 & 1363 & 6416 & 0.76 & 0.75 & -- \\
\hline BM3 & 10 & $13: 18$ & -- & 6886 & -- & -- & -- & -- & -- & 1530 \\
\hline 111 & 35 & $13: 20$ & 1261 & 5964 & 0.70 & 1616 & 5719 & 0.70 & 0.70 & -- \\
\hline 112 & 90 & $13: 21$ & 1249 & 6268 & 0.73 & 1626 & 5994 & 0.73 & 0.73 & -- \\
\hline BM4 & 7 & $13: 22$ & -- & 6744 & -- & -- & -- & -- & -- & 1510 \\
\hline 113 & 10 & $13: 23$ & 1236 & 6160 & 0.72 & 1635 & 5820 & 0.72 & 0.72 & -- \\
\hline 114 & 55 & $13: 24$ & 1223 & 6316 & 0.74 & 1645 & 5991 & 0.74 & 0.74 & - \\
\hline 115 & 15 & $13: 25$ & 1212 & 6218 & 0.73 & 1655 & 5815 & 0.72 & 0.72 & -- \\
\hline 116 & 40 & $13: 26$ & 1188 & 6012 & 0.70 & 1665 & 5816 & 0.72 & 0.71 & -- \\
\hline BM5 & 8 & $13: 27$ & -- & 6565 & -- & -- & -- & -- & -- & 1470 \\
\hline 117 & 20 & $13: 28$ & 1185 & 6152 & 0.72 & 1674 & 5860 & 0.73 & 0.72 & -- \\
\hline 118 & 90 & $13: 29$ & 1174 & 6016 & 0.69 & 1684 & 5724 & 0.70 & 0.70 & -- \\
\hline 119 & 35 & $13: 30$ & 1151 & 6414 & 0.74 & 1694 & 5740 & 0.71 & 0.73 & -- \\
\hline 120 & 65 & $13: 31$ & 1140 & 6178 & 0.71 & 1704 & 5782 & 0.72 & 0.71 & -- \\
\hline BM6 & 11 & $13: 32$ & -- & 6579 & -- & -- & -- & -- & -- & 1470 \\
\hline Means & & & & & & & & & $\begin{array}{l}0.72 \\
\pm .02\end{array}$ & $\begin{array}{l}1490 \\
\pm 20\end{array}$ \\
\hline
\end{tabular}


can and found not to leak a significant fraction of their gaseous radon activity.

The accuracy of the calibration was checked by comparing the three sealed standards with gamma-ray analys is by an independent method at a separate laboratory as indicated in Table 4.5. The instrument used by Battelle, Pacific Northwest Laboratory was an anticoincidence-shielded, multidimensional gammaray spectrometer ${ }^{21}$ which analyzed the $609-\mathrm{keV}$ and $1121-\mathrm{keV}$ peaks from ${ }^{214} \mathrm{Bi}$ in coincidence. Adjustments for the can geometry were reported to be the major source of uncertainty, which was estimated at approximately five percent for each of the counts. The bias of approximately four percent was on the order of the uncertainty of the measurements being compared, as indicated in Table 4.5.

Because the above intercomparison involved standards in different counting geometries and configurations, the agreement is considered excellent. In attempting to estimate the accuracy of the radium and radon-daughter gamma-așsays. in this work, however, the above bias need not be considered. This is because the samples were counted in identical configurations to that of the pitchblende standard. Since the standard was characterized to a relative uncertainty of 0.7 percent and its mass was known to a similar degree of precision, the major source of uncertainty in the present measurements was in small variations in self-absorption and geometry which resulted from the sealed cans being partially filled. A variable efficiency curve was developed to account for these effects, which could cause variations on the order of 15-20 percent, but were probably corrected to an accuracy of approximately five percent. 
TABLE 4.5

INTERLABORATORY COMPARISON OF RADIUM DETERMINATIONS

Sample

$\frac{{ }^{226} \mathrm{Ra} \text { Activity }}{(\mathrm{dpm} / \mathrm{g})}$

Laboratory

Pitchblende $\quad 6060 \pm 40$

DOE Health Services Laboratory, Idaho Falls, Idaho

\begin{tabular}{|c|c|c|c|}
\hline Pitchblende & 6060 & $956^{a}$ & $\begin{array}{l}\text { Rogers \& Associates } \\
\text { Engineering Corp. }\end{array}$ \\
\hline$V T-1$ & & $590 \pm 4^{b}$ & $\begin{array}{l}\text { Rogers \& Associates } \\
\text { Engineering Corp. }\end{array}$ \\
\hline VT-2 & & $722 \pm 10^{b}$ & $\begin{array}{l}\text { Rogers \& Associates } \\
\text { Engineering Corp. }\end{array}$ \\
\hline Pitchblende & 6060 & $989 \pm 49^{C}$ & $\begin{array}{l}\text { Battelle, Pacific Northwest } \\
\text { Laboratory }\end{array}$ \\
\hline VT-1 & & $612 \pm 31^{c}$ & $\begin{array}{l}\text { Battelle, Pacific Northwest } \\
\text { Laboratory }\end{array}$ \\
\hline VT-2 & & $758 \pm 38^{c}$ & $\begin{array}{l}\text { Battelle Pacific Northwest } \\
\text { Laboratory }\end{array}$ \\
\hline
\end{tabular}

\footnotetext{
a System was calibrated by a $157.7 \mathrm{~g}$ aliquot of this standard.

b Uncertainty based on standard deviation of five replicate counts.

c Uncertainty based on counting statistics and, predominantly, uncertainty in geometry correction.
} 



\section{SAMPLE COLLECTION AND CHARACTERIZATION}

Soil samples studied as components in the multilayer tailings cover tests were intended to be representative of some of the materials which may be used for final disposal of the high-priority inactive uranium mill tailings piles as classified by the U.S. Department of Energy. (11) Because the final disposal sites for the inactive tailings piles have not yet been defined, the choice of sampling sites was made from the possible sites suggested by the Phase II Engineering Assessments (22-26) conducted for the Department of Energy in 1976-1977. The cover material samples were obtained between August 12 and September 9 of 1980, and were maintained at approximately their ambient moisture level in most cases throughout the experiments. The following sections describe these sites in greater detail, give the sample collection and handling procedures, and the results of engineering tests, sample moisture and drainage tests, and radium and emanation measurements.

\subsection{SAMPLE SITE DESCRIPTIONS}

The uranium mill tailings used for radon sources for all of the tests were obtained from the west central region of the Vitro tailings pile at Salt Lake City, Utah. The sampling point was near the drill hole "SV-5," as located in Figure 3.14 of Reference 22 , and is located in a region of maximum gamma activity for the Vitro pile ${ }^{(22)}(1.5-2.0 \mathrm{mR} / \mathrm{h})$.

Cover materials characteristic of the possible disposal sites for the Vitro tailings pile were collected at the proposed disposal site Number 2 as identified in the Phase II Energy Assessment. (22) The site is located 
approximately $10.5 \mathrm{~km}$ north of Interstate 80 , and about $5.5 \mathrm{~km}$ west of the Gray Back Mountains and is accessible from the Knolls interchange of I- 80 . A bulk sample of overburden-type material was obtained from the top meter of soil (excluding $\sim 15-\mathrm{cm}$ of weathered surface material), and contained about 10 percent water by weight. A core sample at this site, near the abandoned runway, indicated the soil layer to be 1.2-m thick, supported by a layer of wet, white clay (48 percent water by weight) of greater than $1.2-m$ thickness. The water table was encountered at about a 2.3-m depth. A bulk sample of the white clay was obtained, for convenience, from nearby mud flats after removing the $30-\mathrm{cm}$ surface layer of sandy silt. A core sample in the mud flat suggested a water table at $1.0 \mathrm{~m}$, and a gradual transition from white clay to graygreen clay at approximately $0.6 \mathrm{~m}$. Core samples collected at the proposed disposal site No. 3, near Delle, Utah, exhibited similar clay material near the surface, but contained underlying lenses of moist sandy soil at depths of $\sim 0.60-1.2$ meters.

Bulk samples of cover materials were obtained for the Durango, Colorado site from the vicinity of the proposed disposal site(22) No. 2. Samples of a dry ( $\sim 5$ percent moisture) hard clay-type soil were obtained from the 0.15 to $0.8-\mathrm{m}$ depth range at a location $0.6 \mathrm{~km}$ south of the entrance to the Colorado Fish and Game facility, on County Road 211 , or $4.3 \mathrm{~km}$ from the origin of Road 211 which is southwest of Ourango. A bulk sample of dry (3 percent moisture) Mancos Shale was obtained from outcroppings from roadway cuts of County Road 211, in the same vicinity. An additional sample of the claytype soil was obtained from an adjacent irrigated area, again from the 0.15 to 0.8 meter horizon. This soil appeared to be identical to the hard-packed clay sample except for its higher moisture content (15 percent moisture). 
The water table in the vicinity of the sample sites was not identified. Core samples taken to depths of two meters indicated the clayish soil to be present to this depth.

Bulk cover material samples obtained for the Shiprock site were taken in the vicinity of the proposed disposal site ${ }^{(24)}$ No. 1. A sample of brown clayish soil was collected from the 0.3 to $0.8-\mathrm{m}$ horizon near a roadside rest stop on red rock road, $\sim 1 \mathrm{~km}$ from U.S. Highway 666 . The soil was moist (18 percent moisture) and very hard packed. Core samples indicated it to extend to a depth of at least two meters. A bulk sample of dry ( 3 percent moisture) sandy soil was also obtained from a road construction site along Highway 666 , about $6 \mathrm{~km}$ south of Shiprock. The water table was not observed.

A bulk sample of clayish soil was obtained for the Grand Junction tailings site from a stockpile being used in the Pacific Northwest Laboratory field tests. The soil was the "adobe clay" common to the area, and was used in a 15 percent by weight mixture with 85 percent, 3/4-roadbase. A second aggregate composite material was obtained from the Grand Junction field test site, and consisted of 85 percent, 3/4-roadbase and 15 percent commercial bentonite (American Colloid). The latter aggregate was designated $\mathrm{A}+$, and the former A-, in the present tests.

Bulk samples of clay and sandy soil were obtained for the Riverton, Wyoming site in the vicinity of the proposed disposal site ${ }^{(26)}$ No. 11 . The clay was moist ( 16 percent moisture) and was in a natural depression from the 0.15-0.8-m horizon. A coarse-grained, sandy soil was common in the surrounding area, and was sampled approximately $0.3 \mathrm{~km}$ from the natural depression. The sandy soil was usually dry ( $\sim 2$ percent moisture), and comprised a layer of greater than a 2.3-m thickness at the sampling point. 
The sandy soil layer was about one meter thick at the edges of the natural depression. The water table was not observed at this site.

More detailed descriptions of the geology and hydrology of the sampling sites are contained in the Phase II Engineering Assessments (22-26) along with maps illustrating the general site locations and ownership.

\subsection{SAMPLE COLLECTION AND HANDLING}

Soil samples were collected from surface soil materials or exposed outcroppings after first removing the surface layers to avoid root fragments and highly weathered material. Samples were collected over a 0.3 to $0.6-\mathrm{m}$ vertical range to reduce bias from possible stratification and moisture gradients. The samples were shovelled into 210-liter steel drums and sealed in an effort to preserve ambient moisture conditions. The sealed drums were stored for 1-2 months prior to use in the test columns.

Soil samples had the visual appearance of being relatively homogeneous and representative of the bulk of the surrounding soil in the given areas. By contrast, the uranium mill tailings collected from the Vitro tailings site for the radon sources were highly stratified with regions of slimes interspersed with sandy fractions.

In an early experiment aimed at homogenizing the tailings material, several drums of material were air-dried and mixed. However, it was found that the resulting dry powder was difficult to compact, and the efforts to remoisten the dry powder required large quantities of water (25-30 percent by weight) to permit a uniform mixture. Because the tailings sources were desired to have relatively low moisture but be sufficiently compact to avoid later settling, additional tailings were collected and compacted into the 
test columns at their ambient moisture content. The tailings were mixed by shovel prior to loading into the columns in a manner which would comminute any clay-slime lumps to a size of less than $5-10 \mathrm{~cm}$.

\subsection{SAMPLE ENGINEERING PROPERTIES}

In order to characterize the soils in greater detail and to estimate their compaction and moisture properties for engineering purposes, Proctor tests and sieve analyses were performed on the tailings and cover materials by a subcontractor (American Testing Laboratories, Inc. Salt Lake City, Utah). The Proctor test results are summarized in Table 5.1, and the sieve analyses and soil classifications are listed in Table 5.2. In typical field applications, the actual cover material compactions may be expected to be approximately 85-95 percent of the maximum compactions indicated by the dry densities in Table 5.1. The moisture must be near the optimum in order to achieve a near-maximum compaction.

The specific gravity is also a necessary parameter for calculations of the porosity of the compacted soils. Specific gravities for most of the types of materials being tested here are well-approximated by the single value of $2.7 \mathrm{~g} / \mathrm{cm}^{3}$.

\subsection{SAMPLE MOISTURE ANO ORAINAGE CHARACTERISTICS}

Grab samples collected at $20-30-\mathrm{kg}$ intervals during soil addition to the test columns served as the basis for the initial sample moisture estimates as well as for the radium and emanation coefficient measurements. The grab samples usually consisted of $0.5-\mathrm{kg}$ aliquots, and were immediately sealed in 
TABLE 5.1

RESULTS OF MODIFIED PROCTOR TESTS ON TAILINGS AND COVER MATERIALS

Sample

Vitro Tailings

Vitro Soil

Vitro Clay

Durango Mancos Shale

Durango $\mathrm{Clay}^{\mathrm{b}}$

Shiprock Soil

Shiprock Clay

Grand Junction Clay

Riverton Soil

Riverton Clay
Maximum Dry Density

$\left(\mathrm{g} / \mathrm{cm}^{3}\right)$

1.78

1.93

1.53

2.09

2.00

1.90

1.79

1.92

2.03

1.73
Optimum Moisture ${ }^{a}$ (dry wt\%)

16.4

14.8

24.3

9.0

10.9

10.6

15.3

12.6

12.5

15.3

a Moisture Content at maximum compaction.

b Analysis performed on the dry-ambient aliquot. 
TABLE 5.2

SIEVE ANALYSES OF TAILINGS AND COVER MATERIALS

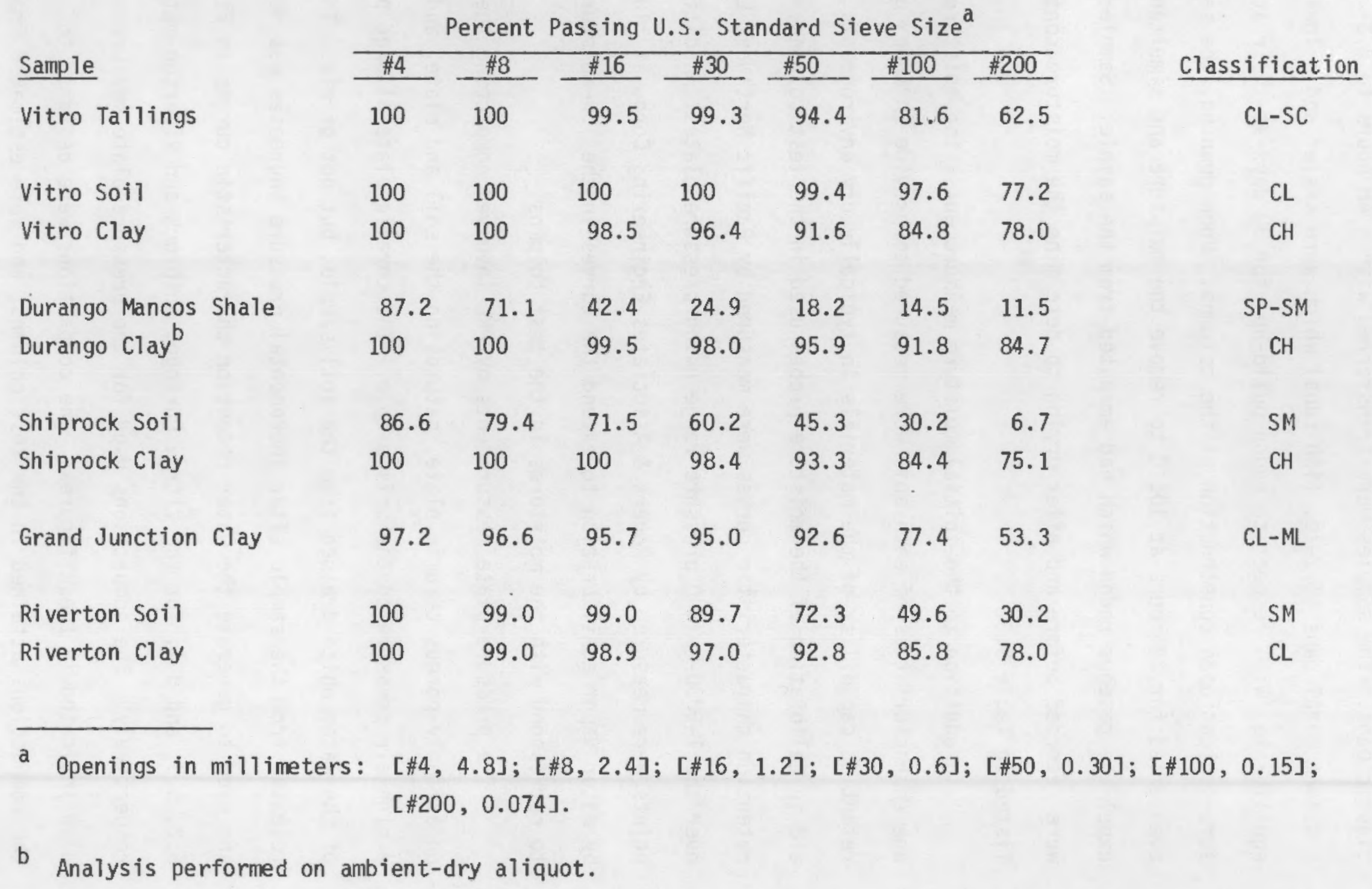


plastic bags. The samples were transferred within 48 hours to $8.3-\mathrm{cm}$ diameter $\times 4.1-\mathrm{cm}$ metal cans (1/2-1b. fish cans) which were sealed and allowed to equilibrate (with respect to radon build-up) for 30 days at their actual moisture content upon construction of the columns. Upon opening, the samples were oven dried for 24 hours at $105^{\circ} \mathrm{C}$ to remove the moisture and simultaneously expel the gaseous radon which had emanated from the sample. Sample weights were recorded before and after drying to determine the moisture contents listed in Table 5.3.

In addition to the initial moisture measurements, the moisture drainage characteristics of each soil were measured to provide an index of the water retention capability of the materials in typically dry environments, and to aid in calibration of the moisture probes used in the test columns. The water retention characteristic curves were measured by Pacific Northwest Laboratory over the $1-5000-\mathrm{cm} \mathrm{H}_{2} \mathrm{O}$ pressure range using pressure plates. Additional data points were measured by Rogers \& Associates Engineering Corp. at $-10^{6}-\mathrm{cm} \mathrm{H}_{2} \mathrm{O}$ by water vapor equilibration to extend the curves in the low-moisture range to correspond with the moistures in the test columns.

The pressure-plate measurements by PNL involved compacting the soils on a finely-porous ceramic plate, saturating the soil and plate, and applying a high air pressure to the soil sample. The ceramic plate allowed passage of the water which drained from the soil sample, but not of air. The water released from the sample after incremental pressure increases was measured and used to generate the water retention characteristic curves in Figures 5.1, $5.2,5.3$, and 5.4, for the Vitro, Durango, Shiprock and Riverton materials, respectively. The compactions used for the pressure-plate measurements are also indicated in these figures. The compactions were designed to approximate the compactions attained in the test columns, and were estimated from weights 
TABLE 5.3

RADIUM ACTIVITIES AND EMANATION COEFFICIENTS OF TEST MATERIALS

\begin{tabular}{|c|c|c|c|c|}
\hline Material & Column & $\begin{array}{r}\text { Initial Moisture } \\
\text { (g water/g soilx100) }\end{array}$ & $\begin{array}{l}\text { Radium Activity } \\
(\mathrm{pCi} / \mathrm{g} \text { dry })^{2}\end{array}$ & $\begin{array}{c}\text { Radon Emanation }{ }^{a} \\
\text { Coefficient } \\
\end{array}$ \\
\hline Tailings & 1 & & $1530 \pm 70(4)$ & $0.22 \pm 0.01(4)$ \\
\hline Riverton Clay & 1 & $19.5 \pm 0.7(2)$ & $2.7 \pm 1.4(2)$ & $0.2^{b}$ \\
\hline Riverton Soil & 1 & $3.3 \pm 0.3(5)$ & $1.2 \pm 0.6(5)$ & 0.2 \\
\hline Tailings & 2 & & $1350 \pm 230(4)$ & $0.21 \pm 0.02(4)$ \\
\hline Durango Wet Clay & 2 & $18.6 \pm 0.4(4)$ & $1.0 \pm 0.8(4)$ & 0.2 \\
\hline Mancos Shale & 2 & $9.1 \pm 0.4(2)$ & $2.7 \pm 0.2(2)$ & 0.2 \\
\hline Durango Dry Clay & 2 & $6.0 \pm 0.3(3)$ & $<0.6(3)$ & --- \\
\hline Tailings & 4 & & $1550 \pm 70(4)$ & $0.21 \pm 0.01(4)$ \\
\hline Shiprock Clay & 4 & $20.3 \pm 1.9(5)$ & $1.9 \pm 0.8(5)$ & 0.2 \\
\hline Shiprock Soil & 4 & $5.8 \pm 1.3(3)^{C}$ & $0.8 \pm 0.2(3)^{c}$ & 0.2 \\
\hline Tailings & 6 & & $1660 \pm 120(4)$ & $0.21 \pm 0.04(4)$ \\
\hline Vitro Soil & 6 & $14.3 \pm 1.1(7)$ & $0.8 \pm 0.6(7)$ & 0.2 \\
\hline Vitro Clay & 6 & $22.2 \pm 17.4(2)$ & $<0.5(2)$ & --- \\
\hline Vitro Soil & 6 & $9.9 \pm 0.8(2)$ & $<0.6(2)$ & -- \\
\hline Tailings & 7 & & $1390 \pm 90(4)$ & $0.23 \pm 0.01(4)$ \\
\hline Mancos Shale & 7 & $9.3 \pm 0.4(4)^{C}$ & $1.3 \pm 0.8(4) c$ & 0.2 \\
\hline Durango Wet $\mathrm{Clay}$ & 7 & $22.4 \pm 1.1(2)^{C}$ & $<0.6(2) c$ & --- \\
\hline Durango Dry $\mathrm{Clay}$ & 7 & $6.6 \pm 0.3(2)$ & $1.4 \pm 0.7(2)^{c}$ & 0.2 \\
\hline Tailings & 8 & & $1450 \pm 80(4)$ & $0.21 \pm 0.03(4)$ \\
\hline Vitro Clay & 8 & $28.5 \pm 3.3(3)$ & $0.5 \pm 0.4(3)$ & 0.2 \\
\hline Vitro Soil & 8 & $13.7 \pm 2.1(7)$ & $1.3 \pm 0.8(7)$ & 0.2 \\
\hline Tailings & 9 & & $1330 \pm 100(4)$ & $0.23 \pm 0.01(4)$ \\
\hline Vitro Soil & 9 & $11.9 \pm 1.8(8)$ & $0.9 \pm 0.5(8)$ & 0.2 \\
\hline
\end{tabular}


TABLE 5.3 (CONT' 0$)$

RADIUM ACTIVITIES AND EMANATION COEFFICIENTS OF TEST MATERIALS

\begin{tabular}{|c|c|c|c|c|}
\hline Material & Column & $\begin{array}{c}\text { Initial Moisture }{ }^{a} \\
(\text { wt \%) }\end{array}$ & $\begin{array}{l}\text { Radium Activity } \\
\quad(\mathrm{pC} i / g \text { dry }) \\
\end{array}$ & $\begin{array}{l}\text { Radon Emanation } \\
\text { Coefficient } \\
\end{array}$ \\
\hline Tailings & 10 & & $1330 \pm 100(4)$ & $0.22 \pm 0.01(4)$ \\
\hline Vitro Clay & 10 & $26.5 \pm 3.4(4)$ & $0.7 \pm 0.3(4)$ & 0.2 \\
\hline Vitro Soil & 10 & 12. $1 \pm 1.8(6)$ & $1.3 \pm 0.9(6)$ & 0.2 \\
\hline Tailings & 11 & & $1510 \pm 210(4)$ & $0.24 \pm 0.01(4)$ \\
\hline A- & 11 & $2.9 \pm 0.3(2)$ & $1.4 \pm 0.3(2)$ & 0.2 \\
\hline Tailings & 13 & & $1540 \pm 150(4)$ & $0.25 \pm 0.02(4)$ \\
\hline Vitro Clay & 13 & $23.5 \pm 1.3(3)$ & $<0.5(3)$ & --- \\
\hline Tailings & 15 & & $1320 \pm 100(4)$ & $0.23 \pm 0.03(4)$ \\
\hline $\mathrm{A}^{+}$ & 15 & $3.2 \pm 0.2(3)$ & $1.2 \pm 0.7(3)$ & 0.2 \\
\hline
\end{tabular}

a Mean \pm standard deviation (number of samples)

b An emanation coefficient of 0.2 was assumed when the uncertainty from counting statistics exceeded $50 \%$ of the mean.

C The number of samples analyzed resulted from a larger number of samples which were composited. 


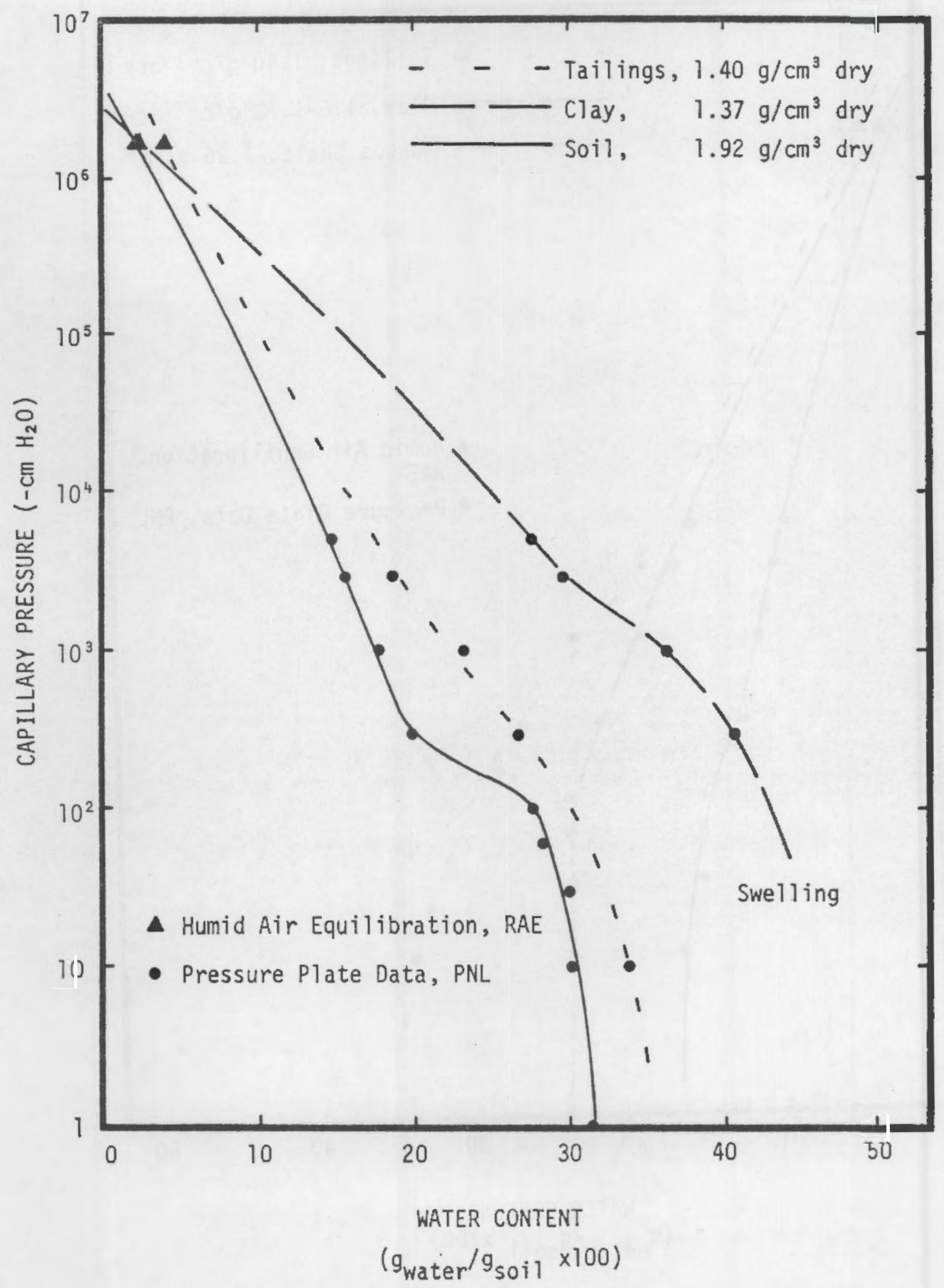

FIGURE 5.1 WATER RETENTION CHARACTERISTIC CURVES FOR VITRO COVER MATERIALS. 


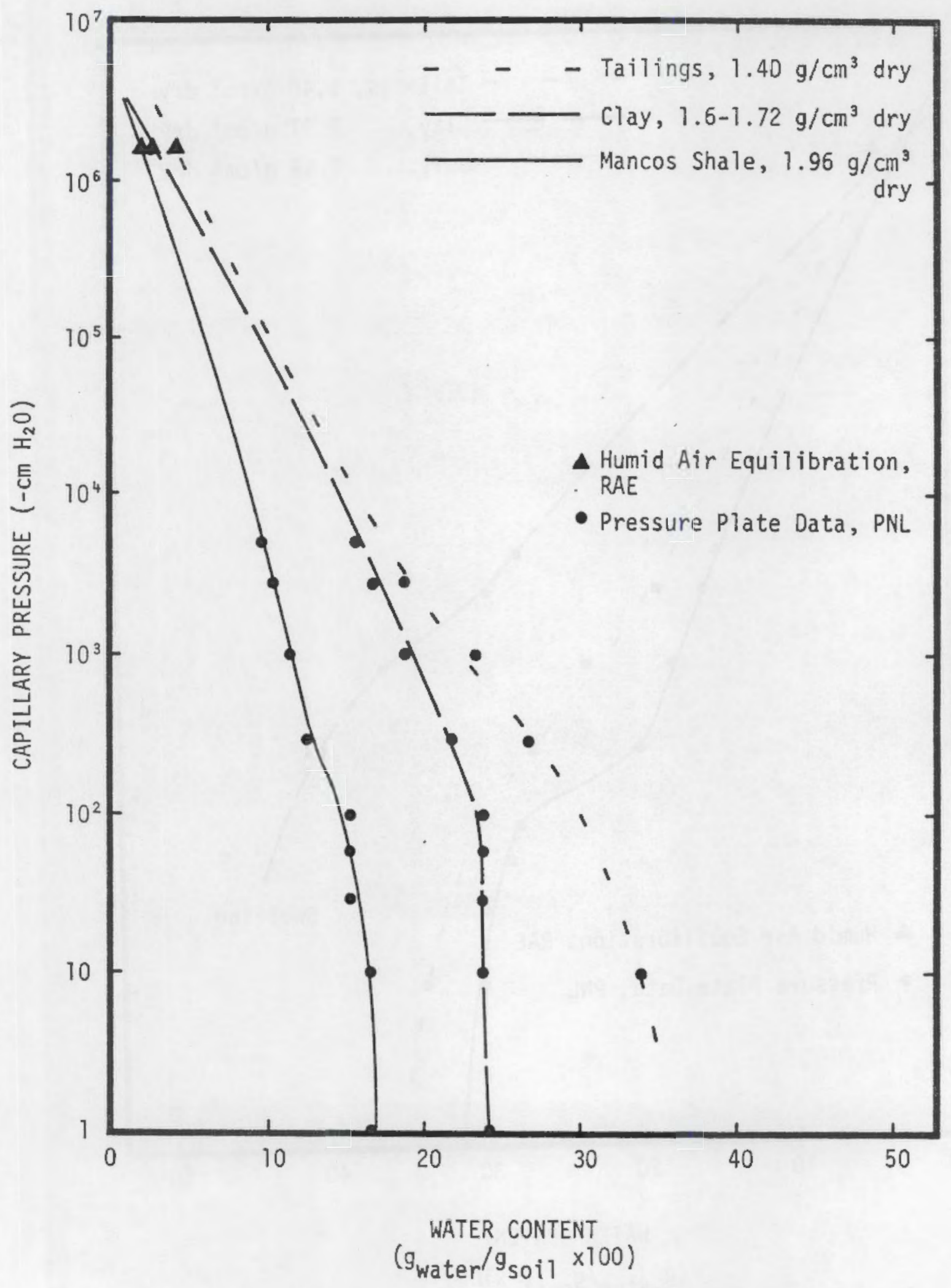

FIGURE 5.2 WATER RETENTION CHARACTERISTIC CURVES FOR DURANGO COVER MATERIALS. 


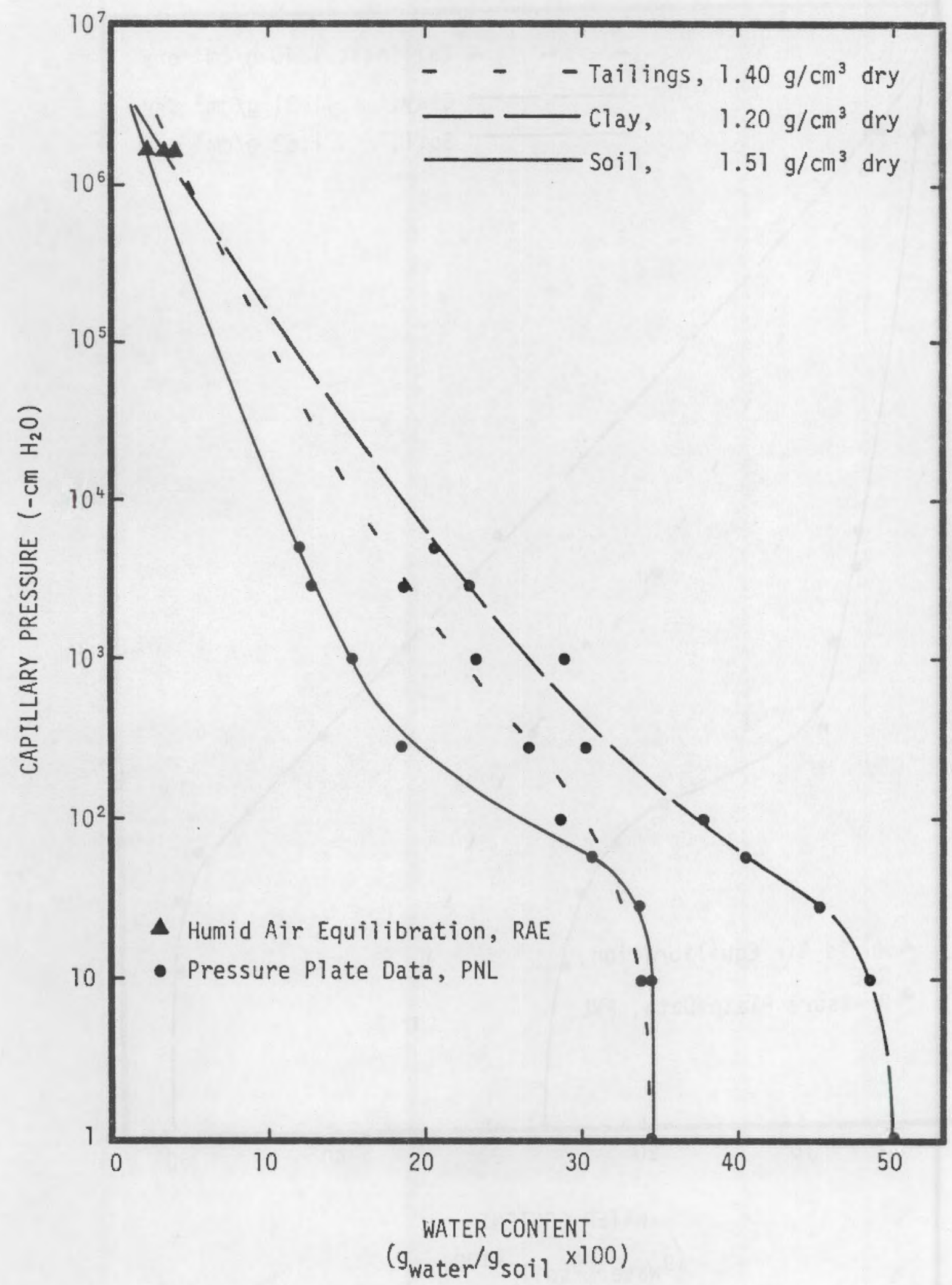

FIGURE 5.3 WATER RETENTION CHARACTERISTIC CURVES FOR SHIPROCK COVER MATERIALS. 


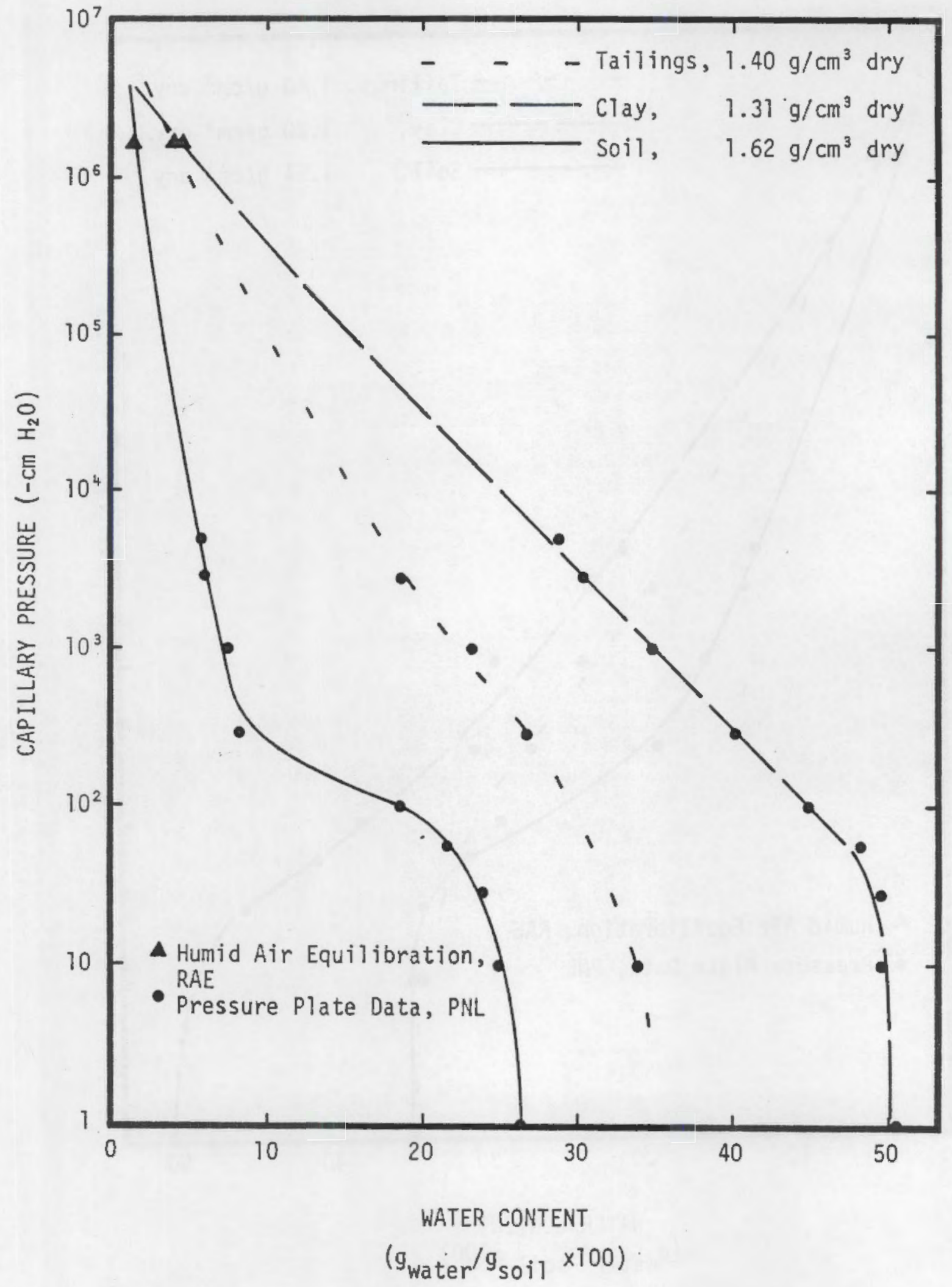

FIGURE 5.4 WATER RETENTION CHARACTERISTIC CURVES FOR RIVERTON COVER MATERIALS. 
and moistures measured during column construction. The compactions are, in general, in agreement with later estimates based on the complete set of grab samples, as reported in Chapter 3.

Significant swelling of the Vitro clay occured at moistures above 40 percent (by weight), preventing use of the data in this range, as noted in Figure 5.1. Although this swelling occured in the pressure-plate apparatus, it would not be expected under the confinement of the test columns of in a tailings cover in which several meters of soil would be on top of the clay.

The additional data points measured by water vapor equilibration involved spreading approximately $0.5 \mathrm{~kg}$ of the finely-divided sample over $a \sim 0.2 \mathrm{~m}^{2}$ area and allowing it to equilibrate for three days with the ambient humidity of the laboratory. The moisture contents of the soils were then determined gravimetrically after drying to constant weight. The relative humidity (R.H.) of the laboratory air was also measured using a dew-point condensation hygrometer (Model 1100-DP, General Eastern Instruments Corp., Watertown, Mass.). The capillary pressures exerted by the soils were then calculated as

$$
P=R T \ln \left(\frac{R H}{100}\right),
$$

where

$$
\begin{aligned}
& R=4.622 \text { bars } /{ }^{\circ} \mathrm{K} \\
& T=\text { Absolute temperature at time of humidity measurement }\left({ }^{\circ} \mathrm{K}\right) \\
& P=\text { Capillary pressure (bars) }
\end{aligned}
$$

\subsection{SAMPLE RADIUM ACTIVITY AND EMANATION COEFFICIENTS}

The grab samples collected during soil addition to the test columns also 
served as the basis for the radium measurements and emanation coefficient measurements. The thirty-day equilibration period permitted the radon gas and its short-lived daughters to reach secular equilibrium with their radium parent. The total radium activity was determined by gamma-ray spectroscopy, with the $609-\mathrm{keV}$ peak from ${ }^{214} \mathrm{Bi}$, after which the sealed cans were opened, and the samples were de-emanated and dried. A subsequent gamma-ray analys is was then conducted to determine the emanation coefficient.

The sealed cans were counted at a distance of approximately one $\mathrm{cm}$ from the $13-\mathrm{cm} \times 13-\mathrm{cm} \mathrm{NaI}(\mathrm{T} 1)$ scintillation detector described previously in Chapter 3 for analyzing charcoal cartridges.

The net peak count rate was compared to the corresponding count rate from a pitchblende ore standard ${ }^{16}$ which was sealed and counted in the same geometric configuration to convert the count rate to picocuries of radium. The radium activity was then divided by the net dry sample weight to express the radium content in $\mathrm{pCi} / \mathrm{g}$ as given in Table 5-3. The results are averaged for each type of material.

Following the gamma-ray analysis, and drying/de-emanation, the samples were immediately gamma-counted, before significant daughter ingrowth, to determine the quantity of radon which was trapped ( $A_{\text {trap }}$ ) in the solid matrix of the soil. The emanation coefficient, $E$, was then computed as the fraction of the total radon activity $\left(A_{\text {tot }}\right)$ which escaped from the soil as a gaseous product,

$$
E=\frac{A_{\text {tot }}-A_{\text {trap }}}{A_{\text {tot }}}
$$

The emanation coefficients of each material are also listed in Table 5.3. 
Emanation coefficients varied from 0.21 to 0.25 for the various tailings samples despite the larger variations in radium activity, which ranged from 1170 to $1470 \mathrm{pCi} / \mathrm{g}$. No correlation was evident between radium activities and emanation coefficients. Due to the low radium contents of nearly all of the cover materials, they did not contribute significantly to the radon flux of the test columns except in cases of very low net fluxes $\left(<\sim 2 \mathrm{pCi} / \mathrm{m}^{2} \mathrm{~s}\right)$. The assumption of emanation coefficients of 0.2 for the soil materials had virtually no impact on the calculated radon fluxes due to the low source strength of these soils. 



\section{EXPERIMENTAL RESULTS AND DISCUSSION}

Radon fluxes and concentrations and soil moistures were monitored over a period of several months in the multilayer test columns, including the period between source preparation and cover compaction, and the final period after the covers were in place. Flux cans proved to be the primary means of sampling radon fluxes, and grab samples of soil gas were used to establish the radon concentration profiles. Moisture measurements were based on the electrical resistance moisture cells which were used with an intermediate calibration in terms of the soil capillary pressure.

This chapter presents the results of these measurements and provides interpretations in terms of radon diffusion parameters. The multilayer diffusion model was used to interpret the data, which represent the first experimental application of the model.

\subsection{RADON RELEASE FROM BARE TAILINGS SOURCES}

The description of radon diffusion and release from the bare tailings source sections of the test columns is simply described by the one-region, one-dimensional diffusion equation. This equation has been derived to be

$$
J=\left(R E_{p}-P C_{0}\right)(\lambda D / P)^{\frac{1}{2}} \tanh \left[x(\lambda P / D)^{\frac{1}{2}}\right]
$$

where

$$
\begin{aligned}
& J=\text { the radon flux }\left(p C i / \mathrm{cm}^{2} s\right) \\
& R=\text { the radium concentration }(p C i / g)
\end{aligned}
$$




$$
\begin{aligned}
& E=\text { the emanation coefficient } \\
& P=\text { the bulk dry density }\left(\mathrm{g} / \mathrm{cm}^{3}\right) \\
& P=\text { the tailings porosity } \\
& C_{0}=\text { the radon concentration in air at the top boundary } \\
& \quad\left(p C i / \mathrm{cm}^{3}\right) \\
& D=\text { the effective radon diffusion coefficient }\left(\mathrm{cm}^{2} / \mathrm{s}\right) \\
& \lambda=\text { the radon decay constant }\left(2.1 \times 10^{-6} \mathrm{~s}^{-1}\right) \\
& X=\text { the tailings thickness }(\mathrm{cm})
\end{aligned}
$$

Equation 6-1 assumes that the flux at the bottom boundary of the source is zero. The concentration of radon in the air immediately above the tailings surfaces was typically measured to be less than $100 \mathrm{pCi} / \mathrm{liter}$, thus making the correction term to the source negligible.

Using the radium concentrations, emanation coefficients and initial moisture measurements reported in Table 5.3, and the thicknesses, densities and porosities reported in Table 3.1, the diffusion coefficients for each tailings source were estimated using Eq 6-1 from the bare tailings source fluxes. These values are reported in Table 6.1. As noted, most of the bare flux measurements were higher than predicted by the radium concentrations and bulk densities of the tailings sources. This was possibly due to the sourcehomogeneity/sampling area problem discussed in Chapter 4. The diffusion coefficients for these cases were accordingly scaled down to reasonable values, and the corresponding adjusted source strengths were used in the subsequent calculations dealing with the cover systems. The sensitivity of the multilayer analysis to this adjustment was small because the flux from the bare tailings is not very sensitive to the variability of their diffusion coefficient, and the flux-limiting components of the columns were the cover materials, not the 
TABLE 6.1

BARE SOURCE FLUXES AND DIFFUSION COEFFICIENTS FOR THE TEST COLUMNS

\begin{tabular}{clc} 
Column & $\begin{array}{c}\text { Radon Flux } \\
\left(\mathrm{pCi} / \mathrm{m}^{2} \mathrm{~s}\right)\end{array}$ & $\begin{array}{c}\mathrm{D} / \mathrm{P} \\
\left(\mathrm{cm}^{2} / \mathrm{s}\right)\end{array}$ \\
\hline 1 & $410 \pm 30(7)$ & 0.006 \\
2 & $350 \pm 20(7)$ & 0.007 \\
4 & $570 \pm 50(5)$ & $0.01^{\mathrm{a}}$ \\
6 & $810 \pm 40(6)$ & $>0.01^{\mathrm{b}}$ \\
7 & $870 \pm 50(6)$ & $>0.01^{\mathrm{b}}$ \\
8 & $750 \pm 10(4)$ & $>0.01^{\mathrm{b}}$ \\
9 & $880 \pm 30(5)$ & $>0.01^{\mathrm{b}}$ \\
10 & $740 \pm 20(4)$ & $>0.01^{\mathrm{b}}$ \\
11 & $600 \pm 30(5)$ & $>0.01^{\mathrm{b}}$ \\
13 & $830 \pm 30(5)$ & $>0.01^{\mathrm{b}}$ \\
15 & $750 \pm 40(6)$ & $>0.01^{\mathrm{b}}$ \\
\hline
\end{tabular}

a Mean \pm standard deviation for $(n)$ measurements of radon flux from the bare source.

b Diffusion coefficients were set equal to $0.01 \mathrm{~cm}^{2} / \mathrm{s}$ and source strengths were scaled to match measured radon fluxes whenever the calculated diffusion coefficient for the tailings exceeded this limit. 
source sections. A parallel calculation of a cover diffusion coefficient in which the bare source flux was assumed to be the cause of the high source diffusion indicated that the relative error from either assumption was less than ten percent.

\subsection{MOISTURE EQUILIBRATION}

After the cover layers were compacted onto the tailings source sections, moisture measurements were conducted via the electrical resistance moisture cel1s. The cell measurements were interpreted by a two-step procedure. First, the cell resistance was converted to a capillary pressure using the universal cell calibration curve in Figure 3.4. The resulting capillary pressures were then converted to weight-percent moisture by using the drainage curves for the given type of soil, as given in Figures 5.1 through 5.4.

The resulting moisture contents for a typical multilayer column are illustrated in Figure 6.1. As might be expected from the drainage curves (Figure 5.1), the moistures tended to stay segregated in the different materials, with clay being the highest and tending to absorb water from the other layers. Moistures in the soil also tended to approach a uniform value with time. The upper region of the tailings source, which apparently dried prior to cover placement, remained in its dry condition relative to the lower part of the tailings mass throughout the course of the experiments. Other columns exhibited similar moisture behavior with clay-type materials remaining at higher moistures than soils, and with tailings sources remaining at a constant, relatively dry moisture leve1.

Temperature measurements conducted with the thermistors in the moisture cells indicated a temperature gradient of about $0.012^{\circ} \mathrm{C} / \mathrm{cm}$ in all columns. 


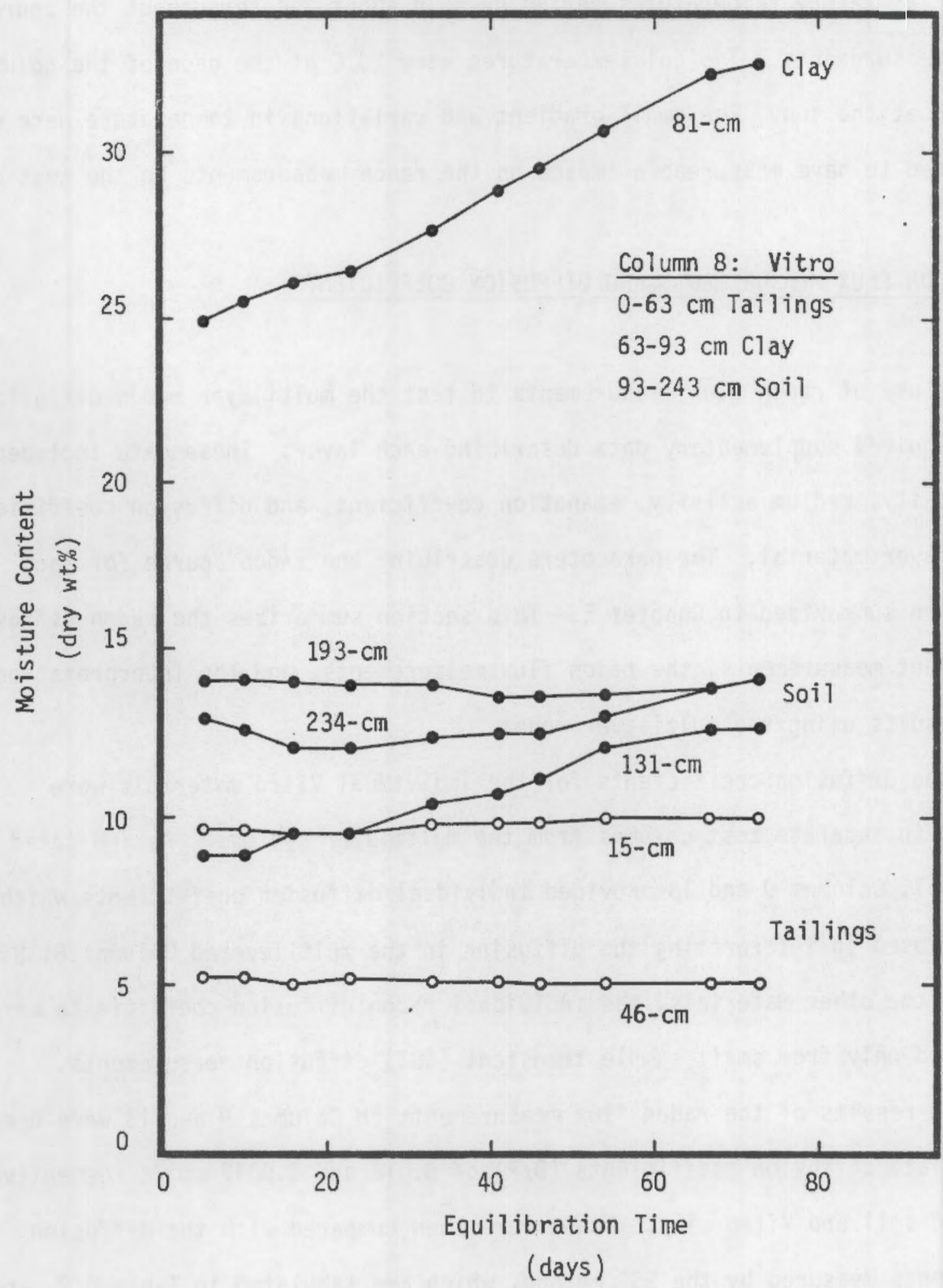

FIGURE 6.1 MOISTURE EQUILIBRATION CURVES FOR COLUMN 8. 
Ambient laboratory temperatures varied by only about $3^{\circ} \mathrm{C}$ throughout the course of the measurements. Typical temperatures were $20^{\circ} \mathrm{C}$ at the base of the columns and $23^{\circ} \mathrm{C}$ at the top. The small gradient and variations in temperature were not considered to have measureable impact on the radon measurements in the test columns.

\subsection{RADON FLUX MEASUREMENTS AND DIFFUSION COEFFICIENTS}

The use of radon flux measurements to test the multilayer radon diffusion model required supplementary data describing each layer. These data included the porosity, radium activity, emanation coefficient, and diffusion coefficient of the layer material. The parameters describing the radon source for each layer were summarized in Chapter 5 . This section summarizes the radon diffusion coefficient measurements, the radon flux measurements, and the interpretation of these results using the multilayer model.

Radon diffusion coefficients for the individual Vitro materials were measured in separate test columns from the multilayer systems. As indicated in Figure 1.1, Columns 9 and 13 provided individual diffusion coefficients which could be used in interpreting the diffusion in the multilayered Columns 6,8 and 10. For the other materials, the individual radon diffusion coefficients were determined only from small sample transient (SST) diffusion measurements.

The results of the radon flux measurements on Columns 9 and 13 were used to calculate diffusion coefficients $(D / P)$ of 0.018 and $0.0047 \mathrm{~cm}^{2} / \mathrm{s}$ respectively for Vitro soil and Vitro clay. These were then compared with the diffusion coefficients measured by the SST method, which are tabulated in Table 6.2, and found to be higher. It was recognized, however, that the SST diffusion coefficients were measured at slightly different moistures and compactions than those in the larger test columns. In order to compare the two sets of diffusion coefficients, a correction was applied to the SST diffusion coefficients to accout for 
TABLE 6.2

SUMMARY OF TIME-DEPENDENT RADON DIFFUSION TESTS

\begin{tabular}{|c|c|c|c|}
\hline Materiàl & $\begin{array}{l}\text { Dry Density } \\
\left(\mathrm{g} / \mathrm{cm}^{3}\right) \\
\end{array}$ & $\begin{array}{l}\text { Mois ture } \\
\text { (dry wt\%) }\end{array}$ & $\begin{array}{c}D / P \\
\left(\mathrm{~cm}^{2} / \mathrm{s}\right)^{a}\end{array}$ \\
\hline $\begin{array}{l}\text { Vitro clay } \\
\text { Vitro soil } \\
\text { Vitro soil }\end{array}$ & $\begin{array}{l}1.30 \\
1.81 \\
1.62\end{array}$ & $\begin{array}{l}27.6 \\
11.6 \\
13.1\end{array}$ & $\begin{array}{l}2.7 \times 10^{-3} \\
1.4 \times 10^{-3} \\
5.9 \times 10^{-3}\end{array}$ \\
\hline $\begin{array}{l}\text { Ourango clay } \\
\text { Durango dry clay } \\
\text { Mancos shale }\end{array}$ & $\begin{array}{l}1.62 \\
1.55 \\
1.93\end{array}$ & $\begin{array}{r}20.0 \\
5.9 \\
9.1\end{array}$ & $\begin{array}{l}1.3 \times 10^{-4} \\
1.7 \times 10^{-2} \\
4.3 \times 10^{-4}\end{array}$ \\
\hline $\begin{array}{l}\text { Shiprock clay } \\
\text { Shiprock soi1 }\end{array}$ & $\begin{array}{l}1.16 \\
1.48\end{array}$ & $\begin{array}{r}20.3 \\
6.0\end{array}$ & $\begin{array}{l}1.5 \times 10^{-2} \\
1.5 \times 10^{-2}\end{array}$ \\
\hline $\begin{array}{l}\text { Riverton } \mathrm{clay} \\
\text { Riverton soil }\end{array}$ & $\begin{array}{l}1.33 \\
1.61\end{array}$ & $\begin{array}{r}19.3 \\
3.4\end{array}$ & $\begin{array}{l}8.7 \times 10^{-3} \\
2.6 \times 10^{-2}\end{array}$ \\
\hline $\begin{array}{l}\text { A- aggregate } \\
\text { Grand Junction soil }\end{array}$ & $\begin{array}{l}1.94 \\
1.72\end{array}$ & $\begin{array}{r}1.6 \\
10.6\end{array}$ & $\begin{array}{l}1.4 \times 10^{-2} \\
6.3 \times 10^{-3}\end{array}$ \\
\hline
\end{tabular}

a

Diffusion coefficients are reported for $22^{\circ} \mathrm{C}$ and $0.90 \mathrm{~atm}$, to correspond to standard laboratory conditions. To convert to $25^{\circ} \mathrm{C}$ and $1-\mathrm{atm}$, multiply by 0.92 . 
the differences in experimental conditions. Two methods were used for this correction, one based on the moisture differences(3) and the other based on the differences in air-filled porosity. ${ }^{(4)}$ The respective soil and clay diffusion coefficients corrected by the moisture method had values of 0.017 and $0.009 \mathrm{~cm}^{2} / \mathrm{s}$ and those corrected by the air porosity method had values of 0.010 and $0.0038 \mathrm{~cm}^{2} / \mathrm{s}$. The correction based on moistures thus gave better results for the more porous soil, while the correction based on air porosity gave better results for the moist clay.

In order to interpret the multilayer diffusion experiments on both a total porosity basis and on an air porosity basis, as discussed in Chapter 2, the necessary diffusion coefficients for these separate analyses were calculated. Diffusion coefficients for the total porosity calculations were taken from the SST values in Table 6.2 and corrected for moisture differences using the diffusion-moisture correlation in Reference 3. Diffusion coefficients for the air porosity calculations were similarly taken from the SST values in Table 6.2, but were corrected for air-porosity differences using the diffusion porosity correlation in Reference 4 . The resulting diffusion coefficients for each layer of the test columns are presented in Table 6.3 with the corresponding moistures and air porosities. The radon fluxes calculated from these diffusion coefficients are also listed and compared with the measured fluxes. The moistures and mean radion fluxes in Table 6.3 are averaged over the period beginning one month after column construction and ending 1-2 months later. The air porosities were calculated from Eqs 3-1 and 3-2.

As indicated in Table 6.3, the radon fluxes predicted from the total porosity calculations are in slightly better agreement with the measured radon fluxes than those determined using air-filled porosities. This generalization is based on the number of columns for which the agreement is better, on the standard relative error of the fluxes, and on the average relative bias of the 
TABLE 6.3

\section{COMPARISON OF MEASURED RADON FLUXES WITH FLUXES CALCULATED FROM TRANSIENT DIFFUSION MEASUREMENTS}

\begin{tabular}{|c|c|c|c|c|c|c|c|c|}
\hline \multirow[b]{2}{*}{ Column } & \multirow[b]{2}{*}{ Material } & \multirow[b]{2}{*}{$\begin{array}{l}\text { Mois ture } \\
\text { (dry wt\%) }\end{array}$} & \multirow[b]{2}{*}{$\begin{array}{c}\text { Air } \\
\text { porosity }\end{array}$} & \multicolumn{2}{|c|}{ Total Porosity } & \multicolumn{2}{|c|}{ Air Porosity ${ }^{b}$} & \multirow[b]{2}{*}{$\begin{array}{l}\text { Measured Elux } \\
\left(\mathrm{pCi} / \mathrm{m}^{2} \mathrm{~s}\right) \\
\end{array}$} \\
\hline & & & & $\underset{\left(\mathrm{cm}^{2} / \mathrm{s}\right)}{\mathrm{DP}}$ & $\begin{array}{c}\mathrm{Flux} \\
\left(\mathrm{pCi} / \mathrm{m}^{2} \mathrm{~s}\right)\end{array}$ & $\begin{aligned} & \mathrm{D}_{\mathrm{a}} \leqslant \mathrm{p} \\
&\left(\mathrm{cm}^{2} / \mathrm{s}\right) \\
&\end{aligned}$ & $\begin{array}{c}\text { Flux } \\
\left(\mathrm{pCt}+\mathrm{m}^{2} \mathrm{~s}\right)\end{array}$ & \\
\hline 1 & $\begin{array}{l}\text { Riverton clay } \\
\text { Riverton soil }\end{array}$ & 2.1 & $\begin{array}{r}0.34 \\
.37\end{array}$ & $\begin{array}{r}0.024 \\
.036\end{array}$ & 140 & $\begin{array}{r}0.012 \\
.028\end{array}$ & 115 & $280 \pm 20(17)$ \\
\hline 2 & $\begin{array}{l}\text { Durango wet clay } \\
\text { Mancos shale } \\
\text { Durango dry clay }\end{array}$ & $\begin{array}{l}16 . \\
7.2 \\
5.3\end{array}$ & $\begin{array}{l}.082 \\
.20 \\
.35\end{array}$ & $\begin{array}{l}.00028 \\
.00065 \\
.020\end{array}$ & 0.2 & $\begin{array}{l}.00014 \\
.00086 \\
.018\end{array}$ & 0.2 & $5.1 \pm 1.4(15)$ \\
\hline 4 & $\begin{array}{l}\text { Shiprock clay } \\
\text { Shiprock soil }\end{array}$ & $\begin{array}{l}15 . \\
6 .\end{array}$ & $\begin{array}{l}.40 \\
.36\end{array}$ & $\begin{array}{l}.041 \\
.015\end{array}$ & 140 & $\begin{array}{l}.018 \\
.015\end{array}$ & 120 & $220 \pm 10(17)$ \\
\hline 6 & $\begin{array}{l}\text { Vitro soil } \\
\text { Vitro clay } \\
\text { Vitro soil }\end{array}$ & $\begin{array}{l}12 . \\
24 . \\
8 .\end{array}$ & $\begin{array}{l}.073 \\
.13 \\
.18\end{array}$ & $\begin{array}{l}.0074 \\
.0049 \\
.018\end{array}$ & 42 & $\begin{array}{l}.0020 \\
.0021 \\
.0056\end{array}$ & 1.3 & $42 \pm 5(17)$ \\
\hline 7 & $\begin{array}{l}\text { Mancos shale } \\
\text { Durango wet clay } \\
\text { Durango dry clay }\end{array}$ & $\begin{array}{r}8.1 \\
17.5 \\
6.0\end{array}$ & $\begin{array}{l}.050 \\
.10 \\
.33\end{array}$ & $\begin{array}{l}.00053 \\
.00021 \\
.017\end{array}$ & 0.5 & $\begin{array}{l}.00017 \\
.00018 \\
.017\end{array}$ & 0.5 & $6.5 \pm 1.5(15)$ \\
\hline 8 & $\begin{array}{l}\text { Vitro clay } \\
\text { Vitro soil }\end{array}$ & $\begin{array}{l}28 . \\
15 .\end{array}$ & .16 & $\begin{array}{l}.0025 \\
.0040\end{array}$ & 9 & $\begin{array}{l}.0027 \\
.0053\end{array}$ & 10 & $10.4 \pm 2.4(19)$ \\
\hline 9 & Vitro soil & 9. & .29 & .0141 & 170 & .0098 & 98 & $220 \pm 20(15)$ \\
\hline 10 & $\begin{array}{l}\text { Vitro clay } \\
\text { Vitro soil }\end{array}$ & 25. & $\begin{array}{l}.16 \\
.21\end{array}$ & $\begin{array}{l}.0041 \\
.0092\end{array}$ & 42 & $\begin{array}{l}.0027 \\
.0067\end{array}$ & 17 & $53 \pm 5(17)$ \\
\hline 11 & A- & 1.6 & .27 & .014 & 540 & .016 & 550 & $540 \pm 30(13)$ \\
\hline 13 & Vitro clay & 23. & .21 & .0058 & 500 & .0037 & 280 & $450 \pm 20(15)$ \\
\hline 15 & At & 1.6 & .24 & .0063 & --- & .0056 & $\ldots$ & $560 \pm 40(13)$ \\
\hline & Standard Relative & Error & & & $48 \%$ & & $65 \%$ & \\
\hline & Average Relative & Bias & & & $32 \%$ & & $55 \%$ & \\
\hline
\end{tabular}

\footnotetext{
a Calculation using total (water \& air-filled) porosity, with $D / P$ adjusted for moisture differences by exponential moisture function (Reference 3 ).

b Calculation using air-filled porosity, with $D_{a} / p$ adjusted for porosity differences by alr porosity function (Reference 4).

C Mean \pm Standard Deviation for $(n)$ measurements.
} 
calculated fluxes. As indicated by the statistics in Table 6.3 , the relative standard error in predicting radon fluxes from measured diffusion coefficients was $48-65 \%$, and the average relative bias was $32-55 \%$. A very large flux error was noted for the two Durango columns, suggesting a large discrepancy between the SST diffusion measurements and the results of the column tests. The relative agreement between measured and calculated fluxes is greatly improved if these two columns are ignored.

A similar analysis of the multilayer diffusion data was based entirely on the predictions of the two diffusion coefficient correlations from References 3 and 4 . This comparison, summarized in Table 6.4 , was conducted to illustrate the precision and accuracy that result when radon fluxes are predicted solely from moistures or porosities of the cover rather than from measured diffusion coefficients. The diffusion coefficients predicted by the exponential soil moisture correlation ${ }^{(3)}$ were used exclusively with total porosity calculations, and those predicted by the air-porosity correlation (4) were used exclusively with air-porosity calculations.

The summary statistics in Table 6.4 indicate that the air-porosity correlation gives slightly better agreement between predicted and measured radon fluxes than the experimental moisture correlation (135\% versus $145 \%$ relative standard errors). The air-porosity correlation also provides better agreement with measured fluxes for the greatest number of columns. However, the bias statistic suggests less bias by the moisture correlation.

Correlation of Tables 6.3 and 6.4 shows that measured diffusion coefficients provide a more reliable basis for predicting radon fluxes than either the moisture or porosity correlations. The measured coefficients tended to predict lower radon fluxes than were actually measured in the multilayer 
TABLE 6.4

COMPARISON OF MEASURED RADON FLUXES WITH FLUXES CALCULATED

FROM PREDICTED DIFFUSION COEFFICIENTS

\section{Moisture Correlation ${ }^{\mathrm{a}}$ Air Porosity Correlation}

\begin{tabular}{|c|c|c|c|c|c|c|c|c|}
\hline Column & Material & $\begin{array}{l}\text { Mois ture } \\
\text { (dry wt\%) }\end{array}$ & $\begin{array}{l}\text { Air } \\
\text { porosity }\end{array}$ & $\left(\mathrm{cll}^{2} / \mathrm{s}\right)$ & $\underset{\substack{\text { Flux } \\
\left(\mathrm{pC} i / \mathrm{m}^{2} s\right)}}{ }$ & $\begin{array}{l}D_{a}<p \\
(\operatorname{cin} / s) \\
\end{array}$ & $\underset{\left(\mathrm{pC} i / \mathrm{m}^{2} s\right)}{\text { Flux }}$ & $\begin{array}{c}\text { Measured } \xi l u x^{c} \\
\left(\mathrm{pC} \mathrm{i} / \mathrm{m}^{\mathrm{T}} \mathrm{s}\right) \\
\end{array}$ \\
\hline 1 & $\begin{array}{l}\text { Riverton clay } \\
\text { Riverton soil }\end{array}$ & 14. 2.1 & $\begin{array}{r}0.34 \\
.37\end{array}$ & $\begin{array}{l}0.0043 \\
.062\end{array}$ & 130 & $\begin{array}{r}0.023 \\
.026\end{array}$ & 120 & $280 \pm 20\langle 17\rangle$ \\
\hline 2 & $\begin{array}{l}\text { Durango wet clay } \\
\text { Mancos shale } \\
\text { Durango dry clay }\end{array}$ & $\begin{array}{l}16 . \\
7.2 \\
5.3\end{array}$ & $\begin{array}{l}.082 \\
.20 \\
.35\end{array}$ & $\begin{array}{l}.0029 \\
.018 \\
.028\end{array}$ & 19 & $\begin{array}{l}.0045 \\
.0126 \\
.024\end{array}$ & 16 & $5.1 \pm 1.4$ (15) \\
\hline 4 & $\begin{array}{l}\text { Shiprock clay } \\
\text { Shiprock soil }\end{array}$ & $\begin{array}{l}15 . \\
6 .\end{array}$ & $\begin{array}{l}.40 \\
.36\end{array}$ & $\begin{array}{l}.0035 \\
.024\end{array}$ & 72 & $\begin{array}{l}.028 \\
.025\end{array}$ & 190 & $220 \pm 10(17)$ \\
\hline 6 & $\begin{array}{l}\text { Vitro soil } \\
\text { Vitro clay } \\
\text { Vitro soif }\end{array}$ & $\begin{array}{l}12 . \\
24 . \\
8 .\end{array}$ & $\begin{array}{l}.073 \\
.13 \\
.18\end{array}$ & $\begin{array}{l}.0065 \\
.00068 \\
.015\end{array}$ & 3 & $\begin{array}{l}.0039 \\
.0076 \\
.0111\end{array}$ & 9 & $42 \pm 5(17)$ \\
\hline 7 & $\begin{array}{l}\text { Mancos shale } \\
\text { Durango wet clay } \\
\text { Durango dry clay }\end{array}$ & $\begin{array}{c}8.1 \\
17.5 \\
6 .\end{array}$ & $\begin{array}{l}.050 \\
.10 \\
.33\end{array}$ & $\begin{array}{l}.015 \\
.0022 \\
.024\end{array}$ & 29 & $\begin{array}{l}.0025 \\
.0056 \\
.022\end{array}$ & 18 & $6.5 \pm 1.5$ (15) \\
\hline 8 & $\begin{array}{l}\text { Vitro clay } \\
\text { Vitro soil }\end{array}$ & $\begin{array}{l}28 . \\
15 .\end{array}$ & .16 & $\begin{array}{l}.00035 \\
.0035\end{array}$ & 1.5 & $\begin{array}{l}.0097 \\
.0104\end{array}$ & 45 & $10.4 \pm 2.4(19)$ \\
\hline 9 & Vitro soil & 9. & .29 & .012 & 140 & .019 & 210 & $220 \pm 20(15)$ \\
\hline 10 & $\begin{array}{l}\text { Vitro clay } \\
\text { Vitro soil }\end{array}$ & $\begin{array}{l}25 . \\
11 .\end{array}$ & $\begin{array}{l}.16 \\
.21\end{array}$ & $\begin{array}{l}.00057 \\
.0080\end{array}$ & 8 & $\begin{array}{l}.0097 \\
.0133\end{array}$ & 73 & $53 \pm 5(17)$ \\
\hline 11 & A- & 1.6 & .27 & .070 & 590 & .018 & 560 & $540 \pm 30(13)$ \\
\hline 13 & Vitro clay & 23. & .21 & .00080 & $112^{\circ}$ & .0133 & 550 & $450 \pm 20(15)$ \\
\hline 15 & $A+$ & 1.6 & .24 & .070 & 730 & .016 & 680 & $560 \pm 40(13)$ \\
\hline & Standard Relative & Error & & & $145 \%$ & & $135 \%$ & \\
\hline & Average Relative & Bias & & & $-15 \%$ & & $-60 \%$ & \\
\hline
\end{tabular}

a $D / P$ calculated from moisture correlation in Reference 3 after converting moistures to wet $w t \%$ as $M /(M+1)$

b $D_{a} / P$ calculated from air-porosity correlation in Reference 4 , assuming the diffusion coefficient in air to be $0.11 \mathrm{~cm}^{2} / \mathrm{s}$.

${ }^{c}$ Mean \pm Standard Deviation for $(n)$ measurements. 
columns, suggesting a possible bias between the SST and open-column diffusion measurement methods. Diffusion coefficients based on soil moistures or porosities predicted slightly higher fluxes than were actually measured. Because of the large and nearly equal standard errors obtained with the total porosity and air-filled porosity calculations, neither method was deemed superior to the other for the present applications. It is vital, however, that either the total porosity or the air porosity definitions and constants be used consistently throughout a given set of calculations.

The errors noted between the calculated and observed radon fluxes were considered to result in large part from difficulty in controlling soil densities. Because the soil densities affect moisture probe calibrations, porosities, and diffusion coefficients, they are critical to the precision and accuracy of the multilayer experiments. The column construction procedures accurately measured the masses and volumes of soil packed into the columns. However, variations in density and moisture within the columns, and between the columns and the SST diffusion samples were probably the principal source of uncertainty in the present experiments.

\subsection{RADON CONCENTRATION PROFILES}

Profiles of the radon gas concentrations were determined from the grab samples collected from the column sampling ports. Because the columns were at equilibrium with respect to radon diffusion, the radon concentration profiles provided an independent measurement of the radon concentration gradients supported by each layer of cover material. They could therefore by used to estimate independently the radon diffusion coefficients of the materials in the test columns.

Figure 6.2 illustrates a typical radon concentration profile as measured 


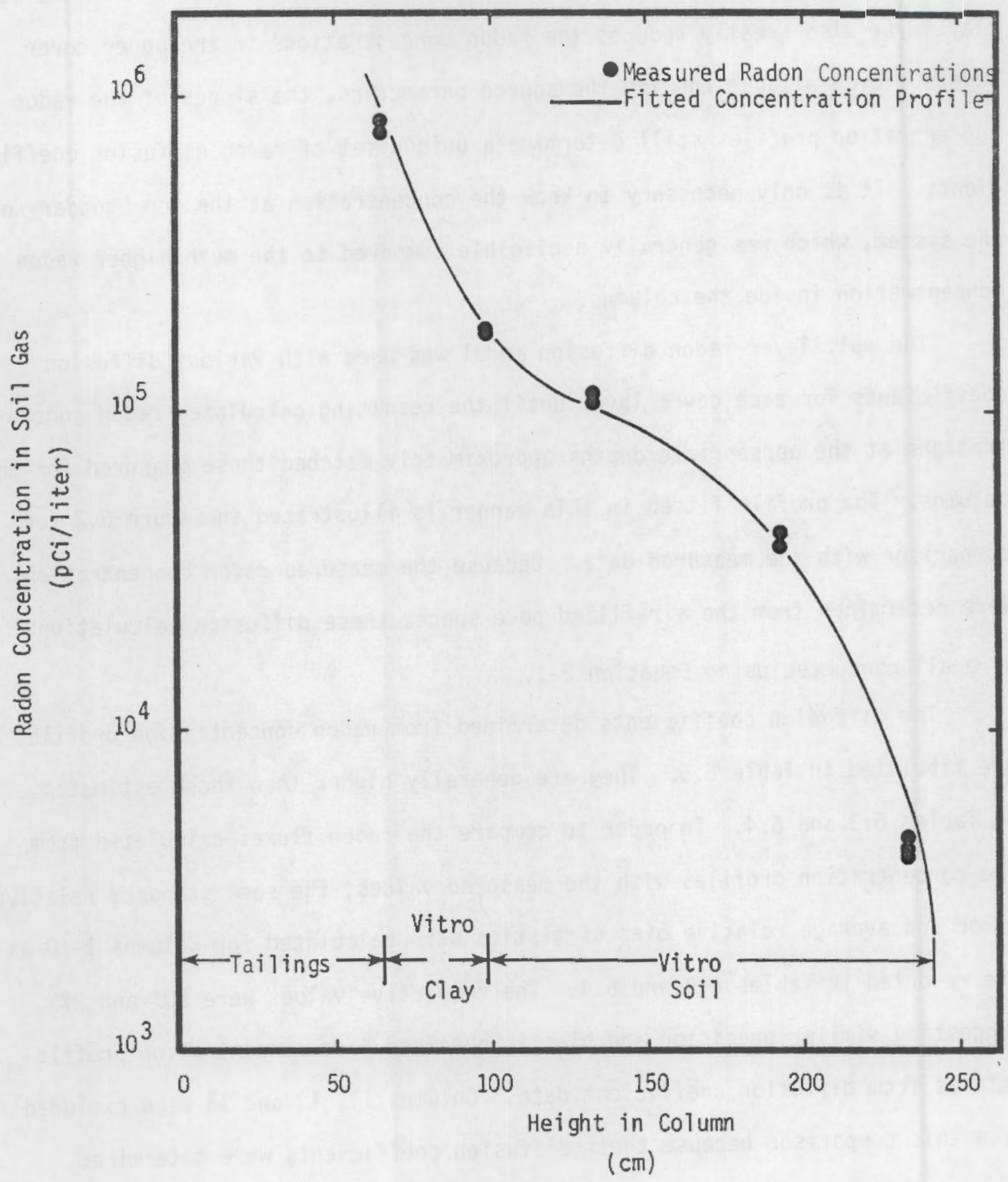

FIGURE 6.2 RADON CONCENTRATION PROFILE IN COLUMN 10. 
on Column 10. As illustrated, the containment of much of the radon by the moist clay layer also greatly reduces the radon concentrations in the upper cover layers. Even without knowing the source parameters, the slopes of the radon concentration profiles still determine a unique set of radon diffusion coefficients. It is only necessary to know the concentration at the top boundary of the system, which was generally negligible compared to the much higher radon concentration inside the columns.

The multilayer radon diffusion model was used with various diffusion coefficients for each cover layer until the resulting calculated radon concentrations at the appropriate depths approximately matched those measured for the columns. The profile fitted in this manner is illustrated in Figure 6.2 for comparison with the measured data. Because the measured radon concentrations were determined from the air-filled pore space, these diffusion calculations were all conducted using Equation 2-1.

The diffusion coefficients determined from radon concentration profiles are tabulated in Table 6.5. They are generally higher than those estimated in Tables 6.3 and 6.4. In order to compare the radon fluxes calculated from the concentration profiles with the measured values, the same standard relative error and average relative bias statistics were calculated for Columns 1-10 as are reported in Tables 6.3 and 6.4 . The respective values were $50 \%$ and $27 \%$, suggesting similar precision and bias is obtained from concentration profile data as from diffusion coefficient data. Columns 11,13 and 15 were excluded from this comparison because their diffusion coefficients were determined from a single concentration value.

In several cases, large differences are apparent between the diffusion coefficients estimated in Table 6.5 and those in Table 6.3. This is not unexpected, since experience with the multilayer model has shown that small differences 
TABLE 6.5

RADON DIFFUSION COEFFICIENTS ESTIMATED FROM RADON CONCENTRATION PROFILES IN TEST COLUMNS

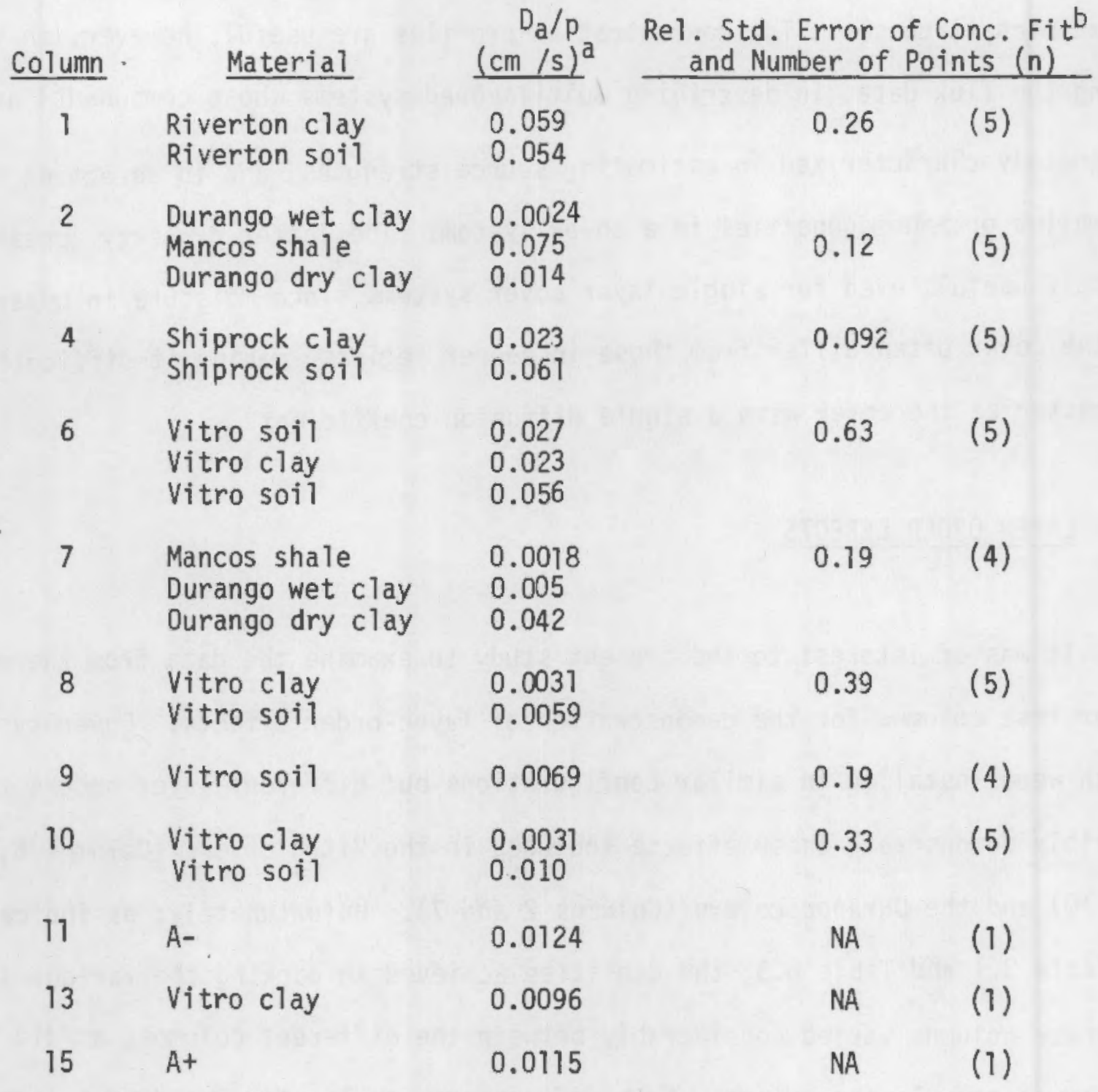

Radon diffusion coefficient divided by air-filled porosity of the
given material, determined solely from concentration profiles, or,
if $n=1$, from the concentration at the interface and the bare source
flux.

${ }^{b}$ Calculated as $\left[\frac{\sum^{n}\left(\frac{C_{\text {calc }}-C_{\text {meas }}}{C_{\text {meas }}}\right)^{2}}{n-1}\right]^{\frac{1}{2}}$ 
in radon concentrations can cause larger variations in diffusion coefficients. The most reliable means of estimating the radon control properties of a given cover system still appears to be that of measuring the actual reduction in radon flux which it causes. The concentration profiles are useful, however, in verifying the flux data, in describing multilayered systems whose components are not adequately characterized in estimating source strengths, and in detecting anomalies or inhomogeneities in a cover system. The latter property appears to be most useful, even for single layer cover systems since moisture in unper narts of the cover often differ from those in deener resions, raking it difficult to characterize the cover with a sinqle diffusion coefficient.

\subsection{LAYER ORDER EFFECTS}

It was of interest to the present study to examine the data from the multilayer test columns for the demonstration of layer-order effects. Cover systems which were installed in similar configurations but different layer orders to possibly demonstrate these effects included in the Vitro covers (Columns 6,8 and 10) and the Durango covers (Columns 2 and 7). Unfortunately, as indicated in Table 3.1 and Table 6.3, the densities achieved in packing the various layers of these columns varied considerably between the different columns, as did the moistures to a lesser extent. Such differences complicated the direct comparisons of radon fluxes or flux reductions between these columns to infer layer-order effects.

An additional complicating factor was the large difference in porosity or diffusion coefficient required for adjacent materials to exhibit a significant layer-order effect. Although there was considerable difference in the types of 
soils used in the cover layers, their diffusion coefficients and porosities at the test compactions were not sufficiently different to demonstrate large layer order effects.

A cursory comparison of the radon flux reductions achieved for the Vitro columns indicates that the cover in Column 6 reduced the source radon flux to a slightly greater extent than the cover in Column 10. This was qualitatively expected to result from the difference in layer-order. The comparison of flux attenuations between Columns 6 and 8 shows a larger difference in the opposite direction. This difference can be readily explained by the greater moisture content in Column 8, however, which would more than offset any expected layerorder effect. A similar comparison of the Durango covers in Columns 2 and 7 also suggested the expected moisture effect, with a two-fold greater reduction of radon flux when the wet clay layer was separated from the tailings source by the Mancos shale layer.

Due to the differences in compactions and moistures in the cover layers being compared, a calculation was performed for each multilayer column to determine mathematically the expected difference in radon flux which would result from interchanging the two bottom layers of cover material. The diffusion coefficients reported in Table 6.3 were used in these calculations. The results indicated that layer-order effects on the order of 10 percent or less would be expected by inverting most of the cover systems. The largest layer-order effect was predicted for Column 4, which was predicted to change effectiveness by only 20 percent.

The results of the layer-order calculations indicate that, although a qualitative indication of layer-order effects was observed, the effects were less pronounced once the competing differences in porosity and diffusion coefficient were accounted for. The calculated layer-order effects, which were on the order of 10 percent cannot be considered statistically significant in view of the uncertainties in measured radon fluxes and in the physical parameters characterizing 
the covers. Although layer-order effects were not explicitly demonstrated, their prediction by multilayer diffusion theory is still considered valid. It is expected that radon flux measurements on a more heterogeneous multilayer system would permit their explicit measurement due to their larger magnitude and hence greater precision.

\subsection{MOISTURE ADDITION TO COLUMNS 6 AND 10}

Additional water was injected into the clay layers of columns 6 and 10 in an effort to illustrate the effects of moisture on the performance of these covers. It was also desired to determine the mobility of the added moisture in the multilayer systems. The water was injected after completion of the Task 2 diffusion measurements by means of a perforated, 0.3-mm diameter copper tube which extended to the center of the clay layers. The water addition was done slowly, over a period of 19 days by maintaining a $1-\mathrm{m}$ pressure head of water on the injection ports. A total of 1.5 liters of water were added to the clay layer in Column 6 , and 1.7 liters of water were added to the clay layer in Column 10.

Radon fluxes were monitored on the two columns during and after water addition, and are illustrated in Figures 6.3 and 6.4. As illustrated, the radon flux from Column 6 was reduced from 43 to $23 \mathrm{pCi} / \mathrm{m}^{2} \mathrm{~s}$, or by a factor of 0.53 as a result of the moisture addition. The flux from Column 10 was reduced from 54 to $21 \mathrm{pCi} / \mathrm{m}^{2} \mathrm{~s}$, or by a factor of 0.39 due to the added moisture. The gradual rise in radon flux from Column 6 during May suggested redistribution of the water, permitting more rapid diffusion. The moistures monitored from a single moisture cell in the center of each clay layer are also plotted in Figures 6.3 and 6.4 . Although these show the qualitative increase as water was 


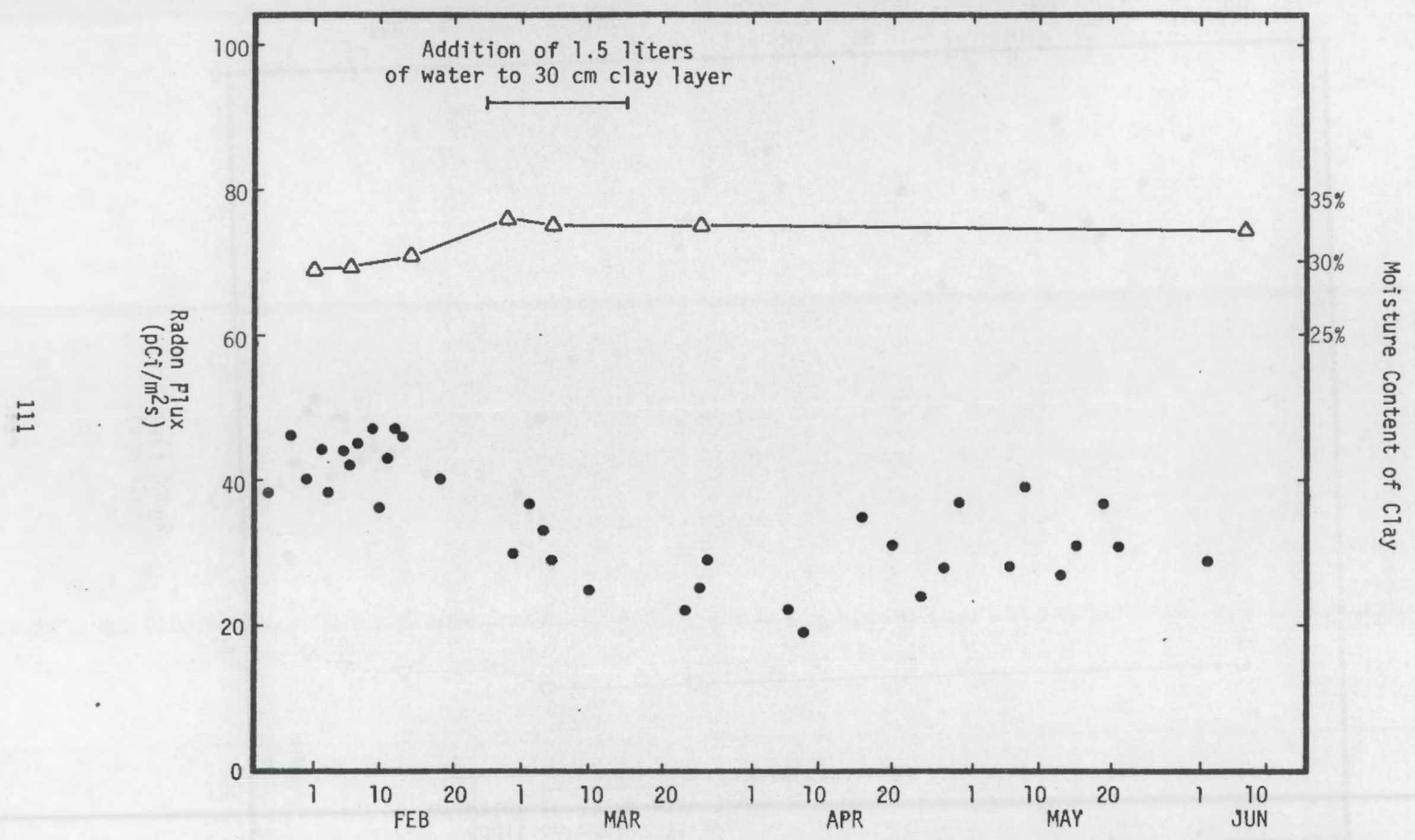

Figure 6.3 Effects of Moisture Addition on Radon Flux in Column 6. 


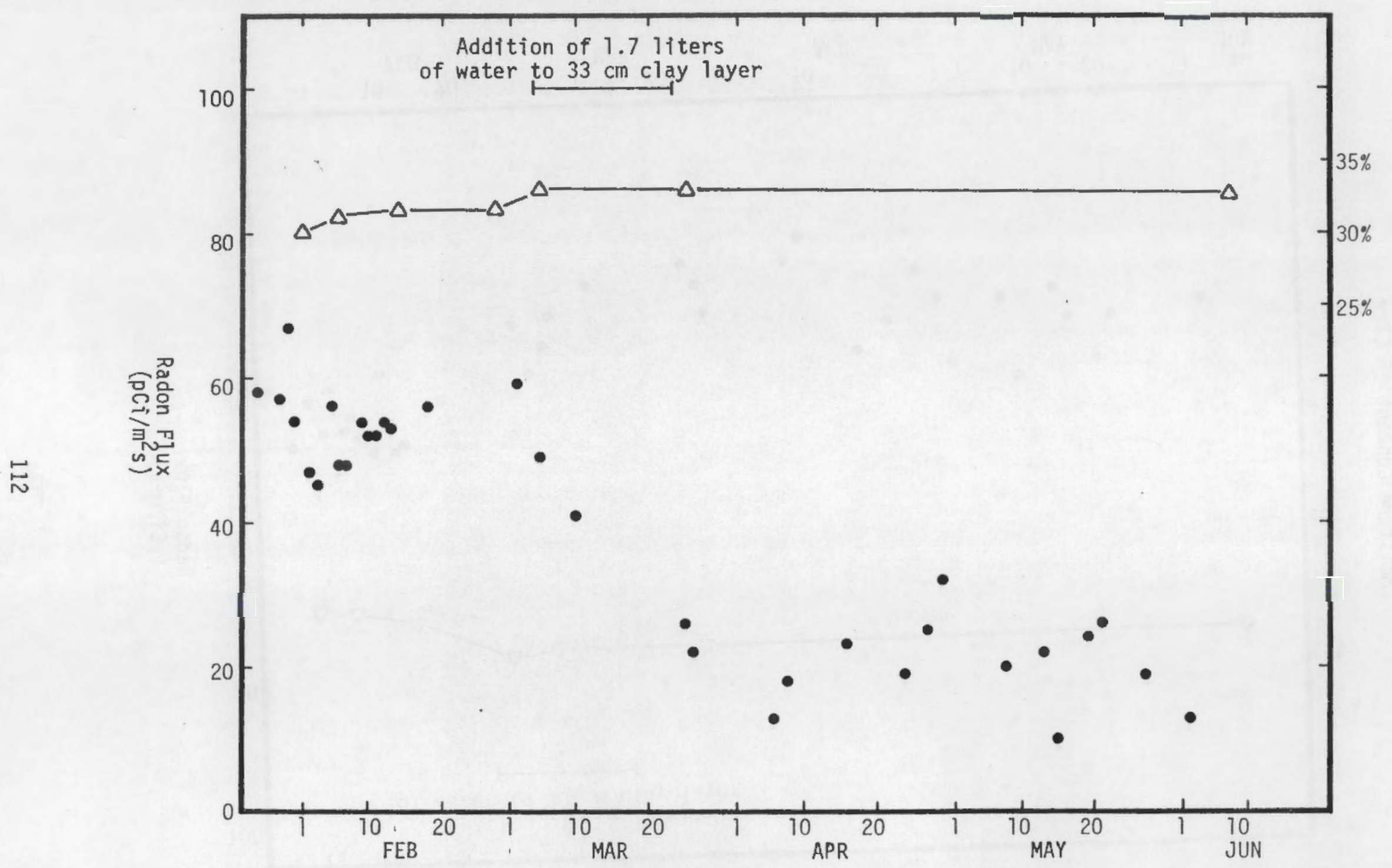

Figure 6.4 Effects of Moisture Addition on Radon Flux in Column 10. 
added, they tend to indicate higher moistures than were observed gravimetrically when the columns were disassembled several months later. This may be due to the proximity of the moisture cells to the water injection tubes, and also to the difficulty in characterizing the clay moisture from a single point.

In order to compare the observed flux decreases with those expected from the moisture additions, the diffusion-moisture and diffusion-porosity correlations $(3,4)$ were again used. It was first assumed that the added water was uniformly distributed in and contained by the respective clay layers. This lead to calculated water contents equal to saturation, however, which should have caused much greater flux reductions than were observed. The expected changes in radon flux based on the measured $2 \%$ moisture increases were then calculated as the ratio of radon flux reductions achieved by the clay layers using the initial and final moistures or air porosities to estimate the clay diffusion coefficients. The respective flux reductions for Columns 6 and 10 using the moisture correlation ${ }^{(3)}$ were 0.64 and 0.59 , and using the air-porosity correlation, ${ }^{(4)} 0.55^{\circ}$ and 0.83 . The measured flux reduction in Column 6 was thus slightly greater than calculated, and that for Column 10 was significantly greater than calculated.

The assumption of water containment and uniform distribution in the clay layers was questioned due to the continuing flux change from Column 6 , and the expected moisture equilibration in the columns. In order to assess the moisture conditions in these columns, they were disassembled and sampled in August 1981, nearly 3 months after the data collection period. The radon fluxes just prior to the disassembly were 26 and $17 \mathrm{pCi} / \mathrm{m}^{2} \mathrm{~s}$ from Columns 6 and 10 respectively. This was in reasonable agreement with the previous flux averages as indicated by Figures 6.3 and 6.4. Moisture cell readings were also similar to the earlier values at the time of disassembly.

Grab sampies were collected from soil above and below the clay layers for gravimetric moisture measurements, and a more complete set were collected from three levels in the clay layers. A total of 15 samples collectec in each 
clay layer were analyzed for both moisture and density. The moisture results are summarized in Table 6.6, and show that regions of high and low moistures existed in the clay layers, but that these did not generally transcend the entire clay layer. The mean dry densities of the clay samples were $1.32 \pm 0.14 \mathrm{~g} / \mathrm{cm}^{3}$ for Column 6 , and $1.50 \pm 0.20 \mathrm{~g} / \mathrm{cm}^{3}$ for Column 10, a reverse trend than was estimated from the original column construction data. This may also explain the greater flux reduction in Column 10 .

The measured moisture profiles are illustrated in Figures 6.5 and 6.6 for Columns 6 and 10, and show the high water retention by the clay layers, as predicted by the capillary pressure curves in Chapter 5 . The moisture gradient at the top of Column 6 suggests possible moisture loss by evaporation. The deeper clay layer in Column 10 does not exhibit obvious moisture transfer except possibly to the underlying tailings. Comparison of the quantities of added water with the moisture changes in the clay suggests that significant water was lost from both clay layers particularly the one in Column 10 . If the loss was indeed into the tailings source section, the greater flux reduction in Column 10 may have resulted from the reduced diffusion from the source.

In view of the variations observed in water distributions and densities, and the remaining questions on water loss from the clay layers, more detailed analysis of the radon flux changes in Columns 6 and 10 appears unjustified. Further experiments dealing. with water addition to diffusion columns are in progress. However, the problems resulting from moisture evaporation and uniform distribution have been minimized in the later tests by installing a series of porous ceramic cups in the soil layer. The moisture in the soil is maintained constant by controlling the capillary pressure on the cups with a hanging water column. This arrangement also permits variation of water contents in a wellcontrolled manner without altering the soil compaction. 
TABLE 6.6

MOISTURES MEASURED ON CLAY SAMPLES

( $\%$ dry wt)

\begin{tabular}{|c|c|c|c|c|c|c|}
\hline & & Column & & & olumn 10 & \\
\hline & Top & Middle & Bottom & Top & Middle & Bottom \\
\hline Center & 29.2 & 27.2 & 28.7 & 27.3 & 26.5 & 28.2 \\
\hline North & 29.0 & 25.6 & 26.7 & 25.8 & 24.6 & 27.7 \\
\hline East & 28.3 & 27.7 & 29.3 & 27.9 & 28.3 & 26.4 \\
\hline South & 29.6 & 28.5 & 29.9 & 26.9 & 28.7 & 31.3 \\
\hline West & 29.6 & 26.8 & 29.0 & 26.2 & 26.8 & 27.6 \\
\hline
\end{tabular}




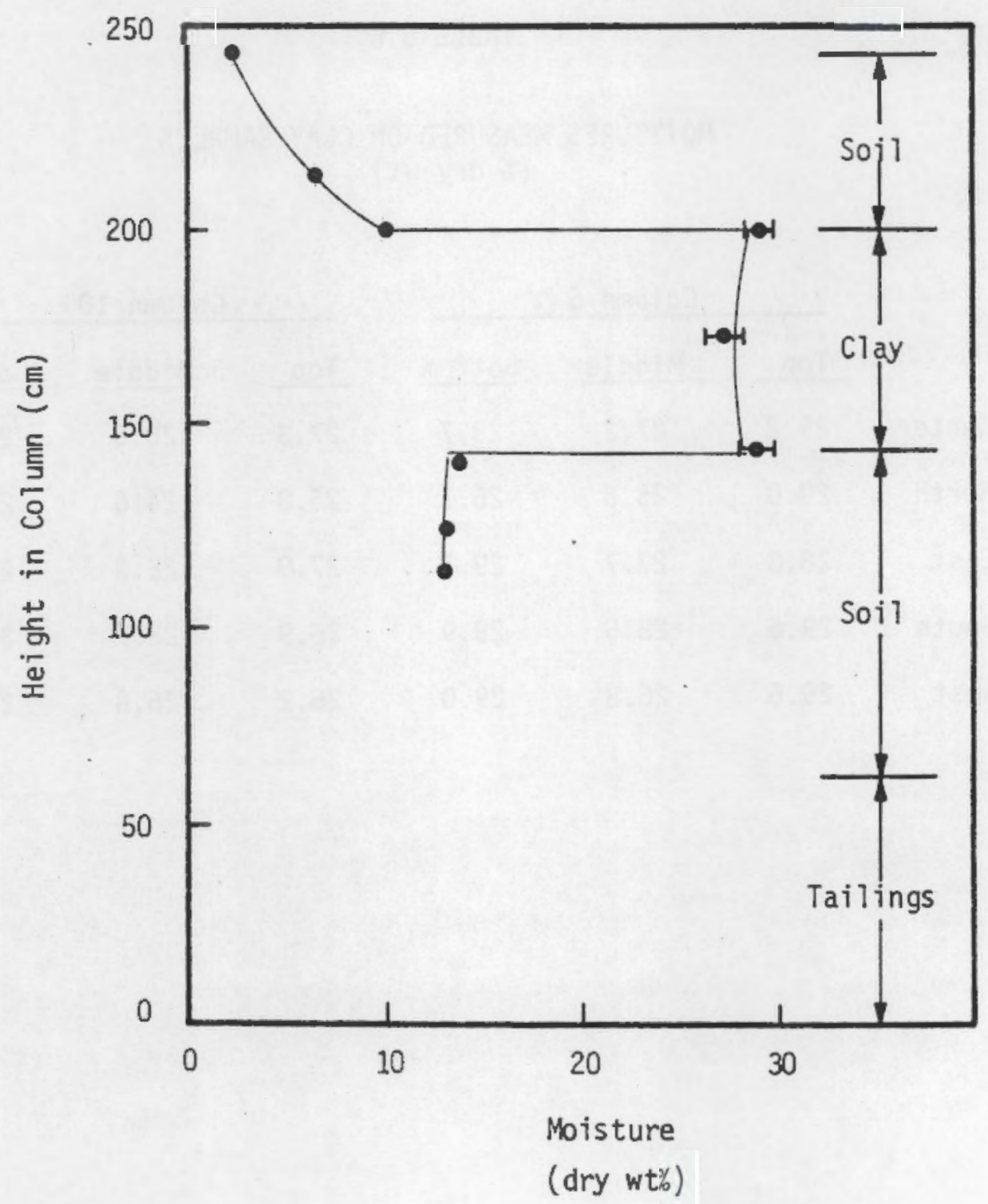

FIGURE 6.5 MOISTURE PROFILE AFTER WATER ADDITION TO COLUMN 6. 


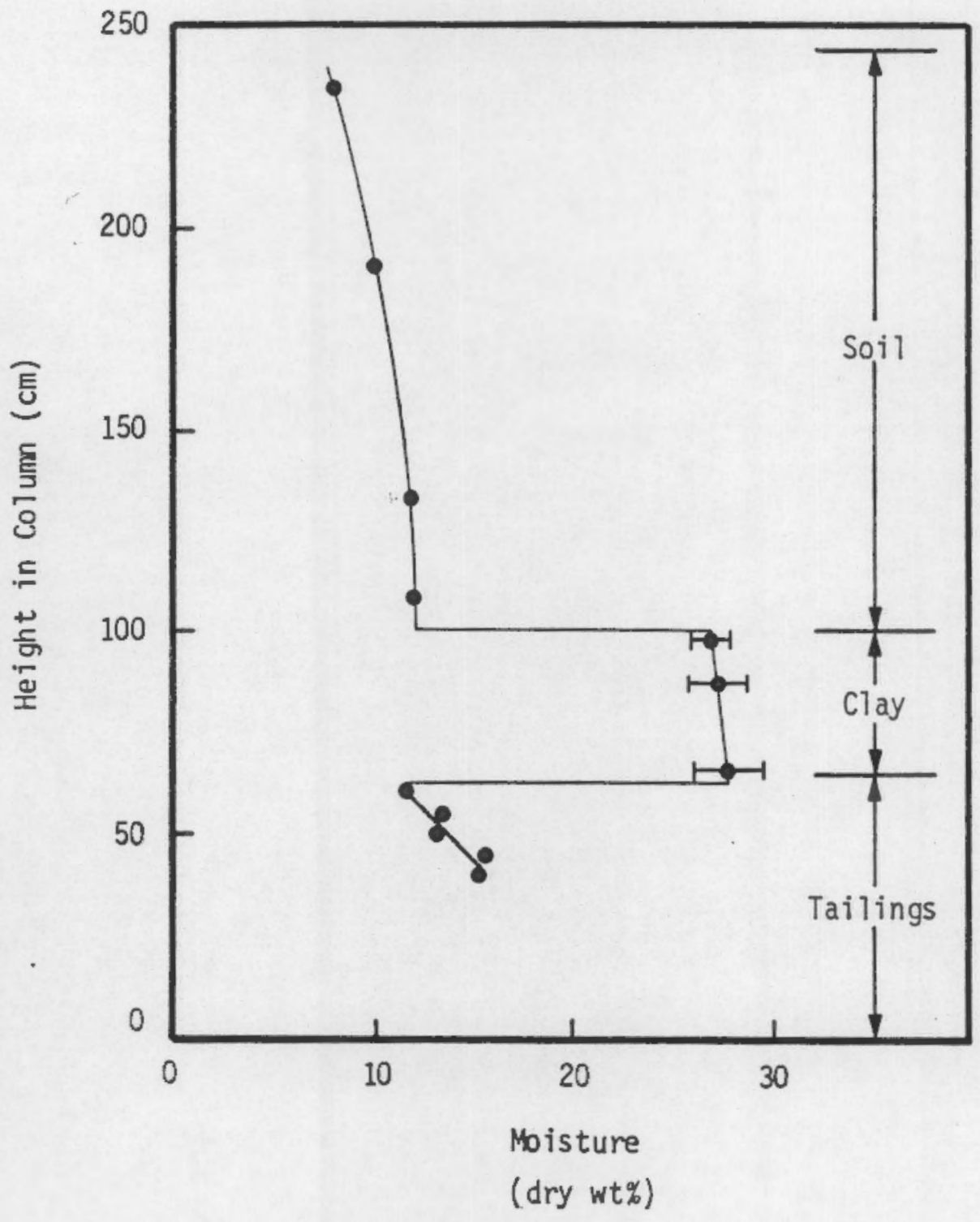

FIGURE 6.6 MOISTURE PROFILE AFTER WATER ADDITION TO COLUMN 10. 



\section{CONCLUSIONS AND RECOMMENDATIONS}

Several significant conclusions were drawn from the present research. These concerned the multilayer radon diffusion model, the experimental methods, and the results of the multilayer tests. The following summary discusses these conclusions and, where applicable, the recommendations for continued research effort.

The multilayer radon diffusion model was shown to be adequate for the interpretation of the present multilayer diffusion tests. The model was applied in two modes, one considering diffusion in the total pore space and the other considering diffusion in only the air-filled pore space. The resulting diffusion coefficients were generally slightly higher, as expected, for the air-filled pore space. However, both methods predicted radon fluxes which were similar to the measured fluxes when used consistently in the data analysis. Radon concentration profiles were only interpreted using the air-filled porosity mode, which was considered most directly applicable to the measured radon concentrations in the soil gas.

A parametric analys is of layer-order effects in multilayer tailings covers indicated that porosity differences between adjacent layers affected radon flux independently from differences in the diffusion coefficients of the layers. Layer-order effects were enhanced by these two contributions, which usually occur together in earthen materials. Although different soil types were used in the multilayer test columns, their porosities and diffusion coefficients did not differ sufficiently to demonstrate layer-order effects with statistical significance. Calculated layer-order effects in the multilayer test columns amounted to 5 to 20 percent effects on radon fluxes.

Several conclusions drawn from the quality control measurements were 
significant to this and related research. The effect of moisture on radon flux sampling with charcoal canisters was shown to be significant ( 43 percent lower collection efficiency) when the canister contained artificially high moistures (about 50 percent water). Normal moisture uptakes during 1 to 2 days, however, were only sufficient to cause about three percent loss in radon collection efficiency.

The effects of radial diffusion during flux sampling were also noted to be important. Accumulations of high radon concentrations inside sampling devices lowers observed radon fluxes by lowering the surface concentration gradient and by causing radial diffusion toward the edges of the sampler where the gradient is higher. Radial diffusion around an obstruction at the soil surface was observed experimentally in this study. In flux-can sampling this problem was minimized by short sampling times and large can volumes to avoid high concentration build-ups. In charcoal-canister sampling it was noted that the air path between the soil surface and the charcoal should be minimized to avoid the radial diffusion problem. This important design criterion for charcoal flux samplers was implemented in subsequent related studies which are still in progress.

An estimate of bias due to radial diffusion around a sampling device can be obtained by measuring its radon sampling efficiency as a function of the sampling time interval. Such measurements suggested the constraints on sampling interval for the samplers used in this study. A comparison of fluxes sampled by flux cans with those sampled by charcoal canister indicated that the two methods gave equivalent results within the uncertainties of their respective calibrations.

The question of edge-effects in small-diameter, radon diffusion columns has often been posed. Fluxes measured from the center of the $30-\mathrm{cm}$ columns in this study were compared to those measured from the entire column cross-sections. 
The comparison showed no significant channeling of radon along the column walls. Other quality assurance measurements, including radon diffusion rates through the experimental materials and calibration measurements, indicated that radon leakage from seams or ports in the test systems or biased gamma assays were not a problem.

It was determined that radon fluxes are more accurately and precisely predicted using measured diffusion coefficients than using moisture or porosity correlations alone. The correlations showed merit, however, in estimating fluxes within a factor of 2 to 3 , and particularly for use in adjusting diffusion coefficients to account for moisture or porosity differences. The comparison of radon diffusion coefficients measured in open test columns with those determined in the closed transient system suggested slightly higher diffusion rates in the open columns.

Due to the large effects of moisture and compaction on radon diffusion coefficients, these parameters require careful control in diffusion studies. It was observed that materials such as clays may tend to absorb moisture from adjacent layers, and that the moisture distribution in a multilayer cover system must be monitored and considered as a dynamic system over the time scale used for this study. Injected moisture gave greater reduction in radon fluxes, as expected, but considerable uncertainty was associated with the bulk moisture changes which resulted from the injections. Prior measurement of the drainage characteristic curves for the soils in a cover system may aid in selection of initial moistures for the system components. Additional work in progress will help determine radon diffusion characteristics under various moisture conditions without the complicating uncertainty of varying compactions. This work is utilizing a hanging water column to control and vary the capillary pressure in the cover test layer. 
In summary, the multilayer radon diffusion model predicted radon fluxes which were in reasonable agreement with observed values. The complexity of interactions in multilayer covers requires greater characterization and control of moisture effects. However, once the individual diffusion coefficients and source terms are known for each layer, the multilayer diffusion equations are adequate to describe the system. 


\section{REFERENCES}

1. Uranium Mil1 Tailings Radiation Control Act of 1978. PL-959604 (1978).

2. Rogers, V.C., Sandquist, G.M., and Nielson, K.K., "Radon Attenuation Effectiveness and Cost Optimization of Composite Covers for Uranium Mill Tailings," U.S. Department of Energy Report UMTRA-DOE/ALO-165, June 1981.

3. Rogers, V.C., et al, "Characterization of Uranium Tailings Cover Materials for Radon Flux Reduction." U.S. Nuclear Regulatory Commission Report NUREG/CR-1081, 1980.

4. Nelson, R.W., Gee, G.W. and Oster, C.A. "Radon Control by Multilayer Earth Barriers." Symposium on Uranium Mill Tailings Management, Ft. Collins. p. $79-88,1980$.

5. Macbeth, P.J., et al, "Laboratory Research on Tailings Stabilization Methods and Their Effectiveness in Radiation Containment." U.S. Department of Energy Report GJT-21, 1978.

6. Thamer, B.J., et al, "Radon Diffusion and Cover Material Effectiveness for Uranium Tailings Stabilization." Ford Bacon and Davis Utah report to U.S. Department of Energy. FBDU-258, 1980.

7. Koehmstedt, P.L., Hartley, J.N. and Davis, R.K., "Use of Asphalt Emulsion Sealants to Contain Radon and Radium in Uranium Tailings. "Pacific Northwest Laboratory Report, BNWL-2190, 1977.

8. Cline, J.F., Gano, K.A. and Rogers, L.E., "Loose Rock as Biobarriers in Shallow Land Burial," Health Physics, 39, (1980), 497-504.

9. U.S. Nuclear Regulatory Commission, "Generic Environmental Impact Statement on Uranium Milling," NUREG-0706, 1980. 
10. Nielson, K.K., Rogers, V.C., "Radon Flux Through Multilayered Covers Over Uranium Mill Tailings," Trans. Am. Nucl. Soc., 34, (1981), 131.

11. Federal Register Volume 44, No. 173, (1980), 51917.

12. Wilkening, M.H., and Hand, J.E., "Radon Flux at the Earth-Air Interface," J. Geophys. Res., 65, (1960), 3367-3370.

13. Lucas, H.F., "Improved Low-Level Alpha-Scintillation Counter for Radon," Rev. Sci. Instrum., 28, (1957), 680-683.

14. Chase, G.D. and Rabinowitz, J.L., Principles of Radioisotope Methodology, Third Edition, Burgess Pub. Co., Minneapolis, 1967.

15. Countess, R.J., "Radon-222 Flux Measurement with a Charcoal Canister," Health Physics, 31, (1976), 455.

16. Sill, C.W. and Hindman, F.D., "Preparation and Testing of Standard Soils Containing Known Quantities of Radionuclides," Anal. Chem.. 46, (1974), pp. 113-118.

17. Thomas, J.W., "Evaluation of Activated Carbon Canisters for Radon Protection in Uranium Mills," U.S. A.E.C. Health and Safety Laboratory Report, HASL-280, 1974.

18. Lucas, H.F., "Alpha Scintillation Radon Counting," Argonne National Laboratory Workshop on Methods for Measuring Radiation Around Uranium Mills, 3, (9), (1977), 69-79.

19. Percival, D.R. and Martin, D.B., "Sequential Determination of Radium-226, Radium-228, Actinium-227 and Thorium Isotopes in Environmental and Process Waste Samples," Anal. Chem., 46, (1974), 1742 - 1749.

20. Sill, C.W., and Willis, C.P., "Radiochemical Determination of Lead-210 in Mi11 Products and Biological Materials," Anal. Chem., 37, (1965), 1661-1671. 
21. Wogman, N.A., Robertson, D.E., and Perkins, R.W., "A Large Detector, Anticoincidence Shielded Multidimensional Gamma-Ray Spectrometer," Nucl. Instr. Meth., 50, (1967), 1-10.

22. U.S. Department of Energy, "Phase II - Title I Engineering Assessment of Inactive Uranium Mill Tailings - Vitro Site," GJT-1, 1976.

23. U.S. Department of Energy, "Phase II - Title I Engineering Assessment of Inactive Uranium Mill Tailings - Durango Site," GJT-6, 1977.

24. U.S. Department of Energy, "Phase II - Title I Engineering Assessment of Inactive Uranium Mi11 Tailings - Shiprock Site," GJT-2, 1977.

25. U.S. Department of Energy, "Phase II - Title I Engineering Assessment of Inactive Uranium Mill Tailings - Grand Junction Site," GJT-9, 1977.

26. U.S. Department of Energy, Phase II - Title I Engineering Assessment of Inactive Uranium Mill Tailings - Riverton Site," GJT-19A, 1978. 



\section{DISTRIBUTION}

No. of

Copies

OFFSITE

A. A. Churm

DOE Patent Oivision 9800 S. Cass Avenue

Argonne, IL 60439

27 DOE Technical Information Center

W. Ackerman

Dept. of Environmental Quality

Land Quality Oivision

Hathaway Building

Cheyenne, WY 82002

L. Anderson, 0irector

Bureau of Radiation and

Occupational Health

P. 0. Box 2500

Salt Lake City, UT 84110

Alvin Askew

Politech Corporation

2220 Austin National 8ank Tower

Austin, TX 78701

E. 0. Bailey, Administrator

Texas Department of Health

Radiation Control Branch

1100 West 49th Street

Austin, TX 78756

George Birchard

Mail Station 1130-SS

U.S. Nuclear Regulatory

Commission

Washington, OC 20555
No. of

Copies

K. J. Bush

Geochemistry and Environmental Chem. Res. Inst. 2693 Commerce Road

Rapid City, SO 57701

50 R. H. Campbell, Project Manager

Uranium Mill Tailings Project office

U.S. Department of Energy

P. $0.80 \times 5400$

Albuquerque, NM 87115

W. R. Chappel

Center for Environmental

Sciences

Univ. of Colorado at Denver

Campus Box 136

Denver, CO 80202

E. Delaney, Remedial Actions

Program Office of Nuclear Waste Management

U.S. Department of Energy, NE-301

Washington, OC 20545

Dave Oreesen

Los Alamos National Laboratory

P. 0. $80 \times 1663$

Los Alamos, NM 87545

L. Fitzrandolph

Arizona Atomic Energy Commission 2929 West Indian School Road Phoenix, AZ 85017 
No. of

Copies

\section{Frank \\ Oregon Dept. of Energy \\ 111 Labor and Industries Building \\ Salem, OR 97310 \\ R. Funderberg \\ Dept. of Health and Welfare \\ State House \\ Boise, ID 83707}

T. M. Gerusky, Director

Bureau of Radiation Protection

P. 0. Box 2063

Harrisburg, PA 17120

Donald H. Groelsema, Remedial

Actions Program

Office of Nuclear Waste

Management

U.S. Department of Energy, $\mathrm{NE}-301$

Washington, DC 20545

A. J. Hazle, Director

Colorado Department of Health

Radiation and Hazardous Waste Division

4210 East 11 th Avenue

Denver, CO 80220

E. L. Keller, Director

Technical Services Division

DOE Oak Ridge Operations Office

P. O. Box E

Oak Ridge, Tennessee 37830

W. Kisieleski

Argonne Nationa? Laboratory

9700 South Cass Avenue

Argonne, Illinois 60439

A. Kluk, Remedial Actions

Program

Office of Nuclear Waste

Management

U.S. Department of Energy, NE-301

Washington, DC 20545
No. of

Copies

N. 0. Kretz

Argonne National Laboratory

9700 South Cass Avenue,

Bldg. 202

Argonne, IL 60439

D. E. Large, Program Manager

Radioactive Waste Management Program

Oak Ridge Operations Office

P. 0. Box E

Oak Ridge, Tennessee 37830

S. Lichtman

U.S. Environmental Protection Agency

Criteria and Standards Division

Office of Radiation Programs

Washington, DC 20460

Or. Gergely Markos

Research Institute for

Geochemistry and Environmental

Chemistry

2693 Commerce Road

Rapid City, SD 57701

M. L. Matthews, Project Engineer

Uranium Mill Tailings Project Office

U.S. Department of Energy

P. 0. Box 5400

Albuquerque, NM 87115

J.W. McKiernan, Organization 4542

Sandia National LaboratoryAlbuquerque

P. 0. Box 5800

Albuquerque, NM 87185

A. A. Metry

Weston

Weston Way

West Chester, PA 19380 
D. K. Mount, Director

North Dakota State Dept. of Health

Div. of Environmental Engineering

1200 Missouri Avenue, Room 304

Bismarck, NM 58505

William E. Mott, Director

Environmental and Safety Engineering Division

U.S. Department of Energy, EP-14 Washington, DC 20545

T. N. Narasimhan

Lawrence Berkeley Laboratory

Berkeley, California 94720

\section{R. Neff}

Mound Facility

c/o Dayton Area Office

P. 0. Box 66

Miamisburg, Ohio 45342

John 0. Nelson

Professor, Program Leader

Colorado State University

Fort Collins, CO 80523

William Nixon

Office of Nuclear Materials, Safety and Safeguards

Mail Station 396-SS

U.S. Nuclear Regulatory Commission

Washington, OC 20555

Paul 0'Brien, Organization 4541

Sandia National LaboratoryAlbuquerque

P. 0. Box 5800

Albuquerque, NM 87185

K. R. Porter

Dames and Moore

1626 Cole Boulevard

Golden, CO 80401
Robert W. Ramsey, Jr., Program Manager

Remedial Actions Program, NE-301

U.S. Department of Energy

Washington, DC 20545

20 Vern C. Rogers, President

Rogers and Associates Engineering

445 East 200 South, Suite 303

Salt Lake City, UT 84111

A. Ryon

Oak Ridge National Laboratory

P. 0. Box X

Oak Ridge, Tennessee 37830

Ross A. Scarano, Chief

Uranium Recovery License Branch

Mail Station 483-5S

U.S. Nuclear Regulatory Commission

Washington, OC 20555

W. M. Shaffer

Uranium Recovery Licensing Branch

U.S. Regulatory Commission

Mail Station 461-5S

Washington, DC 20555

George Stukenbroker

$\mathrm{NLO}$, Inc.

P. 0. Box 39158

Cincinnati, Ohio 45239

T. Tamura

Oak Ridge National Laboratory

P. 0. Box $X$

Oak Ridge, Tennessee 37830

J. G. Themelis, Director

Engineering and Safety Division

DOE Grand Junction Office

2597 B-3/4 Road (South Redlands)

P. 0. Box 2567

Grand Junction, CO 81501 
No. of

Cooies

A. Topp, Chief

Radiation Protection Bureau

P. 0. Box 968

Santa Fe, NM 87503

H. Tso, Executive Director

Environmental Protection Commission

The Navajo Nation

Window Rock, AZ

A. S. White, Earth Sciences Division

Lawrence Berkeley Laboratory

Berkeley, CA 94720

J. White, Chief

Reactor Operations Branch

U.S. Department of Energy

Richland Operations Office

825 Jadwin Avenue

P. 0. Box 500

Richland, Washington 99352
No. of

Copies

ONSITE

DOE RL

H. E. Ransom

22 Pacific Northwest Laboratory

G. E. Barr

J. L. Buelt

L. L. Cadwe 11

J. F. Cline

C. H. Dalin

G. W. Gee (3)

H. N. Hartley

J. M. Latkovich

J. W. McKiernan

O. W. Mayer

R. W. Nelson

P. D. O'Brien

L. C. Schwendiman

W. B. Silker

Technical Information (5)

Publishing Coordination (Be) 